\title{
UTILIZAÇÃO DE MODELOS ESTEREOSCÓPICOS HÍBRIDOS NA ATUALIZAÇÃO CARTOGRÁFICA
}

\section{Amilton Amorim}

Tese apresentada à Escola de Engenharia de São Carlos, da Universidade de São Paulo, como parte dos requisitos para a obtenção do título de Doutor em Engenharia Civil. Área: Transportes.

ORIENTADOR: Prof. Dr. Irineu da Silva

São Carlos

2000 
à minha filha Amanda e à minha esposa Margarete que comigo passaram todos os momentos felizes e, principalmente, compartilharam as horas de angústias e tristezas... aos meus pais e irmãos que me ensinaram a viver .... apoiaram .....e confiaram na minha capacidade.... 


\section{AGRADECIMENTOS}

A realização deste trabalho foi possível graças à valiosa colaboração, direta ou indireta, de diversas pessoas e instituições. Manifesto minha gratidão a todas elas e de forma especial...

Ao Prof. Dr. Irineu da Silva, pela orientação competente, dedicada e por todas as sugestões imprescindíveis ao desenvolvimento do trabalho. Com certeza ganhei mais um amigo...

Ao Prof. Dr. Antonio Maria Garcia Tommaselli, pela co-orientação precisa, competente e paciência durante os longos períodos de discussão. Um dos grandes incentivadores deste trabalho

Ao Grupo de Pesquisa em Fotogrametria, principalmente, ao Prof. Dr. João Fernando Custódio da Silva, pela disponibilização do C++ Builder 3; Prof. Dr. Júlio Kyioshi Hasegawa, pelo auxilio imprescindível no desenvolvimento dos programas e disponibilização de rotinas já desenvolvidas; Prof. MsC. Maurício Galo, pela disponibilização do programa CCESC e, por valiosas discussões e críticas.

Aos Engenheiros Luciano Aparecido Junqueira de Oliveira e Renata Rocha Falcon, pela grande participação na elaboração dos programas.

As empresas Aerocarta S/A e Base Aerofogrametria e Projetos S/A, pela colaboração e valiosas informações fornecidas.

Aos mestrandos Daniel Rodrigues dos Santos e Humberto Rodrigues Francisco, pela colaboração nos levantamentos de campo por GPS.

Aos amigos João Carlos Chaves e Eliana Ederle Dias Chaves, pelo companheirismo e apoio, principalmente durante a conclusão dos créditos. 
A Graça e à Cidinha, pela dedicação e por não me deixarem falhar com meus compromissos no Departamento de Cartografia.

A Bibliotecária Cláudia, pela organização da ficha catalográfica.

Ao programa de Pós-graduação em Transportes da Escola de Engenharia de São Carlos - EESC, Universidade de São Paulo - USP, especialmente à Heloísa pelo atendimento competente.

À FUNDACTE - Fundação de Ciências, Tecnologia e Ensino, da Faculdade de Ciências e Tecnologia - FCT - UNESP de Presidente Prudente, pela disponibilização do GPS Trimble 4600.

À FUNDUNESP - Fundação para o Desenvolvimento da UNESP, por ter financiado parte do projeto, possibilitando a aquisição das fotografias aéreas convencionais.

À CAPES, pelo apoio financeiro durante a realização do curso.

Aos colegas e amigos do Departamento de Cartografia da FCT-UNESP, pelo apoio e concessão de quatro anos de afastamento parcial.

Aos demais amigos e familiares, pelo apoio e incentivo... 


\section{SUMÁRIO}

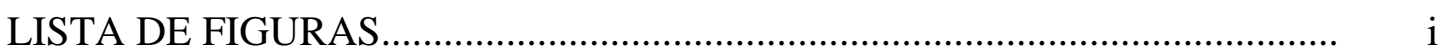

LISTA DE TABELAS...........................................................................

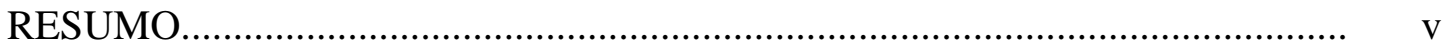

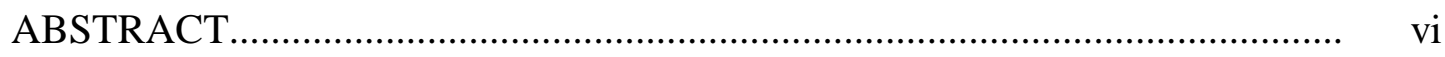

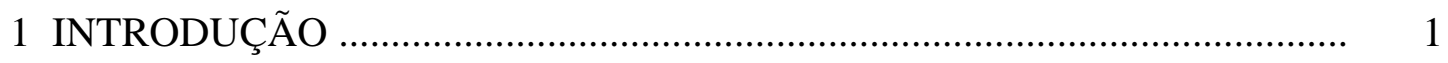

1.1 Considerações iniciais........................................................................ 1

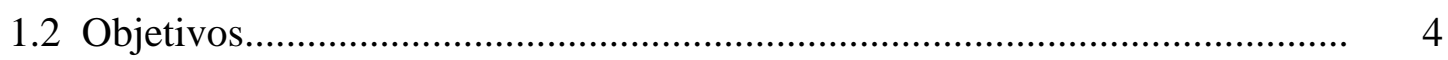

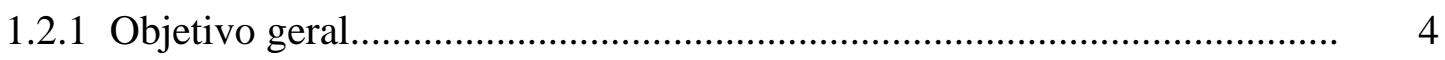

1.2.2 Objetivos específicos..................................................................... 5

2 ATUALIZAÇÃO CARTOGRÁFICA......................................................... 6

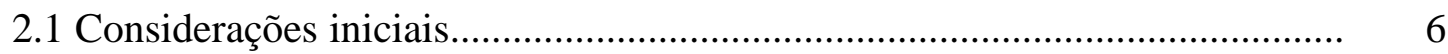

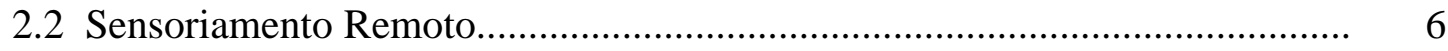

2.3 Sistema global de posicionamento (GPS) …............................................ 7

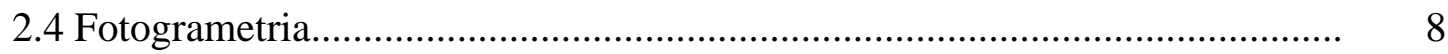

2.4.1 Visão estereoscópica............................................................................ 9

2.4.1.1 Método dos estereoscópios .............................................................. $\quad 10$

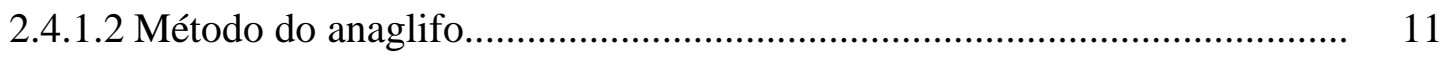

2.4.1.2.1 Método do anaglifo por impressão.................................................... 11

2.4.1.2.2 Método do anaglifo por projeção..................................................... 11

2.4.1.3 Método do cintilamento. .................................................................... 12

2.4.2 Formação de um modelo estereoscópico. .................................................. 13

2.4.2.1 Orientação interior............................................................................ 14

2.4.2.2 Orientação exterior.............................................................................. 18 
2.4.2.3 Resseção espacial.................................................................................... 19

2.4.2.4 Equação de colinearidade........................................................................ 19

2.4.2.5 Calibração de câmaras............................................................................ 26

2.4.3 Retificação de imagens digitais............................................................. 30

2.5 Detecção de alterações............................................................................ 32

2.5.1 Detecção de alterações a partir de imagens digitais................................... 33

2.5.2 Limiarização.................................................................................. 34

2.5.3 Técnicas digitais de detecção de alterações.............................................. 34

2.5.3.1 Diferenciação de imagem univariada. ................................................ 34

2.5.3.2 Regressão de Imagem.......................................................................... 35

2.5.3.3 Racionamento de Imagem................................................................. 36

2.5.3.4 Subtração do fundo........................................................................... 36

2.5.4 Avaliação das técnicas digitais de detecção de alterações apresentadas..... 36

2.5.5 Experimentos realizados por outros pesquisadores................................ 37

3 CÂMARAS DIGITAIS ....................................................................... 40

3.1 Considerações iniciais............................................................................ 40

3.2 Sensor CCD e captura de imagem ...................................................... 41

3.3 Características técnicas de algumas câmaras digitais................................... 41

3.3.1 Câmaras de amador …..................................................................... 41

3.3.1.1 Câmara Kodak - DC210 (Zoom) ...................................................... 42

3.3.1.2 Câmara Kodak - DC 5000 …..................................................................... 42

3.3.2 Câmaras para uso profissional …………................................................. 43

3.3.2.1 Câmara Kodak - DCS 660 ………........................................................ 43

3.3.2.2 Câmara Kodak - Mega Plus 16.8i......................................................... 44

3.3.2.3 Câmara LMFS (F-979F) ............................................................... 45 
3.3.2.4 Câmara DMC (Z/I Imaging) ………………………………………….... 45

3.3.2.5 Câmara inCAM (inpho GmbH) ……………………………………….. 46

3.3.3 Câmara de imageamento contínuo. ………………………………………... 46

3.3.4 Comparação entre as câmaras apresentadas.................................................. 48

3.4 Princípios da formação da imagem digital....................................................... 49

3.5 Câmaras digitais e aplicações fotogramétricas................................................. 51

4 PROPOSTA METODOLÓGICA......................................................... 52

4.1 Formação de modelos estereoscópicos híbridos...……………………………. 54

4.2 Procedimento para a detecção de alterações...................................................... 57

4.3 Extração de feições .................................................................................... 59

4.3.1 Digitalização direta …………………………………………………... 59

4.3.2 Restituição fotogramétrica …………………………………………….. 59

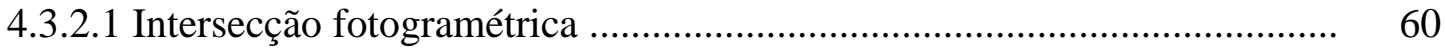

4.3.2.2 Monorestituição.....................................................................................

5 IMPLEMENTAÇÃO DE UM PROTÓTIPO DE SISTEMA DE ATUALIZAÇÃO CARTOGRÁFICA.............................................................. 67

5.1 Considerações iniciais................................................................................ 67

5.2 Desenvolvimento do protótipo......................................................................... 67

5.3 Funcionamento do protótipo ……………………………………………... 75

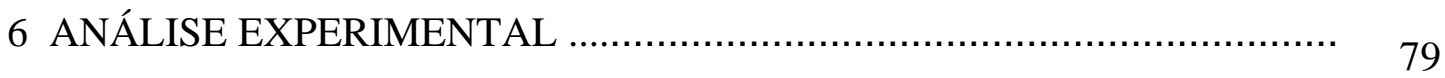

6.1 Experimentos com o método de orientação do modelo estereoscópico

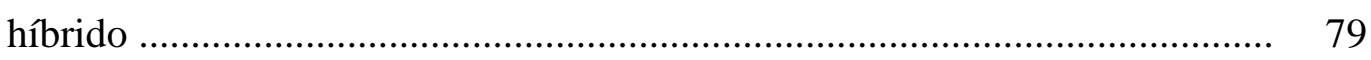

6.1.1 Materiais e equipamentos..................................................................... $\quad 79$

6.1.2 Definição da área teste................................................................................ 80

6.1.3 Aquisição das fotografias aéreas digitais..................................................... 80

6.1.4 Experimentos executados sem a calibração prévia da câmara digital.......... 81 
6.1.4.1 Apoio utilizado para os experimentos.................................................. 81

6.1.4.2 Formação dos modelos estereoscópicos.................................................. 82

6.1.4.2.1 Orientação do modelo estereoscópico convencional.............................. 82

6.1.4.2.2 Orientação do modelo híbrido.............................................................. 82

6.1.4.2.3 Orientação do modelo estereoscópico com duas fotos aéreas digitais... 84

6.1.5 Experimentos executados com a calibração prévia da câmara digital......... 85

6.1.5.1 Calibração da câmara digital.............................................................. 85

6.1.5.2 Orientação do modelo híbrido com os parâmetros calibrados.............. 87

6.1.5.2.1 Análise de detecção de tendências......................................................... 88

6.1.5.2.2 Análise de precisão (qui quadrado) ..................................................... 89

6.1.5.2.3 Testes com o par (Foto 0309 / DCP 311) ........................................... 91

6.1.5.2.4 Testes com o par (Foto 0310 / DCP 311)............................................ 92

6.1.6 Análise dos resultados dos experimentos com o método de orientação do modelo estereoscópico híbrido................................................................ 94

6.2 Detecção de alterações em imagens multitemporais..................................... 94

6.2.1 Visualização estereoscópica utilizando estereoscópio de espelho................ 95

6.2.2 Visualização estereoscópica por cintilamento ou luz intermitente.............. 95

6.2.3 Visualização estereoscópica por anaglifo. .............................................. 98

6.3 Atualização cartográfica utilizando a metodologia proposta........................ 102

6.3.1 Digitalização direta sobre a fotografia digital........................................ 102

6.3.2 Monorestituição das feições de interesse................................................. 107

7 CONCLUSÕES E RECOMENDAÇÕES ................................................ 115

8 REFERÊNCIAS BIBLIOGRÁFICAS....................................................... 120 


\section{LISTA DE FIGURAS}

FIGURA 01 - Geometria da cobertura estereoscópica

FIGURA 02 - Formação do modelo estereoscópico a partir da equação de colinearidade

FIGURA 03 - Retificação de uma fotografia.

FIGURA 04 - Geometria epipolar.

FIGURA 05 - Câmara Digital KODAK - DC 210 (utilizada neste trabalho)........

FIGURA 06 - Câmara Digital KODAK - DC 5000.

FIGURA 07 - Câmara Digital KODAK - DCS 660.

FIGURA 08 - Câmara Digital KODAK - Mega Plus 16.8i.

FIGURA 09 - CCD (KAF-16801), utilizado na câmara digital Kodak - Mega Plus $16.8 \mathrm{i}$

FIGURA 10 - Câmara F-979F 45

FIGURA 11 - Câmara DMC (Z/I Imaging) 46

FIGURA 12 - Câmara inCAM (inpho GmgB) 46

FIGURA 13 - Sensor digital multiespectral (three-line), LH - System 47

FIGURA 14 - Característica geométrica do sensor digital trilinear

FIGURA 15 - Matriz de formação da imagem digital 49

FIGURA 16 - Princípio da formação da imagem para câmaras CCD 50

FIGURA 17 - Processo esquemático da metodologia proposta 53

FIGURA 18 - Formação de um modelo estereoscópico híbrido 54

FIGURA 19 -Triângulo definidor do mini MNT. 66 
FIGURA 20 - Tela inicial do Sistema de Atualização de Mapeamentos - SAM.. 75

FIGURA 21 - Orientação interior da fotografia convencional ........................... 76

FIGURA 22 - Resultados da orientação interior ................................................ 76

FIGURA 23 - Fotografias, convencional e digital, retificadas ............................. 77

FIGURA 24 - Formação do modelo anaglifo ....................................................... 77

FIGURA 25 - Janela de extração de feições .......................................................... 78

FIGURA 26 - Posição das fotografias digitais (DCP 311 e DCP 305) em relação às fotografias convencionais ....................................................... 80

FIGURA 27 - Fotografia aérea digital (DCP 311) com pontos de apoio ............. 81

FIGURA 28 - Campo de calibração ............................................................. 85

FIGURA 29 - Fotografia aérea DCP 311, destacando uma feição existente ........ 96

FIGURA 30 - Fotografia aérea DCP 305, com a feição de interesse eliminada ... 96

FIGURA 31 - Modelo estereoscópico por cintilamento (DCP305 / DCP 311), destacando a feição de interesse ............................................... 97

FIGURA 32 - Modelo estereoscópico por anaglifo (DCP 305 / DCP 311), destacando a feição de interesse

FIGURA 33 - Parte da fotografia aérea convencional 0310 ............................. 100

FIGURA 34 - Modelo estereoscópico por anaglifo (DCP 311 / 0310) …............. 100

FIGURA 35 - Rede de pontos de apoio e verificação ........................................ 104

FIGURA 36 - Detalhe da feição definida pelos pontos 5, 6 e 7 ......................... 108

FIGURA 37 - Detalhe da feição definida pelos pontos 15, 16, 17 e 18 ............... 111 


\section{LISTA DE TABELAS}

TABELA 01 - Quadro comparativo entre as câmaras apresentadas

TABELA 02 - Rotinas utilizadas no programa 68

TABELA 03 - Coordenadas da marcas fiduciais calibradas 70

TABELA 04 - Modelo de representação das feições no formato DXF 74

TABELA 05 - Coordenadas dos pontos de apoio (SAD-69) 82

TABELA 06 - Discrepâncias entre as coordenadas dos pontos levantados em campo e seus correspondentes calculados após a orientação do modelo híbrido

TABELA 07 - Discrepâncias entre as coordenadas dos pontos levantados em campo e seus correspondentes calculados após a orientação do modelo digital.

TABELA 08 - Resultados da calibração da câmara digital DC 210 86

TABELA 09 - Pontos determinados fotogrametricamente (SAD-69)

TABELA 10 - Comparação das análises dos testes com 2 e 3 pontos de apoio (Fotos 0309 / DCP 311)

TABELA 11 - Comparação das análises dos testes com 2 e 3 pontos de apoio (Fotos 0310 / DCP 311)

TABELA 12 - Coordenadas dos pontos de apoio e verificação 103

TABELA 13 - Comparação das discrepâncias calculadas nos testes 1, 2 e 3....... 105

TABELA 14 - Comparação das análises estatísticas dos testes 1, 2 e 3 106

TABELA 15 - Coordenadas dos pontos 2, Cx D’água e 8, no espaço imagem 109 
TABELA 16 - Resultados da intersecção fotogramétrica na determinação das coordenadas dos pontos 2, Cx D’água e 8 , no espaço objeto 109

TABELA 17 - Coordenadas dos pontos 5, 6 e 7, no espaço imagem 110

TABELA 18 - Coordenadas dos pontos 5, 6 e 7, no espaço objeto 110

TABELA 19 - Discrepâncias das coordenadas calculadas, dos pontos 5, 6 e 7, em relação aos pontos de verificação

TABELA 20 - Coordenadas dos pontos 19, GE e ASA, no espaço imagem 112

TABELA 21 - Resultados da intersecção fotogramétrica na determinação das coordenadas dos pontos 19, GE e ASA, no espaço objeto 112

TABELA 22 - Coordenadas dos pontos 15, 16, 17 e 18, no espaço imagem 113

TABELA 23 - Coordenadas dos pontos 15, 16, 17 e 18, no espaço objeto 113

TABELA 24 - Discrepâncias das coordenadas calculadas, dos pontos 15, 16, 17 e 18 , em relação aos pontos de verificação 113

TABELA 25 - Custos percentuais de um aerolevantamento convencional 116 


\section{RESUMO}

AMORIM, A. (2000). Utilização de modelos estereoscópicos híbridos na atualização cartográfica. São Carlos, 2000. 124p. Tese. Escola de Engenharia de São Carlos, Universidade de São Paulo.

Um dos problemas que vêm sendo discutidos pela comunidade cartográfica brasileira é a atualização de documentos cartográficos, gerando estudos que procuram alternativas confiáveis, rápidas e econômicas para esta atividade. Este trabalho apresenta uma proposta metodológica rápida e econômica de atualização cartográfica, onde a premissa básica será a utilização de um estereopar híbrido, composto por uma fotografia aérea $23 \times 23 \mathrm{~cm}$ (que foi utilizada no mapeamento existente) digitalizada matricialmente, e por uma imagem aérea digital recente obtida com uma câmara digital. Além disso, este trabalho apresenta discussões e resultados sobre a visualização estereoscópica do estereopar híbrido, quando utilizada para a detecção das alterações, e a extração das feições identificadas, completando assim o processo de atualização cartográfica. Esta estratégia de combinação de fontes diferentes de dados, para a formação de modelos estereoscópicos, pode acelerar o processo de revisão e atualização cartográfica reduzindo os custos e obtendo resultados satisfatórios.

Palavras chaves: Atualização Cartográfica, Fotogrametria, Detecção de Alterações, Intersecção Fotogramétrica, Monorestituição. 


\section{ABSTRACT}

AMORIM, A. (2000). Use of hybrid estereopairs in the cartographic updating. São Carlos, 2000. 124p. Tese. Escola de Engenharia de São Carlos, Universidade de São Paulo.

Updating of cartographic documents have been discussed by the Brazilian cartographic community, generating studies that look for reliable, fast and economical alternatives for this activity. This work presents a fast and economical methodological proposal for cartographic updating, in which the basic approach is the use of a hybrid stereo-pair, composed by a $23 \times 23 \mathrm{~cm}$ scanned aerial photography (that was used in the existing mapping), and by a recent digital aerial image, acquired by a digital camera. Besides that, discussions and results on the stereoscopic visualization of the hybrid stereo-pair are presented, focusing on change detection and extraction of the identified features, aiming cartographic updating. This strategy of combinating different sources of data, for stereoscopic models reconstruction can speed up the revision process and cartographic updating, reducing the costs and obtaining reliable results.

Key words: Cartographic Updating, Photogrammetry, Change Detection, Photogrammetric Intersection, monorestitution. 


\section{INTRODUÇÃO}

\subsection{Considerações iniciais}

A atualização cartográfica tem sido objeto de estudo de vários pesquisadores nos últimos anos, objetivando, geralmente, implementar metodologias que possibilitem essa atividade com mais rapidez e precisão e que sejam economicamente viáveis, procurando se beneficiar ao máximo do acentuado desenvolvimento tecnológico.

Pode-se notar que cidades de médio porte, ainda através de muito esforço financeiro, têm contratado serviços de aerolevantamento, com o objetivo específico de auxiliar na atividade de planejamento municipal.

Num país onde a produção cartográfica em escalas grandes, para utilização em planejamento municipal, é ainda muito pequena, a abordagem deste assunto parece utópica. Mas quando se fala em aerolevantamento com o objetivo principal de apoiar administrações públicas, os interesses são múltiplos e coerentes.

Segundo AMORIM (1993), a partir da constituição de 1988 os municípios brasileiros vêm passando por uma adaptação quanto ao sistema administrativo, ou seja, várias concepções mudaram com a municipalização de diversas atividades, detectando-se atualmente uma crescente demanda por informações atualizadas e sistematizadas, que dêem suporte à administração pública. 
Com a concepção atual de administração pública planejada, a necessidade de cartografia atualizada é evidente e fundamental para o êxito dessa atividade (AMORIM \& SILVA, 1994).

A tão esperada organização administrativa dos municípios torna-se um objetivo cada vez mais perto de ser alcançado, mas para isso existe a necessidade de conhecer a realidade física da área em questão. Este problema é parcialmente resolvido com a cartografia atualizada da referida área.

Contratar um serviço de aerolevantamento envolve recursos financeiros, nem sempre disponíveis nos cofres públicos. Além disso, um mapeamento se desatualiza com o decorrer do tempo, pela própria atividade humana, que é muito dinâmica.

As empresas de aerolevantamento, normalmente, não são contratadas para a execução de atualizações cartográficas, que poderiam utilizar um mapeamento anterior (desatualizado) e/ou novas fontes de informação, como por exemplo, fotografias aéreas recentes, imagens de satélite e levantamentos topográficos. $\mathrm{Na}$ realidade, por falta de metodologias adequadas, implementadas nas empresas, executa-se um novo aerolevantamento, fato este que pode inviabilizar essa atividade pelo alto custo.

O avanço da tecnologia, nas áreas de informática e eletrônica, tem colaborado em muito com o desenvolvimento de Sistemas Fotogramétricos Digitais, e este fato traz à comunidade científica mundial novas e tentadoras expectativas para a exploração de recursos de automação em Fotogrametria (MILLER et al., 1996; GRUEN, 1996; YOICHI, 1996).

Acredita-se que, com estas áreas em constante desenvolvimento, pode-se implementar procedimentos econômicos e produtivos para a atualização cartográfica, 
acoplados aos Sistemas de Informações Geográficas, viabilizando projetos dessa natureza (AL-GARNI,1996).

A utilização de ferramentas automáticas e/ou semi-automáticas, para a atualização cartográfica, é de fundamental importância atualmente, visto que se encontra em expansão a utilização de Sistemas de Informações Geográficas no planejamento municipal, sendo que estes utilizam bancos de dados gráficos, sujeitos a alterações e, portanto, necessitando de atualizações constantes (AGOURIS \& STEFANIDIS, 1996; ANDERS \& FRITSCH, 1996; MASAHARU et al., 1996; JOHNSSON, 1996).

De acordo com LUGNANI (1985), na atualização cartográfica, quer sejam usadas técnicas convencionais quer recursos tecnológicos mais avançados, ocorrem duas dificuldades principais, que constituem pontos críticos, tais como detectar as variações ocorridas no espaço objeto e preservar o apoio de campo. Em seu trabalho esse autor propôs recursos para minimizar estas grandes dificuldades da atualização cartográfica. No que diz respeito à detecção das variações no espaço objeto foi proposto um dispositivo adaptável a restituidores analógicos, semi-analíticos e analíticos (o qual será discutido no capítulo 2) que facilita a detecção. Quanto à preservação do apoio de campo, foi proposto o uso de feições para o estabelecimento do controle terrestre. As propostas apresentadas por ele mostram a preocupação com esta tarefa inesgotável que, em muitos casos, deveria ter prioridade sobre a elaboração de novas cartas.

Nota-se, portanto, que até hoje os principais avanços ainda são em termos de produção de mapeamentos, ou seja, as ferramentas mais modernas, elaboradas com o 
auxílio das novas e avançadas tecnologias, não trazem grandes avanços no que diz respeito à atualização de mapeamentos.

Atualmente, com o acentuado avanço tecnológico na área de Fotogrametria digital, podem-se perceber algumas facilidades para resolver problemas como os citados por LUGNANI (1985).

Nesse sentido, este trabalho propõe uma metodologia alternativa para a atualização cartográfica, que utiliza fotografias aéreas convencionais, usadas na elaboração do mapeamento existente desatualizado, e fotografias aéreas digitais (obtidas a partir de uma câmara digital), visando extrair apenas as feições de interesse para a atualização cartográfica (novas), agilizando esse processo.

Dessa forma, a metodologia proposta, neste trabalho, procura solucionar os principais problemas, citados por LUGNANI (1985), no que diz respeito à identificação das feições novas e à preservação do apoio de campo.

\subsection{Objetivos}

\subsubsection{Objetivo geral}

O objetivo geral deste trabalho é estudar uma metodologia alternativa para a atualização cartográfica, com vistas na economia e produtividade. A metodologia está fundamentada na integração de informações de diferentes épocas, ou seja, deverá se servir de um aerolevantamento desatualizado com suas respectivas fotografias aéreas e de fotografias aéreas recentes obtidas com uma câmara fotográfica digital. 


\subsubsection{Objetivos específicos}

- Analisar a viabilidade da integração de imagens geometricamente diferentes, com vistas na formação de modelos estereoscópicos;

- Pesquisar procedimentos alternativos para a detecção de alterações, a partir de modelos estereoscópicos híbridos;

- Implementar um protótipo de Sistema Fotogramétrico Digital para a atualização cartográfica, a partir da metodologia proposta, utilizando ao máximo as rotinas existentes e, adaptando-as para o compilador $\mathrm{C}++$ Builder;

- Realizar experimentos, com dados reais, que comprovem a eficiência da metodologia proposta, indicando suas aplicabilidades e restrições. 


\section{ATUALIZAÇÃO CARTOGRÁFICA}

\subsection{Considerações iniciais}

Os interesses dos usuários de cartografia são múltiplos, pois a diversidade de trabalhos executados com o auxílio do mapeamento é grande. Juntamente com a escassez de recursos financeiros em determinados trabalhos, este fato proporciona uma busca constante por métodos alternativos de atualização de mapeamentos, que nem sempre atendem aos requisitos mais básicos da Cartografia, deixando a desejar em termos de precisão e eficiência.

De acordo com LUGNANI (1985), fatos como este dão origem a um vasto espectro de procedimentos, muitos dos quais nem são de interesse, pela precariedade do produto, pela peculiaridade do tratamento ou pela ineficiência.

Neste capítulo será feita uma breve abordagem de alguns métodos de atualização cartográfica, dando ênfase maior aos que foram efetivamente utilizados neste trabalho.

\subsection{Sensoriamento Remoto}

A atualização cartográfica por imagens orbitais é objeto de estudo de vários pesquisadores. Essas imagens mostram-se eficientes principalmente quando se trata de atualização de mapeamentos em escalas pequenas e em grandes áreas, visto que a 
área imageada é geralmente grande. A restrição comum a esse método reside no fato de a resolução das imagens não ser compatível com a precisão de produtos cartográficos em escalas grandes.

As imagens mais conhecidas e utilizadas para a atualização cartográfica são as dos satélites Landsat e Spot, das quais a que apresenta maior resolução espacial é a imagem pancromática do satélite Spot, com resolução de 10 metros.

Com o avanço tecnológico, a tendência normal é o aumento significativo da resolução espacial. Como exemplo, pode-se citar a imagem do satélite Ikonos que apresenta uma resolução de 1 metro. Esta resolução poderá proporcionar boas condições para a realização de novos estudos com o objetivo de atualização de documentos cartográficos em escalas grandes.

A detecção das alterações, ou seja, a identificação das feições a serem extraídas para atualizar os documentos cartográficos, geralmente é feita através da comparação entre as imagens do mesmo local, em datas diferentes, ou até mesmo comparando a imagem nova com o documento cartográfico a ser atualizado. A comparação entre o mapa e a imagem recente é feita visualmente, o que se constitui tarefa cansativa, morosa e muitas vezes ineficiente. Entretanto, além da comparação visual, existem técnicas utilizando processamento de imagens digitais que analisam as respostas espectrais de cada elemento, identificando as alterações ocorridas. Algumas dessas técnicas serão discutidas na seção 2.5.

\subsection{Sistema global de posicionamento (GPS)}

Uma técnica de mapeamento muito utilizada atualmente é a determinação direta de posição a partir do GPS (Global Positioning System). O sistema GPS é 
formado por 24 satélites, com órbita conhecida, emitindo constantemente sinais que são captados pelos rastreadores na superfície terrestre. Entre os receptores utilizados em cartografia existem equipamentos que apresentam diferença de custo variando de acordo com a precisão, sendo que a necessidade de precisão depende da aplicação.

Um exemplo de aplicação onde se necessita de grande precisão é o estabelecimento de uma rede geodésica de apoio para a restituição fotogramétrica ou uma rede de pontos para o controle de qualidade, ambos em documentos cartográficos de escalas grandes.

Atualmente, o grande atrativo desse sistema é a rapidez e a precisão com que as informações são coletadas em campo e processadas em gabinete.

Quando se trata de atualização, principal objetivo deste trabalho, novamente se depara com a dificuldade na detecção das alterações ocorridas no espaço objeto, pois a determinação da posição passa pela etapa da detecção da mesma e sua classificação como objeto de interesse para a atualização.

O sistema GPS, por si só, não proporciona nenhuma ferramenta de detecção de alterações. Portanto, neste caso, pode-se adotar uma combinação de métodos utilizando-se, por exemplo, a detecção de alterações por levantamento de campo, intercomunicação sistematizada entre órgãos e instituições de registro imobiliário, ou ainda por imagens aéreas.

\subsection{Fotogrametria}

No caso da detecção de alterações por diferenças observadas em imagens, orbitais ou obtidas por sensores fotográficos (fotografias aéreas convencionais, digitais e de pequeno formato), num primeiro momento somente os aspectos 
semânticos das imagens são considerados, mas por outro lado observa-se que atualmente, utilizando recursos de processamento digital de imagens, os aspectos geométricos passam a exercer um papel importante nessa atividade.

A fotografia aérea tem tido um papel fundamental na produção de mapeamentos em toda a superfície terrestre. Os resultados dos produtos cartográficos têm-se mostrado de grande eficiência, principalmente em termos de rapidez e precisão, além de proporcionar boas condições de trabalho em áreas de difícil acesso.

A evolução da Fotogrametria nos últimos anos tem contado com significativa contribuição da Informática, uma vez que cálculos matemáticos complexos podem ser programados, obtendo bons resultados, principalmente em termos de redução de tempo e aumento de precisão nos trabalhos fotogramétricos.

De acordo com LUGNANI (1987), o desenvolvimento de equipamentos, programas e técnicas de modelagem de erros sistemáticos proporcionou sensível elevação da precisão e confiabilidade dos resultados obtidos em Fotogrametria.

Por ter fundamental importância na metodologia proposta neste trabalho, serão abordados, neste capítulo, não só os aspectos semânticos da imagem, de interesse para a detecção de alterações, mas também os aspectos geométricos da formação de modelos estereoscópicos em Fotogrametria, além da determinação da posição de feições de interesse.

\subsubsection{Visão estereoscópica}

Estereoscopia é o fenômeno natural resultante da aplicação dos princípios da visão binocular à visualização de duas fotografias de um mesmo objeto, obtidas a partir de pontos de vista distintos. Quando se observa duas fotografias ao mesmo tempo e cada uma com um olho diferente, o observador poderá ver o objeto em três 
dimensões. Na prática, para obter a chamada visão binocular faz-se necessário direcionar os campos de visão do olho direito para a fotografia da direita e do olho esquerdo para a fotografia da esquerda. Existem várias maneiras de conseguir realizar esta tarefa, sendo que serão tratadas nas seções seguintes as mais conhecidas e que foram objeto de estudo deste trabalho.

A diferença na posição relativa de cada imagem ocorre apenas segundo a direção definida pelos centros de projeção (paralaxe). Esta paralaxe é a mesma para objetos situados a uma mesma distância do observador e é maior para objetos mais próximos deste. Sendo assim, a diferença de distância entre dois objetos e o observador produz uma diferença de paralaxe.

\subsubsection{Método dos estereoscópios}

Estes instrumentos são munidos de lentes e espelhos ou simplesmente lentes e são utilizados para visualizar em três dimensões as áreas superpostas das fotografias tomadas simultaneamente.

Afirma ANDRADE (1998); “... os estereoscópios munidos apenas de lentes consistem em um par de lentes convergentes, de distância focal igual ao comprimento de seu suporte. Desta maneira os raios de luz emergentes dessas lentes e oriundas de um mesmo ponto no plano focal onde são colocadas as fotografias, serão paralelos, como se o ponto estivesse situado no infinito. Isto acarretará a focalização dos cristalinos (lentes dos olhos) para o infinito, através da mudança de curvatura de suas superfícies. Conseqüentemente, o paralelismo entre os eixos ópticos dos olhos, permite que na retina de cada um projete-se a imagem fotográfica que lhe corresponde". 
O estereoscópio munido de lentes e espelhos permite um afastamento maior das fotografias aéreas que, pelas suas dimensões, ficam parcialmente superpostas quando examinadas num estereoscópio munido apenas de lentes.

\subsubsection{Método do anaglifo}

Este, um dos mais antigos, foi um método bastante utilizado em instrumentos fotogramétricos de projeção ótica.

De modo geral, pode-se dizer que este método consiste em direcionar os campos de visão dos olhos, cada um para uma fotografia, através da aplicação dos filtros vermelho e ciano (verde e azul). Existem duas variantes deste método, ou sejam, por impressão ou projeção.

\subsection{Método do anaglifo por impressão}

De acordo com ANDRADE (1998), no método anaglifo por impressão, uma das imagens, a da esquerda, por exemplo, é impressa com tinta vermelha e a da direita com tinta ciano. Dessa forma, com o filtro vermelho, o observador vê a imagem ciano em tons de cinza e, com o filtro ciano, verá a imagem vermelha em tons cinza. Portanto, quando o observador utiliza óculos com lentes, vermelha e ciano nos olhos direito e esquerdo respectivamente, a imagem tridimensional será formada em tons de cinza.

\subsection{Método do anaglifo por projeção}

Analogamente ao método anaglifo por impressão, pode-se dizer que a imagem da esquerda é agora projetada sobre uma tela branca, com um filtro vermelho, e a outra com um filtro ciano. 
Se o observador utilizar óculos cuja lente da direita for vermelha e a da esquerda for ciano, o olho esquerdo vê apenas a imagem da esquerda e o olho da direita, apenas a imagem da direita, formando assim a imagem tridimensional em tons de cinza.

\subsubsection{Método do cintilamento.}

Este método, de obtenção da visão estereoscópica, foi idealizado a partir de um dispositivo ótico-mecânico que separa os campos visuais dos olhos, esquerdo e direito, disponibilizando uma fotografia de cada vez numa freqüência maior do que $24 \mathrm{~Hz}$.

Segundo ANDRADE (1998), este método se baseia no fato de que uma imagem projetada na retina do olho humano permanece sensível pelo cérebro por cerca de 1/24 do segundo após ser ocultada.

Na prática, para a obtenção da visão estereoscópica através deste método, podem-se utilizar dispositivos óticos, mecânicos ou digitais.

Atualmente, para a Fotogrametria Digital, utiliza-se um sistema composto por monitores de computadores e óculos cintiladores para criar o efeito do cintilamento.

De acordo com WOLF \& DEWITT (2000), os monitores com a freqüência de $120 \mathrm{~Hz}$ apresentam os melhores resultados visuais. No entanto, a freqüência da maioria dos monitores é maior do que $60 \mathrm{~Hz}$ e esta técnica utiliza-se desse fato para separar os campos visuais dos olhos, projetando alternadamente as imagens da direita e da esquerda, durante aproximadamente 1/60 de segundo, usando o entrelaçamento dos monitores de vídeo e vedando, com óculos de cristal líquido, o campo visual do olho direito, enquanto a imagem da esquerda está sendo projetada e vice-versa. 
Dessa forma, o olho humano vê as duas imagens continuamente, obtendo-se a almejada visão tridimensional.

LUGNANI (1985), em sua proposta de adaptação de um instrumento restituidor, utilizou uma obstrução ótica com freqüência variável no trajeto ótico (ou na iluminação) da observação de uma das fotografias (mais recente). Nessas condições, considerando um par de fotografias de diferentes datas, ao se fazer variar a freqüência, as diferenças entre as imagens passam a piscar ou cintilar no modelo.

\subsubsection{Formação de um modelo estereoscópico.}

Uma área pode ser mapeada tridimensionalmente a partir de duas fotografias aéreas tomadas com uma câmara ocupando duas posições distintas (Cp e Cp'), proporcionando uma superposição de parte da mesma área, como mostra a Figura 01.

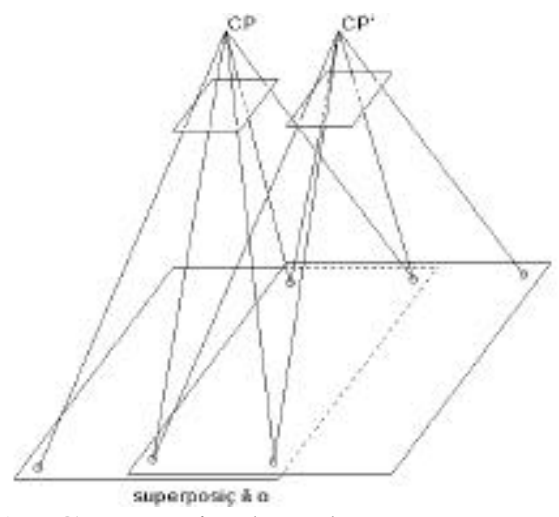

Figura 01 - Geometria da cobertura estereoscópica.

Cada fotografia pode ser considerada como um registro dos raios luminosos que partem do espaço objeto, passando pelo sistema de lentes da câmara e sensibilizando o filme fotográfico. Esse feixe de raios pode ser reconstruído através de instrumentos restituidores mecânicos ou analiticamente. Combinando-se os feixes de duas fotografias consecutivas (superposição) dá-se origem ao chamado modelo estereoscópico. 


\subsubsection{Orientação interior}

A reconstrução do feixe de raios de uma fotografia aérea pode ser feita inserindo um diapositivo em um projetor, executando a centragem do mesmo em um porta-placa através das marcas fiduciais e ajustando a distância focal nos projetores. Essa operação, chamada orientação interior analógica, recupera a geometria interna do feixe de raios.

No caso analítico e digital, para essa operação necessita-se da distância focal calibrada, bem como das coordenadas calibradas das marcas fiduciais e do ponto principal, fornecidas pelo certificado de calibração da câmara.

Um procedimento muito conhecido para realizar essa tarefa é a aplicação da transformação afim no plano (6 parâmetros) que, de acordo com TOMMASELLI (1987), é o mais aceitável para esta operação, utilizando-se as coordenadas das marcas fiduciais, fornecidas pelo certificado de calibração da câmara, como coordenadas fixas.

O modelo matemático matricial, da transformação afim, é apresentado pela equação (1).

$$
\left[\begin{array}{l}
x^{\prime} \\
y^{\prime}
\end{array}\right]=\left[\begin{array}{ll}
a 1 & a 2 \\
a 3 & a 4
\end{array}\right] *\left[\begin{array}{l}
X \\
Y
\end{array}\right]+\left[\begin{array}{c}
x_{0}^{\prime} \\
y_{0}^{\prime}
\end{array}\right]
$$

onde:

X e Y são as coordenadas calibradas das marcas fiduciais (fixas);

x`e y`são as coordenadas das marcas fiduciais, no espaço imagem;

a1, a2, a3, a4, x’’ e y’o são os parâmetros de transformação.

Esse procedimento, além de absorver as componentes lineares do trabalho do filme, executa a transformação para o sistema fiducial. 
No caso específico da Fotogrametria Digital, as imagens são obtidas a partir de um dispositivo CCD sólido, que de acordo com SHORTIS \& BEYER (1996) podem ser considerado plano, fato este que simplifica o procedimento de orientação interior, tornando necessárias apenas as translações em x e y, a transformação do sistema levógiro para o sistema dextrógiro e um fator de escala.

Segundo WOLF \& DEWITT (2000), a etapa de orientação interior pode, ainda, considerar os efeitos dos erros sistemáticos, calculando-se os efeitos das distorções radial simétrica e descentrada, além da refração fotogramétrica total (atmosférica e a provocada pelo deslocamento da aeronave). Esse procedimento é chamado de pré-refinamento das coordenadas.

As chamadas distorções das lentes, são responsáveis pelas principais perturbações que os raios de luz sofrem ao atravessar um sistema ótico, e acabam provocando o deslocamento dos objetos pertencentes à imagem.

Sabe-se que essas distorções são decorrentes do processo de fabricação e pelo fato de suas superfícies serem aproximações esféricas, provocando as principais distorções consideradas na calibração de câmaras, que são: radial simétrica e descentrada. A primeira delas é provocada pela aproximação esférica das lentes e a segunda, pelo não-perfeito alinhamento dos eixos das lentes do sistema ótico.

A distorção radial provoca deslocamentos na direção radial, a partir do ponto principal e, de acordo com BROWN (1971), as fórmulas mais utilizadas para a modelagem das componentes x e y são:

$$
\begin{aligned}
& \delta x_{r}=\left(x_{f}^{\prime}-x_{0}\right) \cdot\left(K_{1} r^{2}+K_{2} r^{4}+K_{3} r^{6}\right) \\
& \delta y_{r}=\left(y_{f}^{\prime}-y_{0}\right) \cdot\left(K_{1} r^{2}+K_{2} r^{4}+K_{3} r^{6}\right)
\end{aligned}
$$


Onde:

$x_{f}{ }^{\prime}$ e $y_{f}{ }^{\prime}$ são as coordenadas de imagem com origem no centro da imagem, ou no centro fiducial $(23 \times 23 \mathrm{~cm})$;

$x_{0}$ e $y_{0}$ são as coordenadas do ponto principal em relação ao centro da imagem;

$K_{1}, K_{2}$ e $K_{3}$ são os coeficientes da distorção radial simétrica;

$r=\left(\left(x_{f}{ }^{\prime}-x_{0}\right)+\left(y_{f}{ }^{\prime}-y_{o}\right)^{2}\right)^{\frac{1}{2}}$

Quanto à distorção descentrada, a maioria da literatura sobre esse assunto apresenta o modelo de Conrady-Brown modificado como o mais aceito para modelar as componentes $\mathrm{x}$ e $\mathrm{y}$ :

$$
\begin{aligned}
& \delta x_{d}=\left[P_{1}\left(r^{2}+2\left(x_{f}^{\prime}-x_{0}\right)^{2}\right)+2 P_{2}\left(x_{f}^{\prime}-x_{0}\right) \cdot\left(y_{f}^{\prime}-y_{0}\right)\right] \cdot\left(1+P_{3} r^{2} \ldots\right) \\
& \delta y_{d}=\left[P_{2}\left(r^{2}+2\left(y_{f}^{\prime}-y_{0}\right)^{2}\right)+2 P_{1}\left(x_{f}^{\prime}-x_{0}\right) \cdot\left(y_{f}^{\prime}-y_{0}\right)\right] \cdot\left(1+P_{3} r^{2} \ldots\right)
\end{aligned}
$$

Onde:

$x_{f}{ }^{\prime}$ e $y_{f}{ }^{\prime}$ são as coordenadas de imagem com origem no centro da imagem, ou no centro fiducial $(23 \times 23 \mathrm{~cm})$;

$x_{0}$ e $y_{0}$ são as coordenadas do ponto principal em relação ao centro da imagem;

$P_{1}, P_{2}$ e $P_{3}$ são os coeficientes da distorção descentrada.

$r=\left(\left(x_{f}{ }^{\prime}-x_{0}\right)+\left(y_{f}{ }^{\prime}-y_{o}\right)^{2}\right)^{\frac{1}{2}}$

Geralmente, os termos $P_{3}$ e superiores são desprezados, devido a sua baixa influência nos resultados. Assim, as equações (3) podem ser adotadas da seguinte forma: 


$$
\begin{aligned}
& \delta x_{d}=P_{1}\left(r^{2}+2\left(x_{f}^{\prime}-x_{0}\right)^{2}\right)+2 P_{2}\left(x_{f}^{\prime}-x_{0}\right) \cdot\left(y_{f}^{\prime}-y_{0}\right) \\
& \delta y_{d}=P_{2}\left(r^{2}+2\left(y_{f}^{\prime}-y_{0}\right)^{2}\right)+2 P_{1}\left(x_{f}^{\prime}-x_{0}\right) \cdot\left(y_{f}^{\prime}-y_{0}\right)
\end{aligned}
$$

Segundo GALO (1993), os coeficientes $P_{1}$ e $P_{2}$ também são de pequena magnitude e, em razão da precisão requerida, muitos autores desprezam esses coeficientes. O mesmo acontece com os coeficientes da distorção radial simétrica $K_{2}$ e $K_{3}$, devido a sua pequena influência na modelagem das distorções das lentes.

A refração fotogramétrica, resultante das componentes de refração atmosférica e refração provocada pelo deslocamento da aeronave, provoca um deslocamento na imagem de um objeto fotografado, podendo ser calculada, nas direções x e y, através das equações (5).

$$
\begin{aligned}
& \delta_{x}=x_{f}^{\prime} \cdot\left(1+\frac{r^{2}}{f^{2}}\right) \cdot \varepsilon_{45} \\
& \delta_{y}=y_{f}^{\prime} \cdot\left(1+\frac{r^{2}}{f^{2}}\right) \cdot \varepsilon_{45}
\end{aligned}
$$

Onde:

$\delta_{\mathrm{x}}$ e $\delta_{\mathrm{y}}$ são as distorções provocadas pela refração fotogramétrica nas direções

$$
\mathrm{x} \text { e } \mathrm{y} \text {; }
$$

$x_{f}{ }^{\prime}$ e $y_{f}{ }^{\prime}$ são as coordenadas de imagem com origem no centro da imagem, ou no centro fiducial $(23 \times 23 \mathrm{~cm})$;

f é a distância focal;

$\varepsilon_{45}$ é o ângulo de refração fotogramétrica para um ângulo nadiral de $45^{\circ}$;

$$
r=\left(\left(x_{f}{ }^{\prime}-x_{0}\right)+\left(y_{f}^{\prime}-y_{o}\right)^{2}\right)^{\frac{1}{2}}
$$


As coordenadas x e y observadas podem ser corrigidas a partir das equações (6).

$$
\begin{aligned}
& \mathrm{x}_{\text {corrigido }}=x_{f}{ }^{\prime}-\delta_{\mathrm{x}} \\
& \mathrm{y}_{\text {corrigido }}=y_{f}{ }^{\prime}-\delta_{\mathrm{y}}
\end{aligned}
$$

\subsubsection{Orientação exterior}

De acordo com ANDRADE (1998), uma fotografia aérea estará orientada segundo um referencial adotado, quando for conhecida a posição do ponto onde foi tomada a fotografia (centro de perspectiva), através de suas coordenadas $\mathrm{X}_{0}, \mathrm{Y}_{0}$ e $\mathrm{Z}_{0}$, e quando forem conhecidos os ângulos $(\omega, \varphi, \kappa)$, que definem os movimentos de rotação da câmara no momento da tomada da fotografia, em torno dos eixos de coordenadas (x, y, e z) do sistema fotogramétrico.

Pode-se dizer que um segundo projetor, contendo a segunda fotografia aérea também orientada interiormente, pode ser inclinado e transladado até que assuma a mesma posição em relação à primeira fotografia que a câmara ocupava no momento da tomada da segunda fotografia. Esse processo é chamado de orientação relativa analógica.

Concluído o processo de orientação relativa, o modelo formado precisa ser nivelado e colocado em escala, através de pontos identificados no modelo que tenham coordenadas conhecidas no espaço objeto. A esse processo dá-se o nome de orientação absoluta. As orientações relativa e absoluta fazem parte do processo conhecido como orientação exterior. Ao par estereoscópico assim orientado dá-se o nome de modelo estereoscópico. 


\subsubsection{Resseção espacial}

Segundo LUGNANI (1987), a aplicação da resseção espacial em uma foto consiste em calcular os parâmetros de orientação exterior da câmara $\left(\mathrm{X}_{0}, \mathrm{Y}_{0}, \mathrm{Z}_{0}, \omega, \varphi, \kappa\right)$, a partir das fotocoordenadas $\left(\mathrm{x}_{\mathrm{i}}, \mathrm{y}_{\mathrm{i}}\right)$ de $\mathrm{n}$ pontos $\mathrm{p}_{\mathrm{i}}(\mathrm{n}>3)$, das coordenadas $\left(\mathrm{X}_{\mathrm{i}}, \mathrm{Y}_{\mathrm{i}}, \mathrm{Z}_{\mathrm{i}}\right)$ dos pontos correspondentes no espaço objeto, da constante da câmara f e dos valores aproximados dos parâmetros incógnitos $\left(\mathrm{X}_{0}{ }^{\mathrm{a}}, \mathrm{Y}_{0}{ }^{\mathrm{a}}, \mathrm{Z}_{0}^{\mathrm{a}}\right.$, $\left.\omega^{\mathrm{a}}, \varphi^{\mathrm{a}}, \kappa^{\mathrm{a}}\right)$.

Matematicamente, cada ponto observado dá origem a duas equações; assim sendo, três pontos resultariam em uma solução única. No entanto, são utilizadas observações superabundantes, objetivando a utilização do MMQ (Método dos Mínimos Quadrados).

O relacionamento entre o espaço imagem e o espaço objeto é realizado a partir da equação de colinearidade.

\subsubsection{Equações de colinearidade}

Sabe-se que a geometria de um par de fotografias aéreas com superposição adequada permite a formação de um modelo estereoscópico, por interseção dos raios homólogos.

É com base nesse pressuposto que se desenvolve toda a teoria da Fotogrametria moderna. Essa teoria pode ser encontrada em vários livros textos de Fotogrametria analítica, mas mesmo assim, para orientar e facilitar a leitura deste trabalho, apresenta-se a seguir um resumo dessa teoria.

O espaço objeto e o espaço imagem estão relacionados através da equação de colinearidade: 


$$
\begin{aligned}
& x=f * \frac{m_{11}\left(X-X_{0}\right)+m_{12}\left(Y-Y_{0}\right)+m_{13}\left(Z-Z_{0}\right)}{m_{31}\left(X-X_{0}\right)+m_{32}\left(Y-Y_{0}\right)+m_{33}\left(Z-Z_{0}\right)} \\
& y=f * \frac{m_{21}\left(X-X_{0}\right)+m_{22}\left(Y-Y_{0}\right)+m_{23}\left(Z-Z_{0}\right)}{m_{31}\left(X-X_{0}\right)+m_{32}\left(Y-Y_{0}\right)+m_{33}\left(Z-Z_{0}\right)}
\end{aligned}
$$

onde:

x e y são as coordenadas refinadas, de um ponto $\mathbf{P}$ no espaço imagem e no sistema fotogramétrico;

f é a distância focal calibrada;

$\mathrm{m}_{\mathrm{ij}}$ são os elementos da matriz de rotação, em função dos ângulos de orientação da câmara $(\omega, \varphi, \kappa)$ :

$$
m=\left[\begin{array}{ccc}
\cos \varphi * \cos \kappa & \cos \omega * \operatorname{sen} \kappa+\operatorname{sen} \omega * \operatorname{sen} \varphi * \cos \kappa & \operatorname{sen} \omega * \operatorname{sen} \kappa-\cos \omega * \operatorname{sen} \varphi * \cos \kappa \\
-\cos \varphi * \operatorname{sen} \kappa & \cos \omega * \cos \kappa-\operatorname{sen} \omega * \operatorname{sen} \varphi * \operatorname{sen} \kappa & \operatorname{sen} \omega * \cos \kappa+\cos \omega * \operatorname{sen} \varphi * \operatorname{sen} \kappa \\
\operatorname{sen} \varphi & -\operatorname{sen} \omega * \cos \varphi & \cos \omega * \cos \varphi
\end{array}\right]
$$

$\mathrm{X}_{0}, \mathrm{Y}_{0}, \mathrm{Z}_{0}$ são as coordenadas do centro perspectivo da câmara, no referencial do espaço objeto;

$\mathrm{X}, \mathrm{Y}, \mathrm{Z}$ são as coordenadas do ponto $\mathbf{P}$, no espaço objeto e no sistema de referência estabelecido (cartesiano tridimensional e dextrógiro).

Para a formação de um modelo tridimensional são utilizadas duas fotografias e, portanto, envolvem-se nesse processo dois sistemas fotogramétricos (cada um com origem em um centro de projeção) com dois conjuntos de parâmetros de orientação, sendo que os pontos de referência, no espaço objeto, são comuns às duas fotos, como mostra a Figura 02. 


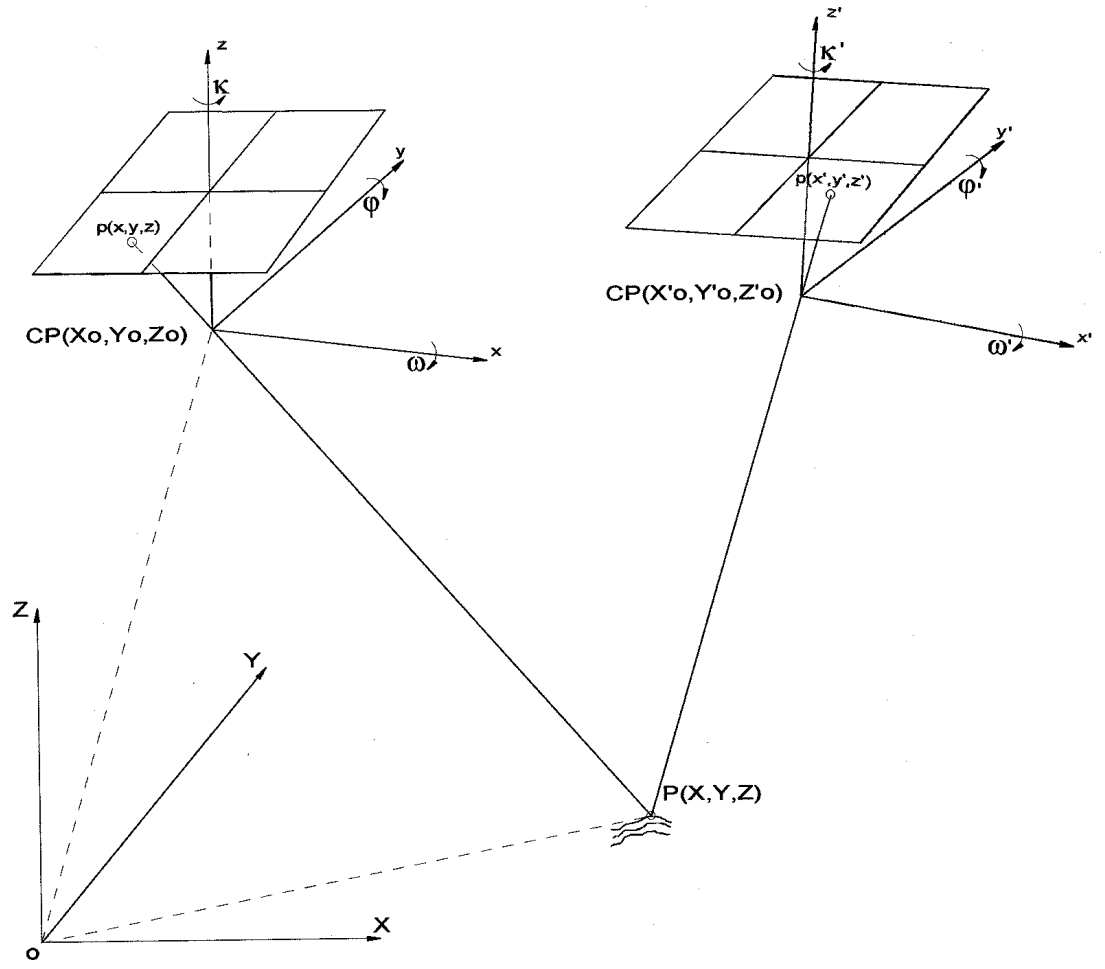

Figura 02 - Formação do modelo estereoscópico a partir da equação de colinearidade.

O modelo matemático da equação de colinearidade é do tipo explícito, ou seja, as quantidades observadas são funções explícitas das quantidades a serem determinadas (incógnitas), ou seja:

$$
\mathrm{L}_{\mathrm{a}}=\mathrm{F}\left(\mathrm{X}_{\mathrm{a}}\right)
$$

Este modelo, linearizado produz:

$$
\text { A. } X+L=V
$$


onde:

$L=L_{0}-L_{b}$

$\mathrm{L}_{\mathrm{b}}=$ vetor das observações $\left(\mathrm{x}_{1}, \mathrm{y}_{1}, \ldots, \mathrm{x}_{\mathrm{n}}, \mathrm{y}_{\mathrm{n}}\right)$

$\mathrm{L}_{0}=\mathrm{F}\left(\mathrm{X}_{0}\right)$

$\mathrm{X}_{0}=$ vetor dos parâmetros aproximados $\left(\kappa^{\mathrm{a}}, \varphi^{\prime \mathrm{a}}, \omega^{\prime \mathrm{a}}, \mathrm{X}_{0}{ }^{\mathrm{a}}, \mathrm{Y}_{0}{ }^{\mathrm{a}}, \mathrm{Z}_{0}{ }^{\mathrm{a}}, \kappa^{\prime \prime \mathrm{a}}, \varphi^{\prime \prime \mathrm{a}}, \omega^{\prime \prime \mathrm{a}}\right.$, $\left.\mathrm{X}_{0}{ }^{, \mathrm{a}}, \mathrm{Y}_{0}{ }^{,}, \mathrm{Z}_{0}{ }^{, a} \mathrm{X}^{1}, \mathrm{Y}^{1}, \mathrm{Z}^{1}, \ldots, \mathrm{X}^{\mathrm{n}}, \mathrm{Y}^{\mathrm{n}}, \mathrm{Z}^{\mathrm{n}}\right)$

$\kappa^{\mathrm{a}}, \varphi^{\mathrm{a}}, \omega^{\mathrm{a}}$ são as rotações aproximadas da câmara;

$\mathrm{X}_{0}{ }^{\mathrm{a}}, \mathrm{Y}_{0}{ }^{\mathrm{a}}, \mathrm{Z}_{0}{ }^{\mathrm{a}}$ são as coordenadas aproximadas do Centro Perspectivo;

$\mathrm{X}^{1}, \mathrm{Y}^{1}, \mathrm{Z}^{1}, \ldots ., \mathrm{X}^{\mathrm{n}}, \mathrm{Y}^{\mathrm{n}}, \mathrm{Z}^{\mathrm{n}}$ são as coordenadas dos pontos no terreno.

A é a matriz das derivadas parciais, resultado da linearização de $F\left(X_{a}\right)$, no ponto de expansão Xo.

$$
A=\frac{\partial F}{\partial X_{a}} \mid X_{0}
$$

$\mathrm{X}_{\mathrm{a}}$ é o vetor dos parâmetros ajustados $\left(\kappa^{\prime}, \varphi^{\prime}, \omega^{\prime}, \mathrm{X}_{0}{ }^{\prime}, \mathrm{Y}_{0}^{\prime}, \mathrm{Z}_{0}^{\prime}, \kappa^{\prime \prime}, \varphi^{\prime \prime}, \omega^{\prime \prime}, \mathrm{X}_{0}^{\prime \prime}, \mathrm{Y}_{0}\right.$ ”, $\left.\mathrm{Z}_{0}{ }^{\prime}, \mathrm{X}^{1}, \mathrm{Y}^{1}, \mathrm{Z}^{1}, \ldots ., \mathrm{X}^{\mathrm{n}}, \mathrm{Y}^{\mathrm{n}}, \mathrm{Z}^{\mathrm{n}}\right)$

$$
\begin{aligned}
& X_{a}=X_{0}+X \\
& X=-\left(A^{T} P A\right)^{-1} \cdot\left(A^{T} P L\right) \\
& \Sigma X=\hat{\sigma}_{0}{ }^{2} \cdot N^{-1}
\end{aligned}
$$

¿X é a matriz variância - covariância dos parâmetros ajustados;

$\hat{\sigma}_{0}^{2}$ é a variância da observação de peso unitário a posteriori;

$N^{-1}=\left(A^{T} P A\right)^{-1}$, ou seja, inversa da matriz normal. 


$$
\begin{aligned}
& P=\sigma_{0}{ }^{2} Q_{11}{ }^{-1} \\
& Q_{11}=\left[\begin{array}{llll}
\sigma_{1}{ }^{2} & & \\
& \sigma_{2}{ }^{2} & & \\
& & \cdot & \\
& & & \sigma_{n}{ }^{2}
\end{array}\right]
\end{aligned}
$$

$\sigma_{i}{ }^{2}$ é a precisão das observações

$\sigma_{0}^{2}=$ Variância a priori

O desenvolvimento anterior considera o caso genérico da orientação relativa, onde se movimentam as duas câmaras, mas pode-se optar por movimentar apenas uma das câmaras, mantendo-se a outra fixa. Esta é a chamada orientação relativa dependente, que utiliza valores fixos (injunções) para os parâmetros de orientação de uma câmara, calculando-se apenas os parâmetros de orientação da outra, fixando-se a escala.

O modelo matemático da injunção relativa é dado pela seguinte equação:

$$
X_{a}=L_{x} \quad \text { ou } \quad L_{x}=G\left(X_{a}\right)=X_{a}
$$

Da equação (8), temos:

$$
\mathrm{L}_{\mathrm{a}}=\mathrm{F}\left(\mathrm{X}_{\mathrm{a}}\right)
$$

Linearizando, temos:

$$
\begin{aligned}
& A . X+L=v \\
& C . X+L x^{\prime}=v x
\end{aligned}
$$

Onde:

$$
\begin{aligned}
& \mathrm{L}_{\mathrm{x}}=\mathrm{L}_{\mathrm{o}}-\mathrm{L}_{\mathrm{x}} \text { e } \mathrm{L}_{\mathrm{o}}=\mathrm{G}\left(\mathrm{X}_{\mathrm{o}}\right) \text { ou } \mathrm{L}_{\mathrm{o}}=\mathrm{X}_{\mathrm{o}} \\
& \mathrm{L}_{\mathrm{o}}=\text { valor do parâmetro estimado } \\
& \mathrm{L}_{\mathrm{x}}=\text { valor do parâmetro fixado (injunção) }
\end{aligned}
$$

Aplicando-se as injunções na equação (12), temos:

$$
X=-\left(A^{T} P A+C^{T} P_{x} C\right)^{-1} \cdot\left(A^{T} P L+C^{T} P_{x} C_{x}\right)
$$


Onde:

$\mathrm{P}_{\mathrm{x}}=$ matriz peso das injunções;

$$
p_{x_{i i}}=\frac{\sigma_{0}^{2}}{\sigma_{x i}^{2}}
$$

$\sigma_{0}^{2}=$ Variância das observações de peso unitário

$\sigma_{\mathrm{xi}}{ }^{2}=$ Variância do valor fixo, correspondente ao valor a ser fixado

$C=\frac{\partial G}{\partial X_{a}} \mid X_{0}$

Para o caso da orientação relativa dependente convencional, considerando-se as injunções absolutas $\left(\kappa^{\prime}, \varphi^{\prime}, \omega^{\prime}, \mathrm{X}_{0}{ }^{\prime}, \mathrm{Y}_{0}{ }^{\prime}, \mathrm{Z}_{0}{ }^{\prime}\right)=0$ e $\mathrm{X}_{0}{ }^{\prime \prime}=$ constante arbitrada , a matriz $\mathrm{C}$ apresenta-se da seguinte forma:

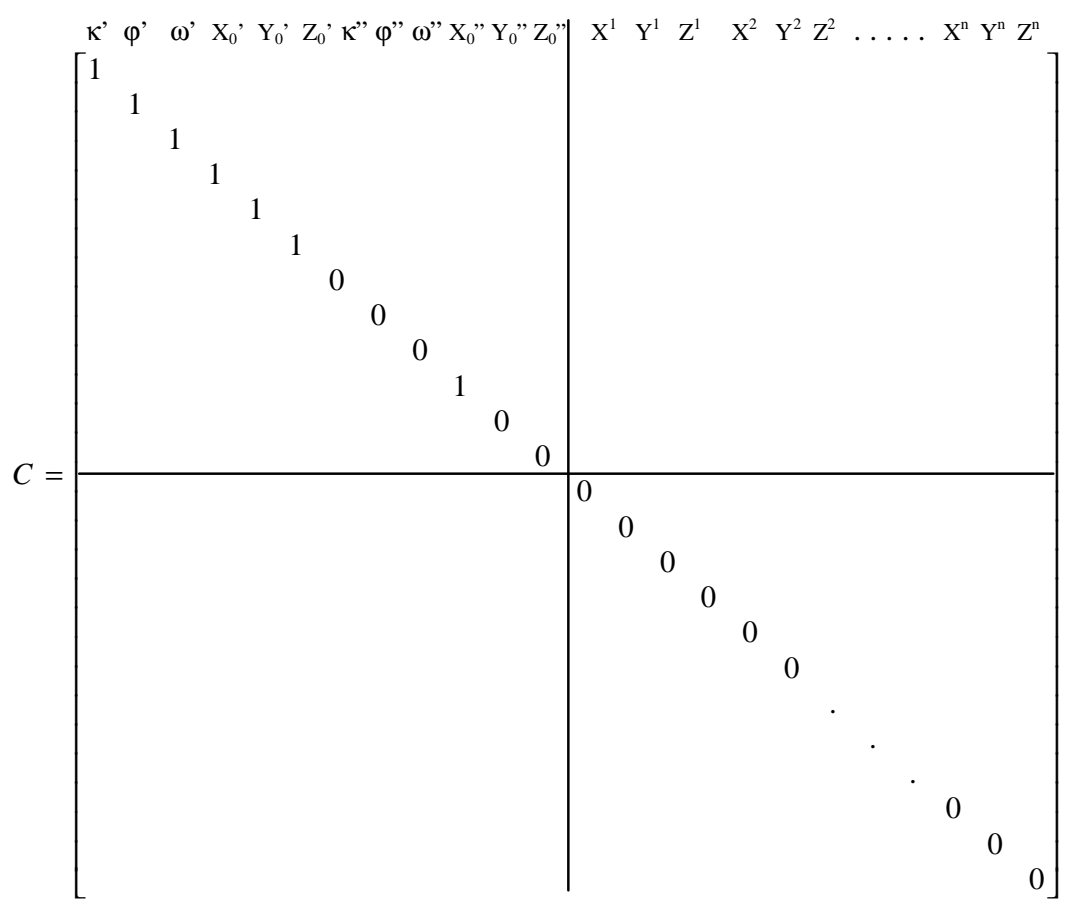

Para o caso da orientação simultânea (fototriângulação com duas fotos), os parâmetros $\kappa^{\prime}, \varphi^{\prime}, \omega^{\prime}, X_{0}{ }^{\prime}, Y_{0}^{\prime}, Z_{0}^{\prime}, \kappa^{\prime \prime}, \varphi^{\prime}, \omega^{\prime \prime}, X_{0}$ ”, $Y_{0}$ ” e $Z_{0}$ ” não são conhecidos, necessitando de pelo menos 6 pontos observados, sendo 3 deles com coordenadas conhecidas. Sendo assim, a matriz C apresenta-se da seguinte forma: 


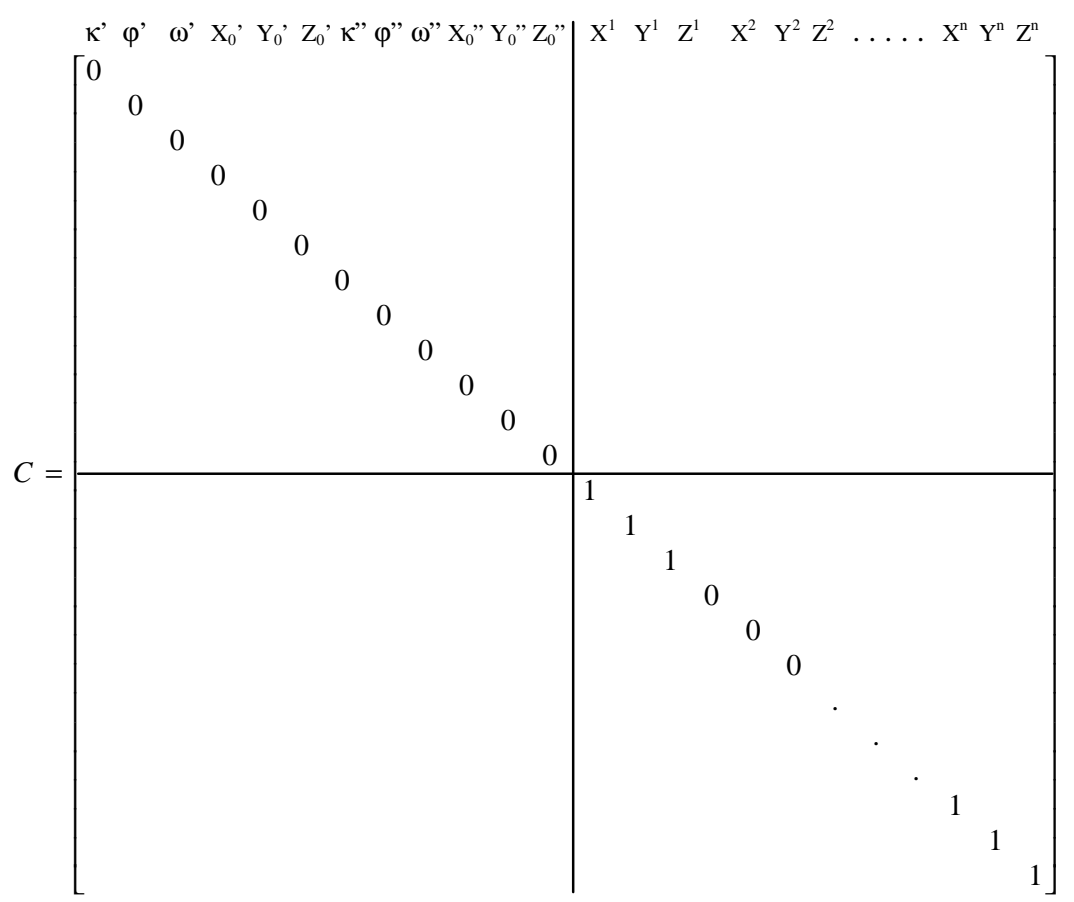

Particularizando-se para o caso proposto, em que a orientação simultânea (relativa dependente) é executada fixando-se os parâmetros de orientação exterior da primeira foto $\left(\kappa^{\prime}, \varphi^{\prime}, \omega^{\prime}, X_{0}, Y_{0}^{\prime}, Z_{0}^{\prime}\right)$ e, utilizando-se um ponto de apoio, a matriz $\mathrm{C}$ apresenta-se da seguinte forma:

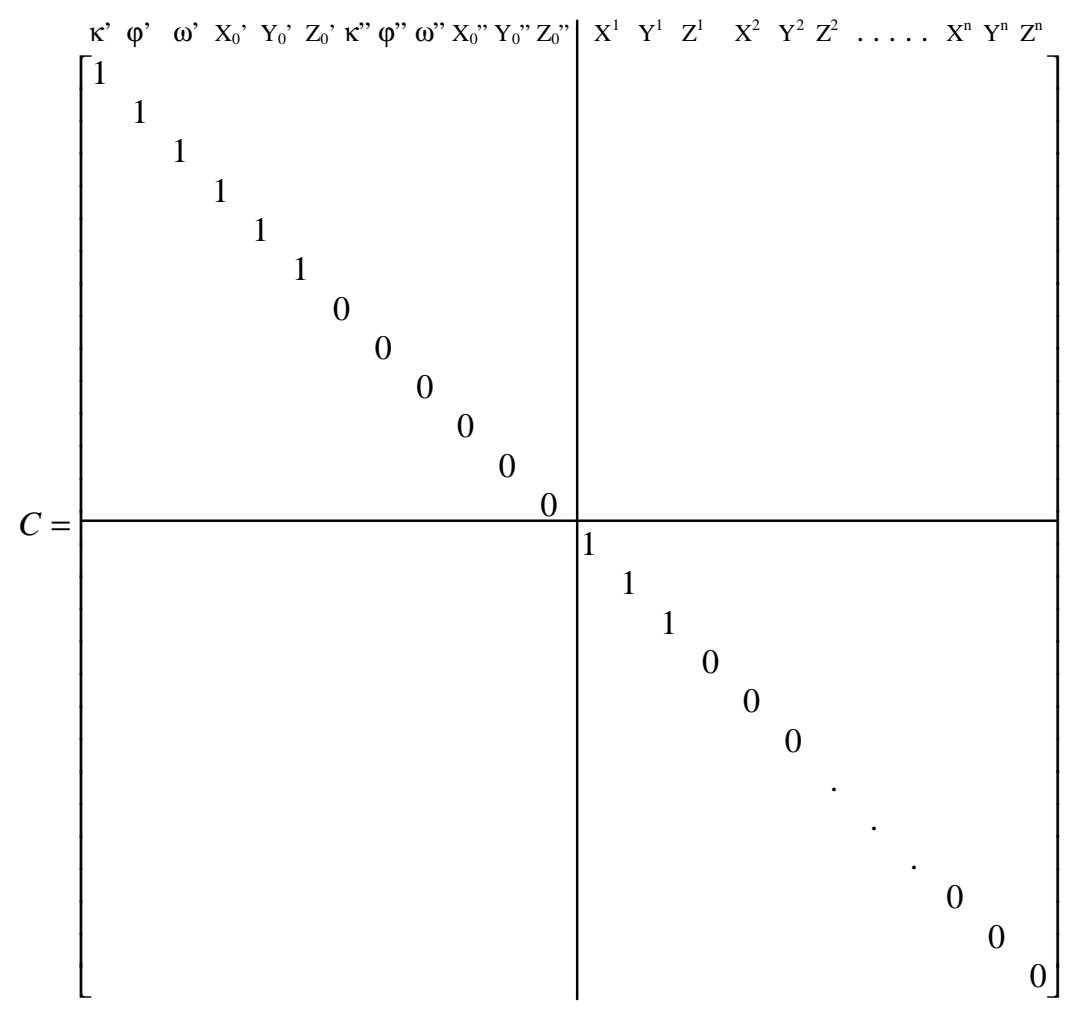


Nota-se, portanto, que qualquer ponto de apoio pode ser utilizado, além disso, podem ser utilizados vários pontos de apoio ou, até mesmo, distâncias conchecidas.

Vale ressaltar que o mesmo modelo pode ser expandido para uma fototriangulação com várias fotografias e até mesmo para calibração, utilizando várias fotos e parâmetros de orientação interior.

\subsubsection{Calibração de câmaras}

As câmaras fotogramétricas convencionais são construídas com o objetivo de obter fotografias com alta qualidade, permitindo que se faça sobre elas medidas com precisão.

Para garantir a confiabilidade nos trabalhos fotogramétricos, é de grande importância o conhecimento do grupo de parâmetros, determinados por um processo de calibração, necessários à reconstrução do feixe perspectivo que gera a imagem fotográfica, no instante da exposição do filme à luz refletida pelo objeto fotografado.

Existem vários métodos utilizados para calibrar uma câmara, entre os quais, optou-se por fazer uma breve abordagem apenas do método utilizado neste trabalho.

Os métodos para a obtenção desses parâmetros foram desenvolvidos com vistas no aparato existente, há muitos anos, (para câmaras analógicas) e, de acordo com GALO (1993), com a modernização dos dispositivos de aquisição de dados, as técnicas devem ser revistas, pesquisadas e atualizadas, visando sua aplicação nesses dispositivos. Tais pesquisas são essenciais, pois algumas das fontes de erro nas câmaras digitais, são completamente diferentes das fontes de erros apresentadas por uma câmara convencional, com a ressalva das distorções provocadas pelo sistema de lentes, discutida na seção 2.4.2.1, uma vez que a teoria desenvolvida para explicar tais distorções é a mesma. 
A não-ortogonalidade e até mesmo a planura do dispositivo $\mathrm{CCD}$, em câmaras como as do tipo utilizado neste trabalho, necessitam de investigações que possibilitem a parametrização desses erros.

Um fato relevante que deve ser considerado é que boa parte das câmaras, digitais e não-métricas, possuem dispositivos de compensação de foco para melhorar a qualidade semântica da imagem e isso faz com que a distância focal possa ser diferente para cada imagem obtida com a mesma câmara, dependendo da altura de vôo. Nesse caso, como alguns parâmetros estão relacionados com a distância focal, é comum o procedimento de autocalibração, que é a determinação dos parâmetros inerentes à câmara e os parâmetros que definem a posição e orientação da câmara no referencial do espaço objeto, além de alguns pontos do espaço objeto, simultaneamente.

Vale dizer que, se todos esses pontos tiverem as coordenadas conhecidas e apenas os parâmetros anteriormente citados forem determinados, esse procedimento é denominado pré-calibração, sendo que esses parâmetros podem ser utilizados para um posterior refinamento das coordenadas.

O modelo matemático funcional utilizado na autocalibração por GALO

(1993) é o modelo de colinearidade, considerando-se os seguintes parâmetros:

- $\quad \mathrm{f}=$ distancia focal;

- $\mathrm{x}_{0}, \mathrm{y}_{0}=$ coordenadas do ponto principal;

- $\mathrm{K}_{1}, \mathrm{~K}_{2}, \mathrm{~K}_{3}=$ coeficientes da distorção radial simétrica;

- $\mathrm{P}_{1}, \mathrm{P}_{2}=$ coeficientes da distorção descentrada;

- $\quad$ A, B = parâmetros de afinidade ${ }^{1}$;

\footnotetext{
${ }^{1}$ São parâmetros que modelam a não-perpendicularidade dos eixos de um comparador e não foram aqui abordados porque não foram considerados na execução dos experimentos deste trabalho.
} 
- $\quad \omega, \varphi, \kappa=$ rotações da câmara em torno dos eixos $\mathrm{X}, \mathrm{Y}$ e $\mathrm{Z}$ respectivamente;

- $\mathrm{X}_{0}, \mathrm{Y}_{0}, \mathrm{Z}_{0}=$ coordenadas do centro perspectivo;

- $\quad \mathrm{X}, \mathrm{Y}, \mathrm{Z}=$ coordenadas dos pontos considerados, no espaço objeto.

O modelo de colinearidade também é utilizado pelo programa CALIBRA, implementado por TOMMASELLI \& NOBREGA (1997), considerando que os erros sistemáticos de maior interesse neste processo são: a distorção das lentes, o deslocamento do centro da imagem e um fator de escala na direção x. Com isso, demonstram em seus estudos que a distorção radial simétrica, em câmaras digitais pode ser modelada por um polinômio simples, desprezando-se os termos de ordem superior das equações (2). Não são considerados os termos da distorção descentrada, porque seu efeito é muito menor que os erros de medida; considera-se o tamanho do pixel e a geometria da câmara. Sendo assim, as equações (2) são apresentadas da seguinte forma:

$$
\begin{aligned}
& \delta x_{r}=\left(x_{f}^{\prime}-x_{0}\right) \cdot\left(K_{1} r^{2}\right) \\
& \delta y_{r}=\left(y_{f}^{\prime}-y_{0}\right) \cdot\left(K_{1} r^{2}\right)
\end{aligned}
$$

Onde:

$x_{f}^{\prime}$ e $y_{f}^{\prime}$ são as coordenadas de imagem com origem no centro da imagem;

$x_{0}$ e $y_{0}$ são as coordenadas do ponto principal em relação ao centro da imagem;

$K_{1}$ é o coeficiente de $1^{\underline{a}}$ ordem da distorção radial simétrica;

$$
r=\left(\left(x_{f}{ }^{\prime}-x_{0}\right)+\left(y_{f}{ }^{\prime}-y_{o}\right)^{2}\right)^{\frac{1}{2}}
$$

Ainda segundo TOMMASELLI \& NOBREGA (1997), o sistema de coordenadas usado no computador é baseado na posição de um pixel na memória, ou seja, as coordenadas estão relacionadas ao número de pixeis, não representando o distanciamento real entre estes na câmara. A transformação do sistema de coordenadas 
da imagem para o sistema de coordenadas do "frame buffer"2 requer, no mínimo, duas translações e uma escala. Normalmente a escala em y é arbitrada como unitária, pois é definida pela distância entre as linhas adjacentes, enquanto a escala em x deve ser calibrada. Essa diferença entre escala em x e escala em y pode ser desconsiderada nas câmaras digitais modernas, que garantem uma geometria "quadrada" para o pixel.

Por convenção, a origem do referencial de máquina "frame buffer" é adotada no canto superior esquerdo da imagem. Mesmo que essa origem fosse estabelecida no centro do "frame buffer" não haveria coincidência com a origem do referencial da imagem (ponto principal), porquanto é fisicamente muito difícil alinhar o eixo ótico da câmara com o ponto central da área de imageamento. O ponto principal é a origem do referencial da imagem em relação ao referencial de máquina.

O modelo matemático, utilizado pelo programa CALIBRA, que relaciona as coordenadas dos pontos de controle no espaço objeto e suas homólogas, no referencial de máquina "frame buffer", considerando apenas os erros sistemáticos de grande magnitude é dado pelas equações (20).

$$
\begin{array}{r}
x_{f}=x_{0}-\delta x_{r}-\left(x_{f}{ }^{\prime}-x_{0}\right) \cdot d s+f * \frac{m_{11}\left(X-X_{0}\right)+m_{12}\left(Y-Y_{0}\right)+m_{13}\left(Z-Z_{0}\right)}{m_{31}\left(X-X_{0}\right)+m_{32}\left(Y-Y_{0}\right)+m_{33}\left(Z-Z_{0}\right)} \\
y_{f}=y_{0}-\delta y_{r}+f * \frac{m_{21}\left(X-X_{0}\right)+m_{22}\left(Y-Y_{0}\right)+m_{23}\left(Z-Z_{0}\right)}{m_{31}\left(X-X_{0}\right)+m_{32}\left(Y-Y_{0}\right)+m_{33}\left(Z-Z_{0}\right)}
\end{array}
$$

Onde: $x_{f}$ e $y_{f}$ são as coordenadas de máquina com origem no "frame buffer";

$x_{f}{ }^{\prime}$ e $y_{f}{ }^{\prime}$ são as coordenadas de imagem com origem no centro da imagem;

$x_{0}$ e $y_{0}$ são as coordenadas do ponto principal em relação ao centro da imagem;

$\delta x_{r}$ e $\delta y_{r}$ são as componentes da distorção radial em x e y respectivamente;

\footnotetext{
${ }^{2}$ Memória de alta velocidade reservada para armazenar uma ou mais cenas, permitindo a sua rápida visualização no display.
} 
$f \quad$ é a distância focal;

ds é o fator de escala na direção x;

$\mathrm{m}_{\mathrm{ij}}$ são os elementos da matriz de rotação, em função dos ângulos de orientação da câmara $(\omega, \varphi, \kappa)$;

$\mathrm{X}_{0}, \mathrm{Y}_{0}, \mathrm{Z}_{0}$ são as coordenadas do centro perspectivo da câmara, no referencial do espaço objeto;

$\mathrm{X}, \mathrm{Y}, \mathrm{Z}$ são as coordenadas do ponto $\mathbf{P}$ no espaço objeto e no sistema de referência estabelecido. (cartesiano tridimensional e dextrógiro)

Segundo TOMMASELLI \& NOBREGA (1997), no caso de imagens digitais, coletadas por câmaras como a utilizada neste trabalho, o fator de escala em x (ds) é desprezível, podendo ser considerado apenas para imagens coletadas por câmaras de vídeo.

\subsubsection{Retificação de imagens digitais}

Sabe-se que as equações de colinearidade, além das aplicações citadas anteriormente, comumente são utilizadas no processo de retificação de imagens obtidas por projeção perspectiva, como é o caso das fotografias aéreas convencionais e digitais.

Segundo WOLF (1983), retificar uma fotografia é construir uma fotografia vertical equivalente ao negativo inclinado, tornando-a teoricamente verdadeira por estar livre das distorções (geométricas) causadas pelos deslocamentos devido à inclinação da câmara. Porém, não se deve esquecer que a imagem ainda não está livre das distorções causadas pelos deslocamentos devido ao relevo, que podem ser minimizados por procedimentos de retificação diferencial ou ortoretificação. A Figura 03 mostra a diferença entre as fotografias, original e retificada. 


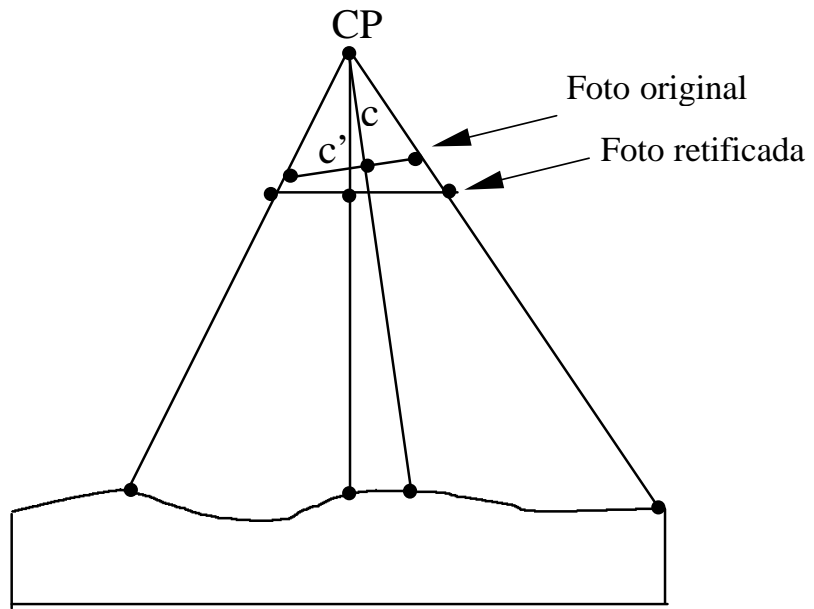

Figura 03 - Retificação de uma fotografia.

Segundo CHO et al. (1992), a maioria dos algoritmos, em Visão Computacional e Fotogrametria Digital, é baseada na suposição de que o estéreo-par digital é registrado em geometria epipolar, isto é, sem paralaxe em y. Essa condição está satisfeita quando os eixos óticos das duas câmaras são paralelos, perpendiculares à base do modelo e são alinhados os eixos x e x', como pode ser visto na Figura 04.

Um estéreo-par em geometria epipolar, sendo $\mathrm{Cp}$ e Cp' os centros de projeção, é mostrado na Figura 04. O plano epipolar é definido pela projeção dos dois centros e do ponto $\mathrm{P}$, no espaço objeto. As linhas epipolares e e e' são as intersecções do plano epipolar com os planos das imagens.

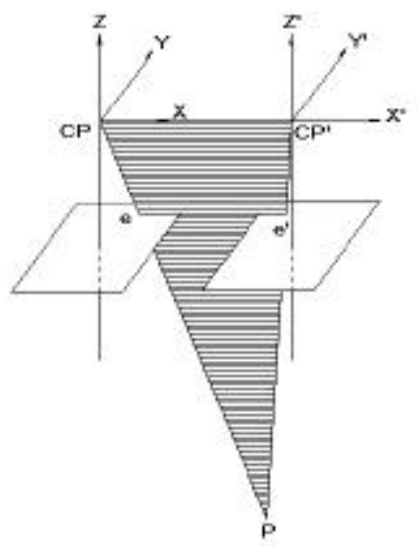

Figura 04- Geometria Epipolar. (Adaptada de CHO et al. (1992)) 
De acordo com ANDRADE (1998), para a retificação de uma fotografia, fazse necessário anular os ângulos $\varphi$ e $\omega$, minimizar as distorções geométricas e aplicar um fator de escala. Além disso, considerando que não existe correspondência biunívoca entre os pixeis da imagem retificada e da imagem original, existe a necessidade da reamostragem, que neste trabalho foi implementada com o processo de interpolação bilinear. (equação 21)

$$
\begin{gathered}
A^{\prime}(k, 1)=A(i, j)+d x *(A(i+1, j)-A(i, j))+d y *(A(i, j+1)-A(i, j)+ \\
+d x * d y *(A(i, j)-A(i+1, j)-A(i, j+1)+A(i+1, j+1))
\end{gathered}
$$

Onde:

dx e dy: diferenças entre os valores calculados, em números reais, das coordenadas definidoras da posição de um pixel e os seus valores inteiros menores;

$\mathrm{A}^{\prime}$ : valor reamostrado do pixel na posição $(\mathrm{k}, 1)$;

A: valor do pixel no "bitmap" original.

\subsection{Detecção de alterações}

Segundo SINGH (1989), a detecção de alterações é um processo de identificação das mudanças no estado de um objeto através da sua observação em épocas diferentes. Essencialmente, esse procedimento envolve a capacidade de quantificação dos efeitos num espaço de tempo, mediante o uso de um conjunto de dados obtidos em duas ou mais datas diferentes. 


\subsubsection{Detecção de alterações a partir de imagens digitais}

A premissa básica no uso de dados de imagem digital para detecção de alterações consiste em que mudanças na superfície terrestre devem resultar em alterações nos valores das radiâncias e essas alterações devem ser grandes, quando comparadas às alterações de radiâncias causadas por outros fatores. Nesses outros fatores, incluem-se, por exemplo, as condições atmosféricas, os diferentes ângulos de incidência dos raios solares, e a diferença de umidade no solo na época da obtenção da imagem. O impacto desses fatores pode ser reduzido parcialmente, pela seleção dos dados apropriados, ou seja, escolhendo uma imagem com condições físicas e ambientais aproximadamente iguais às condições da primeira imagem.

Vários procedimentos de detecção de alterações na superfície terrestre, por meio de dados digitais, que podem auxiliar na atualização cartográfica, têm sido propostos.

A detecção digital de alterações pode ser caracterizada principalmente por procedimentos de transformação de dados, bem como por técnicas de análises usadas para delinear áreas de alterações significativas.

De acordo com GONZALES \& WOODS (1993), as maneiras básicas para a detecção de alterações são: a análise comparativa independente da classificação do produto por diferentes datas e as análises simultâneas de dados multitemporais.

A resolução espacial das duas imagens é essencial para muitos métodos de detecção. Isso requer o uso de algoritmos de retificação geométrica e reamostragem. 


\subsubsection{Limiarização}

Se uma imagem I(x,y) contém objetos brilhantes (alterações) sobre um fundo escuro (sem alterações), então esses objetos podem ser extraídos por uma simples limiarização.

$$
I(x, y)=\left[\begin{array}{ll}
1 & I(x, y)>T \\
0 & I(x, y) \leq T
\end{array}\right.
$$

Onde: $\mathrm{T}=$ valor do limiar fornecido empiricamente ou estatisticamente pelo analista.

Todos os pixeis que pertencem ao objeto (alteração) são codificados como (1), e o fundo (sem alterações) é codificado como (zero). Se houver a necessidade de definir mais do que um objeto limiar, pode-se usar uma técnica de fatiamento de densidade. Nessa técnica, vários objetos de diferentes valores de pixeis são agrupados dentro das fatias predefinidas.

“A limiarização dos níveis de cinza pode ser feita interativamente com um monitor e cursor, mas a seleção do melhor nível de limiar deve ser usualmente associada com um conhecimento a priori ao redor da cena ou interpretação visual para ser significativo. Os valores do limiar podem também ser derivados do histograma da imagem." SCHOWENGERDT (1983) $)^{3}$ apud GONZALES \& WOODS (1993).

\subsubsection{Técnicas digitais de detecção de alterações}

\subsubsection{Diferenciação de imagem univariada.}

Nesta técnica, imagens registradas espacialmente nos tempos $t_{1}$ e $t_{2}$, são subtraídas, pixel por pixel, para produzir mais uma imagem, que representa a alteração entre as duas datas.

\footnotetext{
${ }^{3}$ SCHOWENGERDT, R. A. Techniques for image processing and classification in Remote Sensing. New York, 1983.
} 
Matematicamente, temos:

$$
D x_{i j}{ }^{k}=x_{i j}{ }^{k}\left(t_{2}\right)-x_{i j}{ }^{k}\left(t_{1}\right)+C
$$

onde: $x_{i j}{ }^{k}=$ valor do pixel na banda $\mathrm{k}$, sendo que "i” e "j”" definem a localização do pixel na imagem (linha e coluna);

$\mathrm{t}_{1}=1^{\mathrm{a}}$ data;

$\mathrm{t}_{2}=2^{\mathrm{a}}$ data;

$\mathrm{C}=$ constante para produzir valores positivos.

A entrada dos dados pode ser com a imagem bruta ou após uma filtragem, de acordo com a particularidade da aplicação.

\subsubsection{Regressão de Imagem}

No método da regressão, os pixeis da imagem da $1^{\text {a }}$ data são assumidos como sendo uma função linear dos pixeis da imagem da $2^{\mathrm{a}}$ data. Portanto $x_{i j}{ }^{k}\left(t_{1}\right)$ pode regredir à $x_{i j}{ }^{k}\left(t_{2}\right)$ mediante o uso de uma regressão por mínimos quadrados (x é o valor do pixel, i é a linha, $\mathrm{j}$ é a coluna, e k é a banda). Se $x_{i j}{ }^{k}\left(t_{2}\right)$ for obtido pela regressão linear, a diferença da imagem pode ser definida através da seguinte expressão :

$$
D x_{i j}{ }^{k}=x_{i j}^{\prime}{ }^{k}\left(t_{2}\right)-x_{i j}{ }^{k}\left(t_{1}\right)
$$

A técnica de regressão considera diferenças na média e variância entre valores dos pixeis através de diferentes épocas; portanto, considera fatores que afetam os valores de radiância tais como, condições atmosféricas e ângulo de incidência de raios solares.

Segundo SINGH (1989), o procedimento de regressão é melhor do que a técnica de diferenciação de imagem univariada para a detecção de alterações em áreas urbanas. 


\subsubsection{Racionamento de Imagem}

O racionamento é considerado como um meio relativamente rápido de identificação de áreas com alteração. No racionamento, duas imagens são registradas em diferentes datas com uma ou mais bandas, racionadas em uma imagem, banda por banda. Os dados são comparados em uma base, pixel por pixel:

$$
R x_{i j}{ }^{k}=\frac{x_{i j}{ }^{k}\left(t_{1}\right)}{x_{i j}{ }^{k}\left(t_{2}\right)}
$$

Se a intensidade de energia refletida é quase a mesma em cada imagem, então $R x_{i j}{ }^{k}=1$, e isso indica que não houve alteração.

\subsubsection{Subtração do fundo}

Em análise de detecção de alterações, áreas que não possuem alterações podem ser consideradas como tendo pouca variação do nível de cinza. A subtração do fundo permite remover essas variações pela primeira aproximação com um fundo imagem $\mathrm{f}_{\mathrm{b}} \mathrm{e}$, em seguida, subtraindo tal aproximação da imagem original.

A nova imagem pode ser representada pela expressão:

$$
f_{n}(x)=f(x)-f_{b}(x)
$$

É conveniente aplicar a técnica de subtração do fundo em uma imagem filtrada com um passa baixa (filtro de suavização).

\subsubsection{Avaliação das técnicas digitais de detecção de alterações apresentadas}

Segundo SINGH (1989), diferentes métodos de detecção de alterações produzem diferentes mapas de alterações. Infelizmente, a maioria dos estudos 
preocupa-se com a análise comparativa de algumas técnicas numa aplicação particular e não tem sua conclusão sustentada em análise qualitativa dos resultados.

De acordo com SINGH (1989), alguns estudos comprovam que:

a) O método da regressão, usando Landsat MSS, banda 2, produz alta acuracidade para detecção de alterações, quando esse método é seguido da aplicação de dois outros métodos, que são o Racionamento e a Diferenciação da imagem.

b) Várias técnicas de preprocessamento, tais como suavização e realçamento de bordas, quando combinadas com a imagem bruta, não melhoram a acuracidade da detecção.

c) Uma técnica simples, como, diferenciação de imagem tem um desempenho melhor do que transformações muito mais sofisticadas como PCA (Análise de Componentes Principais) que utilizam a técnica de análise multivariada para reduzir o número de componentes espectrais, deixando apenas os principais, e calculando a variância na imagem multiespectral original.

A conclusão fundamental é que, no mesmo ambiente, várias técnicas podem produzir resultados diferentes.

Esse fato pode ser compreendido no momento em que um valor de radiância entre duas datas é tomado como um indicador de alteração. A diferença pode ser devida a vários fatores, tais como reais alterações (sinal), diferença de iluminação, condições atmosféricas, calibração do sensor, umidade do solo e diferença de registro das duas imagens.

\subsubsection{Experimentos realizados por outros pesquisadores}

Alguns experimentos, realizados por vários pesquisadores da área de Cartografia, têm sido mencionados na literatura, sempre com o objetivo principal de 
identificar as alterações causadas por ações antrópicas, sendo que essas alterações fazem parte do vasto elenco de feições a serem identificadas, possibilitando a definição de suas posições num sistema de referência a fim de produzir a atualização cartográfica.

Segundo JOHNSSON (1996), a revisão semi-automática de bases de dados geográficas através de imagens ou Fotogrametria Digital requer o desenvolvimento de métodos de detecção de alterações em que possam interagir mapas com dados de imagem. A grande maioria das bases de dados geográficos é armazenada na forma vetorial, enquanto as imagens usadas para a atualização são no formato "raster" (matricial). Sendo assim, a imagem deve ser generalizada em um ou vários polígonos para permitir a detecção de alterações entre o mapa e a imagem, e essa detecção deve acontecer no ambiente característico da base de dados.

Uma estrutura para a generalização foi apresentada por JOHNSSON (1996), baseada na estatística descritiva. Medidas estatísticas para descrever a tendência central, dispersão e heterogeneidade espectral, são discutidas quantitativa e qualitativamente para dados de imagem. Neste trabalho, o autor apresenta um estudo de caso que descreve como a detecção de alterações pode ser feita pela regressão entre atributos de polígono derivados do mapa e imagens de diferentes datas. Bons resultados são apresentados na detecção de alterações de reservas florestais. A metodologia utilizada no trabalho em questão não foi muito complexa, pois um mapa temático da área foi digitalizado via scanner e procedeu-se a uma generalização nessa imagem assim como na imagem de satélite atual; a partir daí foi aplicada a técnica de regressão de imagem. 
MASAHARU et al. (1996), apresentam bons resultados na detecção de alterações semi-automáticas, usando fotos aéreas digitais, onde foram aplicadas filtragens para descartar partes desnecessárias da imagem (detalhes desnecessários) além de uma máscara para ocultar partes indesejáveis do mapa (já digitalizado em formato raster) a ser atualizado.

STAMM \& BRIGGS (1999) executaram um trabalho interessante de detecção de alterações usando duas ortofotos de datas diferentes, mas da mesma área e escala. Nesse trabalho foi apresentado um experimento, com as ortofotos datadas de 1997 e 1995, onde foi feita uma composição destas imagens gerando um único arquivo, composto pelo canal vermelho (R) da ortofoto de 1997 e pelo canal verde (G) da ortofoto de 1995, obtendo como resultado a identificação das estradas (destacadas em vermelho), em suas reais posições planimétricas.

Esses resultados e os resultados apresentados por LUGNANI (1985) fizeram com que se optasse por executar um experimento para conhecer e avaliar melhor os procedimentos para a detecção de alterações, proporcionando melhores condições para a definição do método que seria utilizado neste trabalho. Os resultados desse experimento serão apresentados no Capitulo 6. 


\section{CÂMARAS DIGITAIS}

\subsection{Considerações iniciais}

A evolução da Fotogrametria, da metodologia analítica para a digital tem sido acentuada nos últimos anos. Isso tem gerado a necessidade do desenvolvimento de scanners, com alta resolução e precisão geométrica, adequados para a produção de imagens estáveis com a qualidade requerida pela precisão de trabalhos fotogramétricos, além de adquirir dados fotográficos em forma de arquivos compactos. Simultaneamente têm sido desenvolvidos equipamentos para a captura direta de dados digitais, dando início à troca das fotografias convencionais (em negativos) por imagens totalmente digitais, com o uso de câmaras CCD. (MILLS \& NEWTON, 1996),

As câmaras digitais são dispositivos nos quais o sensor é constituído de elementos fotodetectores ao invés de uma película fotográfica sensível, como é o caso das câmaras convencionais. No caso das aplicações em Cartografia, quando se utiliza uma câmara digital ela é do tipo CCD. (GALO, 1993)

De acordo com MILLS \& NEWTON (1996), a continuidade do desenvolvimento da tecnologia CCD (Charge - Coupled Device) e dos sistemas de digitalização matricial, para aquisição direta de imagens digitais e conversão de imagens analógicas para digitais, vem colaborando para o aumento de precisão e redução de custo desses equipamentos. 


\subsection{Sensor CCD e captura de imagem}

A aquisição direta de imagens digitais apresenta algumas vantagens sobre as fotografias convencionais, principalmente pelo fato de não necessitar da conversão analógico-digital, isto é, não se introduzem as distorções provocadas pelo scanner.

Embora a tecnologia da câmara $\mathrm{CCD}$ não seja totalmente nova, desenvolvimentos mais recentes têm apresentado sensores de alta resolução, comparáveis com filmes fotográficos para diversos tipos de aplicações.

Apesar da facilidade em obter informações sobre as câmaras digitais, existe uma certa dificuldade de fazer comparações entre elas, pois não se encontra uma padronização das informações a respeito das especificações técnicas fornecidas.

\subsection{Características técnicas de algumas câmaras digitais}

\subsubsection{Câmaras de amador}

Consideradas de uso comum entre pessoas que registram cenas dos mais variados tipos e interesses, essas câmaras, geralmente, apresentam custos acessíveis à boa parte dos usuários, dependendo do modelo. Por outro lado, normalmente, não são dotadas de grande sofisticação em sua arquitetura e caracterizam-se por apresentarem grande facilidade de uso a fotógrafos com pouca experiência e boa qualidade visual das imagens obtidas. Dois exemplos dessas câmaras são mostrados nas Figuras 05 e 06. 


\subsubsection{Câmara Kodak - DC210 (Zoom)}

Principais Características técnicas:

Visor Colorido: 1.8 "

Resolução do CCD: (1152x864) pixeis

Tamanho do CCD: 10,3 x 7,8 mm

Tamanho real do pixel: $9 \mu \mathrm{m}$

Distância focal real: 4,4 a $8,8 \mathrm{~mm}$

Distância focal, equivalente às câmaras 35 mm: 29 a 58 mm

Quadro do negativo, compatível com as câmaras 35mm: 35 x 26,5 mm

Tamanho do pixel: $0,03038 \times 0,03067 \mathrm{~mm} \quad(35 \mathrm{~mm})$

FONTES: Manual da câmara e Home page da Kodak. (http//www.kodak.com)

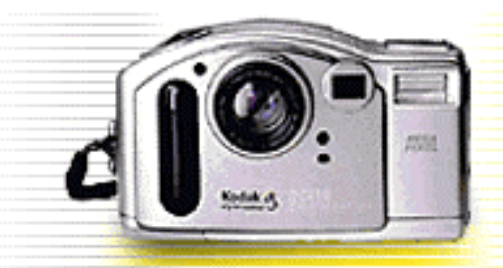

Figura 05 - Câmara KODAK - DC210 (utilizada neste trabalho).

\subsubsection{Câmara Kodak - DC 5000}

\section{Principais Características técnicas:}

Visor Colorido: 1.8 "

Resolução do CCD: (1760 x 1168) pixeis

Tamanho do CCD: 15,84 x 10,51 mm

Tamanho real do pixel: $9 \mu \mathrm{m}$

Distância focal real: 6,5 a $13 \mathrm{~mm}$

FONTE: Home page da Kodak. (http//www.kodak.com) 


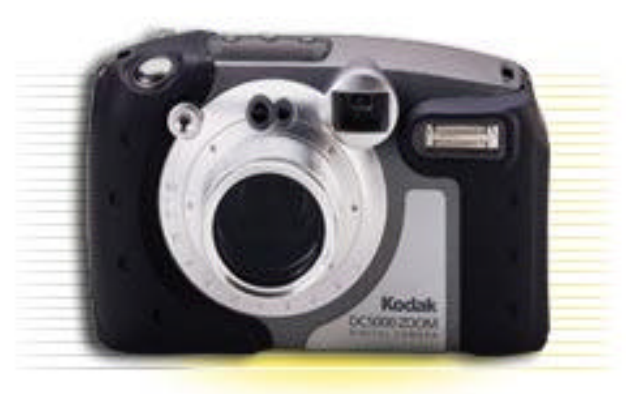

Figura 06 - Câmara Digital KODAK DC5000.

\subsubsection{Câmaras para uso profissional}

Essas câmaras, geralmente, são utilizadas por fotógrafos profissionais que registram cenas que necessitam de excelente qualidade visual. Têm custos mais elevados, quando comparados com os custos das câmaras de amador. Por outro lado, normalmente são dotadas de dispositivos que permitem diferentes regulagens, para a tomada de imagens em diferentes condições, aumentando a qualidade das imagens. Normalmente são utilizadas por fotógrafos com boa experiência. Cinco exemplos dessas câmaras são mostrados pelas Figuras 07 e 08 (Estúdio), 10 (Inteligência), 11 e 12 (Câmaras para uso em cartografia).

\subsubsection{Câmara Kodak - DCS 660}

Visor Colorido: 1.8 "

Resolução do CCD: (3040 x 2008) pixeis

Tamanho do CCD: 27,36 x 18,07 mm

Tamanho real do pixel: $9 \mu \mathrm{m}$

Distância focal real: 6,5 a $13 \mathrm{~mm}$

Lentes da Nikon, cuja distância focal depende do conjunto de lentes utilizado.

FONTE: Home page da Kodak. (http//www.kodak.com) 


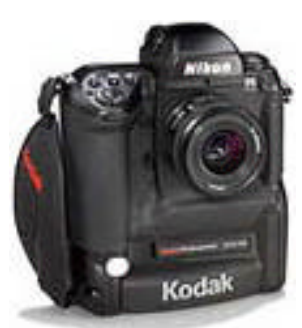

Figura 07 - Câmara Digital KODAK DCS 660.

\subsubsection{Câmara Kodak - Mega Plus 16.8i}

Resolução do CCD: (4096 x 4096) pixeis;

Tamanho do CCD: 36,86 x 36,86 mm;

Tamanho real do pixel: $9 \mu \mathrm{m}$

Lentes da Rolleiflex cuja distância focal depende do conjunto de lentes utilizado.

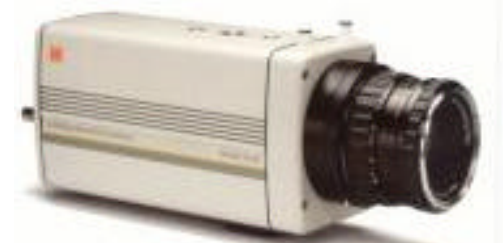

Figura 08 - Câmara Digital KODAK Mega Plus 16,8i.

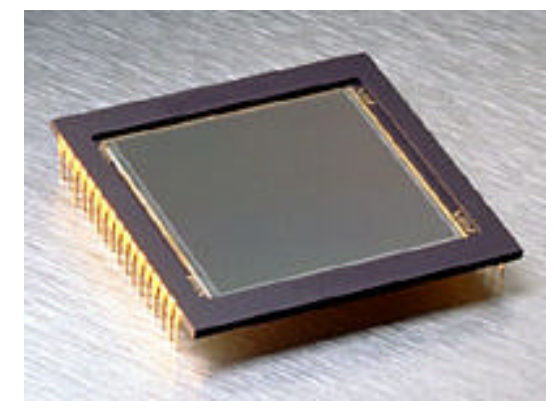

Figura 09 - CCD (KAF-16801), usado na câmara digital KODAK Mega Plus 16,8i. 


\subsubsection{Câmara LMFS (F-979F)}

Tamanho do CCD: 80,6 x 80,6 mm;

Resolução: (9216 x 9216) pixeis;

Tamanho real do pixel: $8,75 \mu \mathrm{m}$

Ângulo de abertura: 118 graus;

Taxa de transferência: de 100 a 170 Mpixeis/Seg.;

FONTE: Workshop: Digital Aerial Cameras for Photogrammetry and Remote Sensing, Stuttgart University, Germany.

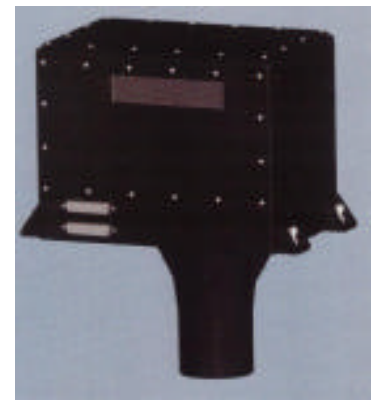

Figura 10 - Câmara F-979F.

\subsubsection{Câmara DMC (Z/I Imaging)}

\section{Multiespectral:}

Resolução: (3000 x 2000) pixeis

Lentes: $25 \mathrm{~mm}$ (Zeiss)

Taxa de transferência: 0,5 frame/Seg.

\section{Pancromática:}

Resolução: (7000 x 7500) pixeis

Lentes: $120 \mathrm{~mm}$ (Zeiss) 
Taxa de transferência: 0,5 frame/Seg.

FONTE: www.ziimaging.com

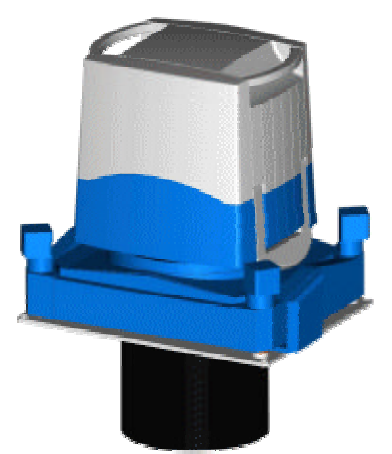

Figura 11 - Câmara DMC (Z/I Imaging).

\subsubsection{Câmara inCAM (inpho GmbH)}

Multiespectral ou Pancromática:

Resolução: (2000 x 3000) pixeis

Lentes: 28,5 mm (Zeiss)

FONTE: www.inpho.de

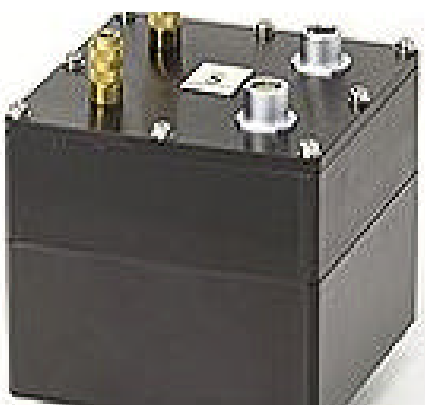

Figura 12 - Câmara inCAM (inpho GmbH).

\subsubsection{Câmara de imageamento contínuo}

Desenvolvida pela LH Systems juntamente com a german aerospace centre, trata-se de um sensor imageador (Figura 13), para ser utilizado em aeronaves; possui três linhas de ccd, com 12000 pixeis em cada linha. 
Esse sensor caracteriza-se por ser um imageador semelhante aos que equipam os conhecidos satélites imageadores, onde a superfície é recoberta por linhas de varredura transversais ao sentido da linha de vôo da aeronave.

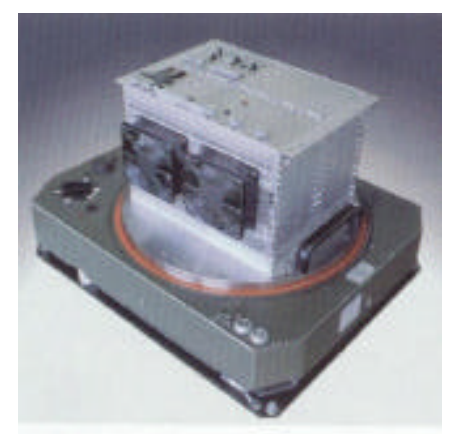

Figura 13 - Sensor digital multiespectral (three-line), LH- System.

Nesse caso o sensor é equipado com três linhas de ccd, que fazem a varredura em três direções, sendo uma na vertical e duas oblíquas, como mostra a Figura 14.

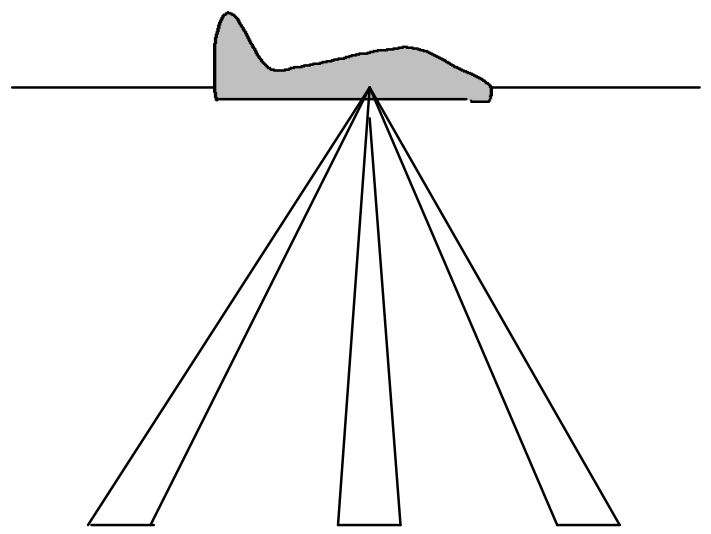

Figura 14 - Característica geométrica do sensor digital trilinear.

Nota-se, pelas características desse sensor, que as imagens geradas não são de projeção central, como é o caso das fotografias aéreas convencionais e digitais utilizadas neste trabalho. Portanto, as imagens geradas com as características geométricas do sensor digital trilinear, em sua forma original, não podem ser 
utilizadas com a metodologia proposta neste trabalho, mas não se descarta a possibilidade de adaptações futuras para a sua utilização.

\subsubsection{Comparação entre as câmaras apresentadas}

As informações técnicas existentes sobre as câmaras digitais apresentadas, nem sempre atendem às necessidades dos usuários, pela diferença entre as aplicações a que se destinam.

Procurou-se, nesta seção, apresentar algumas das informações mais importantes, para as aplicações em Fotogrametria, sintetizadas de forma a dar subsídios ao leitor para uma breve comparação entre as câmaras apresentadas.

Tabela 01 - Quadro comparativo entre as câmaras apresentadas.

\begin{tabular}{|c|c|c|c|c|c|}
\hline Câmara & $\begin{array}{c}\text { Resolução } \\
\text { (pixel) }\end{array}$ & Pixel $(\boldsymbol{\mu m})$ & $\begin{array}{c}\text { Vel. Gravação } \\
(\text { frame/Seg. }\end{array}$ & $\begin{array}{c}\text { Profundidade } \\
(\text { bits/cor })\end{array}$ & Lentes \\
\hline DC 210 & $1152 \times 862$ & 9,0 & 0,143 & 8 & Kodak \\
\hline DC 5000 & $1760 \times 1168$ & 9,0 & - & 8 & Kodak \\
\hline DCS 660 & $3040 \times 2008$ & 9,0 & 0,333 & 12 & Nikon \\
\hline $\begin{array}{c}\text { Mega Plus } \\
16,8 i\end{array}$ & $4096 \times 4096$ & 9.0 & 0,5 & 8 & Rolleiflex \\
\hline $\begin{array}{c}\text { LMFS } \\
\text { F-979F) }\end{array}$ & $9216 \times 9216$ & 8,75 & 2 & 12 & - \\
\hline DMC & $3000 \times 2000$ & - & 0,5 & 12 & Zeiss \\
\hline inCAM & $2000 \times 3000$ & - & - & 12 & Zeiss \\
\hline
\end{tabular}

Pode-se notar, pelas informações apresentadas na Tabela 01, que existem vários modelos, de características e fabricantes diferentes, devendo-se observar o grupo de características que possa tornar uma determinada câmara adequada para uma aplicação específica. 


\subsection{Princípios da formação da imagem digital}

De acordo com GONZALES \& WOODS (1993), a imagem digital pode ser definida como uma função bidimensional de intensidade luminosa $f(x, y)$, onde x e y são as coordenadas espaciais e o valor $\mathrm{f}$ em qualquer ponto $(\mathrm{x}, \mathrm{y})$ é proporcional ao brilho ou nível de cinza da imagem naquele ponto. Esta é uma imagem discretizada tanto nas coordenadas espaciais quanto no brilho, ou seja, só assume valores inteiros.

Pelas afirmações anteriores, uma imagem digital pode ser considerada como uma matriz cujos índices de linhas e colunas identificam espacialmente um ponto, e o valor do elemento correspondente na matriz identifica o nível de cinza ou cor desse ponto, como mostra a Figura 15.

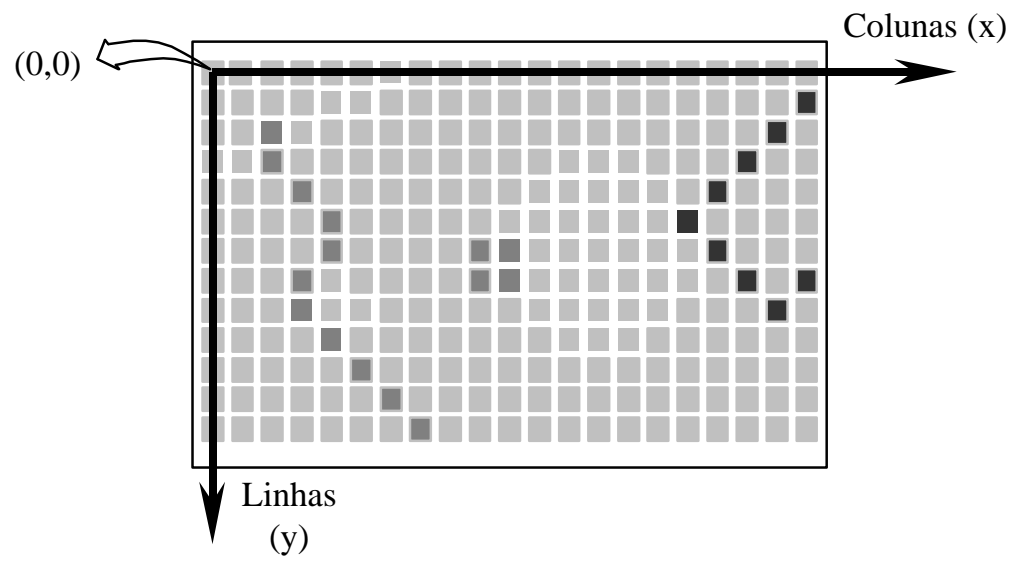

Figura 15 - matriz de formação da imagem digital.

Cada elemento da matriz que forma a imagem recebe o nome de pixel e corresponde ao menor elemento de resolução no terreno.

De acordo com GALO (1993), um feixe luminoso, ao incidir nos elementos sensores, depois de passar pelo sistema de lentes da câmara, provoca a geração de um sinal elétrico proporcional à intensidade de luz incidente. Esses sinais são 
armazenados em capacitores e passam por um processo de amplificação, onde é produzida uma série de voltagens. Essas quantidades são convertidas em grandezas discretas por meio de um conversor analógico/digital. Em seguida esses sinais são armazenados no "frame buffer" e disponibilizados para a visualização.

Para uma melhor visualização desse processo de formação de imagem digital, a Figura 16 mostra o conjunto de dispositivos que possui a câmara digital.

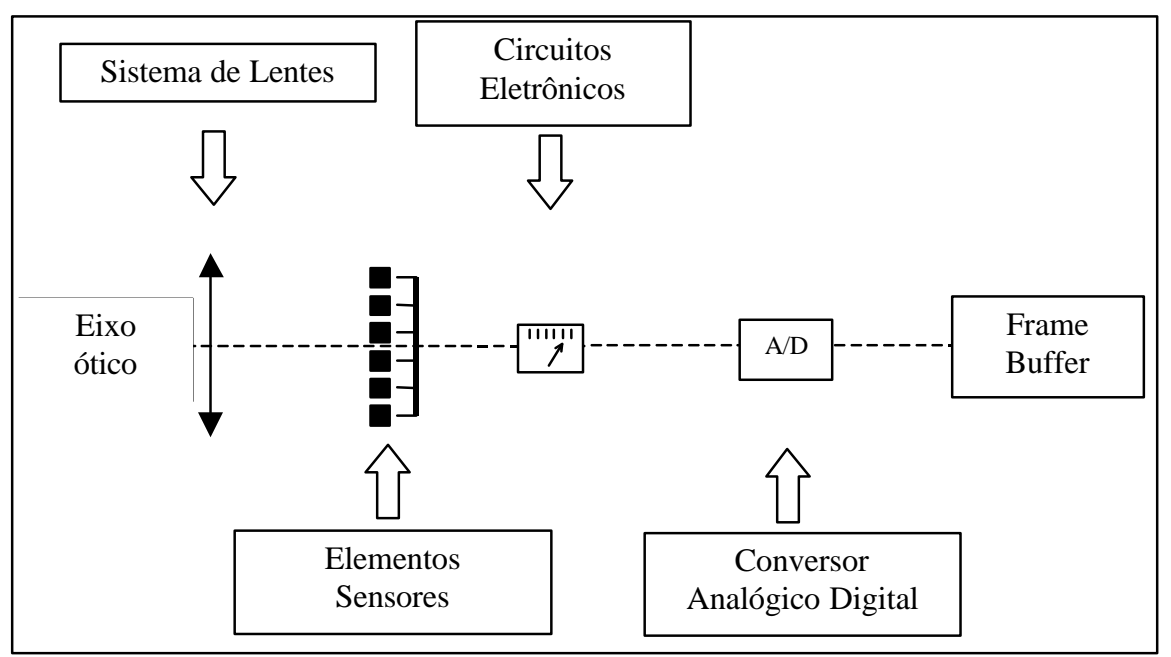

Figura 16 - Princípio da formação da imagem para câmaras CCD. FONTE: GALO (1993).

Como pode ser visto na Figura 16, esse processo de formação de imagem digital tem início no momento em que a radiação eletromagnética atravessa o sistema ótico da câmara. Nesse instante, segundo GALO (1993), o sinal é recebido pela matriz de sensores, passando posteriormente por um processo de discretização, sendo que em cada uma das fases do processo como um todo são introduzidos erros com causas e características diferentes, afetando a qualidade geométrica e visual da imagem. 
Como pode ser observado, a introdução desses erros tem origem geralmente nos dispositivos utilizados para a formação da imagem e, portanto, esses erros podem ser parametrizados e minimizados através da calibração da câmara digital.

\subsection{Câmaras digitais e aplicações fotogramétricas}

Um problema que pode influenciar no êxito das aplicações fotogramétricas destas câmaras reside no fato de que essas imagens, capturadas com altas resoluções, produzem arquivos grandes e a velocidade de gravação é cerca de 8 seg/imagem, para o caso da câmara DC 210. Para a obtenção de imagens aéreas, o intervalo entre duas exposições é geralmente curto (alguns segundos), principalmente em vôos baixos para a obtenção de imagens em escalas grandes.

Tendo como exemplo a câmara DC 210, utilizada neste trabalho, a operação de transferência da imagem é completada em 8 segundos para uma imagem de aproximadamente $300 \mathrm{~KB}$, no formato JPG compactado e 24 bits. Esse tempo dificultou a cobertura fotogramétrica, visto que, neste trabalho, a câmara acoplada à aeronave deslocou-se com uma velocidade de $50 \mathrm{~m} / \mathrm{s}(180 \mathrm{~km} / \mathrm{h})$ e, sendo assim, o intervalo de exposição seria de 7 segundos para uma base de 350 metros.

Nota-se, pelas considerações anteriores, que dessa forma não se consegue superposição de $60 \%$ e, portanto, houve a necessidade de executar o vôo em duas etapas na mesma faixa, obtendo a superposição desejada.

Atualmente existem câmaras digitais mais modernas com maior velocidade e capacidade de armazenamento, e seu custo varia, proporcionalmente, com a resolução espacial, a capacidade de armazenamento e a velocidade de gravação dos dados. 


\section{PROPOSTA METODOLÓGICA}

A estratégia da combinação de fontes diferentes de dados, para a formação de modelos estereoscópicos, foi originalmente mencionada por LUGNANI (1985) que utilizou um modelo estereoscópico híbrido a partir de duas fotografias obtidas com uma mesma câmara fotogramétrica convencional, diferindo apenas pela data de execução dos vôos.

A formação do modelo híbrido aqui proposto constitui-se o principal objeto de estudo deste trabalho, e deverá contribuir para o desenvolvimento de uma nova metodologia de atualização cartográfica.

A metodologia de atualização cartográfica, proposta neste trabalho, é composta por três fases fundamentais que são:

a) Formação do modelo estereoscópico híbrido;

b) Detecção de alterações;

c) Extração de feições.

Nas seções seguintes serão detalhadas as fases fundamentais que compõem a metodologia proposta.

A Figura 17 representa esquematicamente a metodologia proposta. 


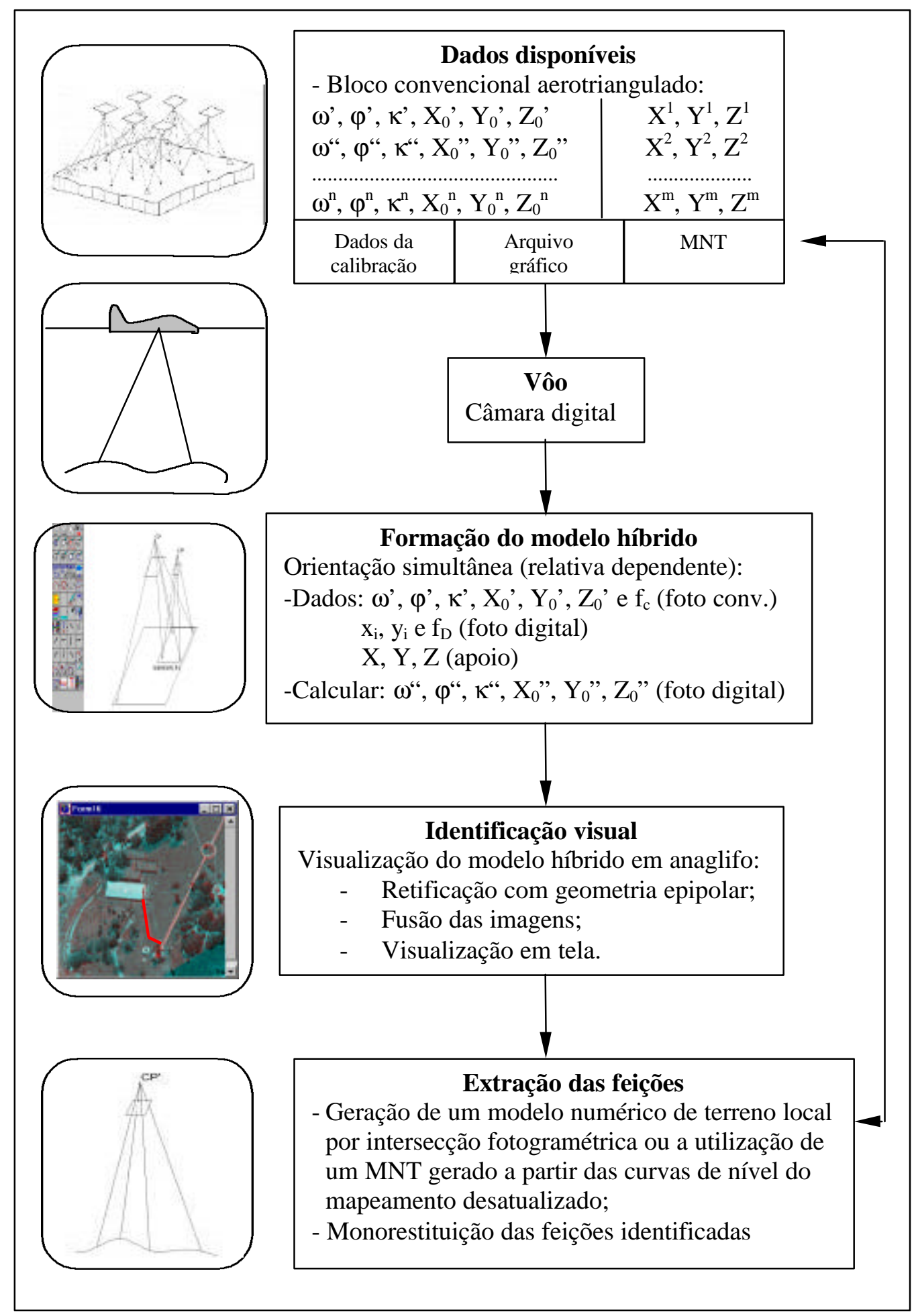

Figura 17 - Processo esquemático da metodologia proposta. 


\subsection{Formação de modelos estereoscópicos híbridos}

A premissa básica deste trabalho é a utilização de um estereopar híbrido composto por uma fotografia aérea $23 \times 23 \mathrm{~cm}$ (que foi utilizada no mapeamento a ser atualizado), digitalizada matricialmente, via scanner e por uma imagem aérea digital recente, como mostra a Figura 18.

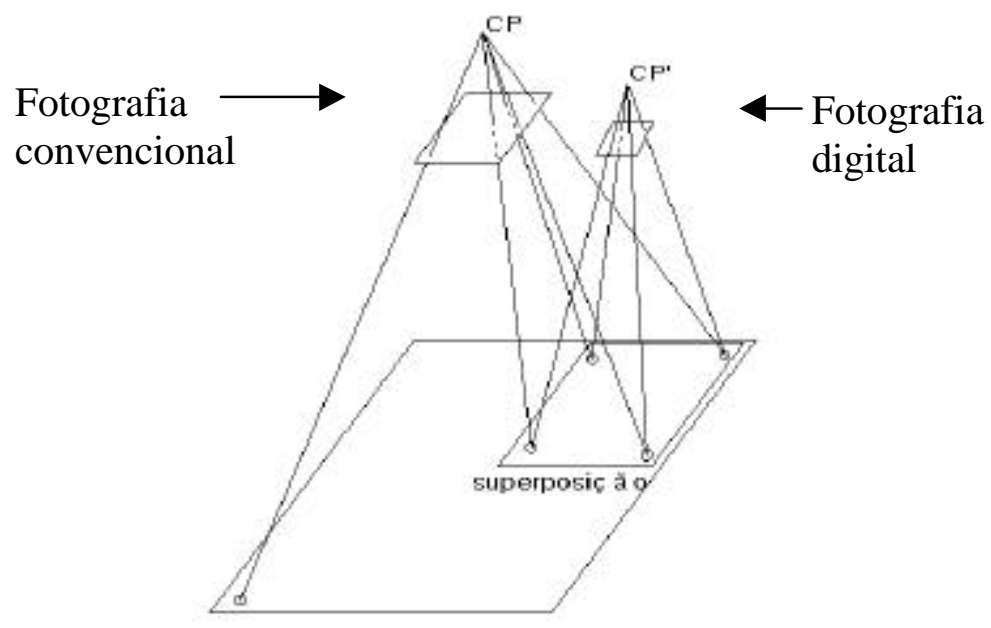

Figura 18 - Formação de um modelo estereoscópico híbrido.

Nota-se que a fotografia digital, mostrada na Figura 18, tem a geometria diferente da fotografia convencional. Partindo-se do princípio de que se têm os parâmetros de orientação, utilizados na formação do modelo estereoscópico convencional, que deu origem ao mapeamento a ser atualizado, esses parâmetros podem ser adotados como injunção para a formação do novo modelo (híbrido). Para isso, faz-se necessária a utilização de um algoritmo de orientação relativa dependente, considerando as variações da distância focal entre as câmaras (vide capitulo 2).

Tomando-se um ponto $\mathbf{P}$ comum às duas fotos e utilizando-se o modelo matemático da equação de colinearidade, podem-se escrever duas equações $\left(\mathrm{x}_{\mathrm{c}}, \mathrm{y}_{\mathrm{c}}\right)$ para este ponto na foto convencional, como mostram as equações (27). 


$$
\begin{aligned}
& x_{C}=f * \frac{m_{11}\left(X-X_{0}\right)+m_{12}\left(Y-Y_{0}\right)+m_{13}\left(Z-Z_{0}\right)}{m_{31}\left(X-X_{0}\right)+m_{32}\left(Y-Y_{0}\right)+m_{33}\left(Z-Z_{0}\right)} \\
& y_{C}=f * \frac{m_{21}\left(X-X_{0}\right)+m_{22}\left(Y-Y_{0}\right)+m_{23}\left(Z-Z_{0}\right)}{m_{31}\left(X-X_{0}\right)+m_{32}\left(Y-Y_{0}\right)+m_{33}\left(Z-Z_{0}\right)}
\end{aligned}
$$

onde:

$\mathrm{x}_{\mathrm{C}}$ e $\mathrm{y}_{\mathrm{C}}$ são as fotocoordenadas (coordenadas de $\mathbf{P}$ no espaço imagem e no sistema fotogramétrico da foto convencional);

f é a constante da câmara fotogramétrica convencional (distância focal calibrada);

$\mathrm{m}_{\mathrm{ij}}$ são os elementos da matriz de rotação, em função dos ângulos de orientação da câmara convencional $(\omega, \varphi, \kappa)$;

$\mathrm{X}_{0}, \mathrm{Y}_{0}, \mathrm{Z}_{0}$ são as coordenadas do centro perspectivo da câmara convencional;

$\mathrm{X}, \mathrm{Y}, \mathrm{Z}$ são as coordenadas do ponto $\mathrm{p}$ no espaço objeto e no sistema referencial estabelecido.

Nota-se que, como a fotografia convencional já foi orientada, quando da formação do modelo estereoscópico, com as duas fotos convencionais, os elementos da matriz de rotação e as coordenadas do centro perspectivo dessa imagem já são conhecidos. A imagem digital permite, entretanto, escrever mais duas equações $\left(\mathrm{x}_{\mathrm{D}}\right.$, $\left.\mathrm{y}_{\mathrm{D}}\right)$ para o mesmo ponto, como segue: 


$$
\begin{aligned}
& x_{D}=f_{D} * \frac{m_{11}^{\prime}\left(X-X_{0}^{\prime}\right)+m_{12}^{\prime}\left(Y-Y_{0}^{\prime}\right)+m_{13}^{\prime}\left(Z-Z_{0}^{\prime}\right)}{m_{31}^{\prime}\left(X-X_{0}^{\prime}\right)+m_{32}^{\prime}\left(Y-Y_{0}^{\prime}\right)+m_{33}^{\prime}\left(Z-Z_{0}^{\prime}\right)} \\
& y_{D}=f_{D} * \frac{m_{21}^{\prime}\left(X-X_{0}^{\prime}\right)+m_{22}^{\prime}\left(Y-Y_{0}^{\prime}\right)+m_{23}^{\prime}\left(Z-Z_{0}^{\prime}\right)}{m_{31}^{\prime}\left(X-X_{0}^{\prime}\right)+m_{32}^{\prime}\left(Y-Y_{0}^{\prime}\right)+m_{33}^{\prime}\left(Z-Z_{0}^{\prime}\right)}
\end{aligned}
$$

onde:

$\mathrm{x}_{\mathrm{D}}$ e $\mathrm{y}_{\mathrm{D}}$ são as fotocoordenadas (coordenadas de $\mathbf{P}$ no espaço imagem e no sistema fotogramétrico da foto digital);

$f_{D}$ é a constante da câmara digital (distância focal calibrada);

$m_{i j}$ são os elementos da matriz de rotação, em função dos ângulos de orientação da câmara digital $\left(\omega_{2}, \varphi_{2}, \kappa_{2}\right)$;

$\mathrm{X}_{0}^{\prime}, \mathrm{Y}_{0}{ }_{0}, \mathrm{Z}^{\prime}{ }_{0}$ são as coordenadas do centro perspectivo da câmara digital;

$\mathrm{X}, \mathrm{Y}, \mathrm{Z}$ são as coordenadas do ponto $\mathrm{p}$ no espaço objeto e no sistema referencial estabelecido.

Como já se conhece a posição real da câmara convencional, determinada na orientação absoluta original (modelo convencional), resta determinar $\mathrm{X}_{0}{ }_{0}, \mathrm{Y}^{\prime}{ }_{0}, \mathrm{Z}_{0}{ }_{0}$, $\kappa_{2}, \varphi_{2}, \omega_{2}$.

Considerando que podem ser escritas 4 equações para cada ponto, com 6 pontos desconhecidos no espaço objeto, podem ser escritas 24 equações, tendo-se 18 incógnitas $\left(\mathrm{X}_{1}, \mathrm{Y}_{1}, \mathrm{Z}_{1}, \ldots, \mathrm{X}_{6}, \mathrm{Y}_{6}, \mathrm{Z}_{6}\right)$ mais as 6 anteriores $\left(\mathrm{X}_{0}^{\prime}, \mathrm{Y}^{\prime}{ }_{0}, \mathrm{Z}^{\prime}{ }_{0}, \kappa_{2}, \varphi_{2}, \omega_{2}\right)$ totalizando 24 incógnitas.

Esse procedimento resolve teoricamente o problema da orientação relativa dependente, faltando ainda conhecer um ponto de apoio ou uma distância para determinar a escala do modelo, executando assim as orientações relativa e absoluta simultaneamente. 
Um experimento, apresentado na seção 6.1, demonstra que esse procedimento funciona de modo adequado.

\subsection{Procedimento para a detecção de alterações}

A identificação das feições que devem ser restituídas, num processo de atualização cartográfica, é uma etapa importante e tem-se tornado uma das maiores preocupações de vários pesquisadores.

Qualificada como um dos pontos críticos da atualização cartográfica, a detecção de alterações foi o principal objeto de estudo da investigação apresentada por LUGNANI (1985), a qual se tornou a maior fonte de motivação para a realização deste trabalho.

A idéia inicial, neste trabalho, para solucionar o problema da identificação das alterações, foi a formação de um modelo estereoscópico híbrido através do método de cintilamento.

LUGNANI (1985) utilizou um instrumento analítico (Planicomp) com oculares óticas convencionais, para a formação de um modelo estereoscópico, onde as fotografias utilizadas foram tomadas com a mesma câmara fotogramétrica; portanto com a mesma geometria e mediante a adaptação de um dispositivo de interrupção de iluminação para uma das fotografias.

A formação do modelo estereoscópico, aqui proposto, foi testada com uma metodologia diferente da utilizada por LUGNANI (1985), ou seja, desta vez com uma fotografia aérea digital e parte de uma fotografia aérea convencional digitalizada, formando o modelo diretamente em meio digital.

A deteç̧ão das alterações, pelo método de cintilamento digital, fica prejudicada pela alta frequiência em que as imagens são mostradas no monitor do 
computador, não produzindo resultados satisfatórios. Por outro lado, o método de detecção das alterações, aqui proposto, resume-se na visualização do modelo estereoscópico híbrido digital por anaglifo, conforme descrito na seção 2.4.1.2. Esse método, de visualização estereoscópica é bastante conhecido na Fotogrametria e foi amplamente utilizado em instrumentos analógicos óticos, como meio de obtenção de visualização estereoscópica para a restituição e construção de cartas planialtimétricas.

Utilizando-se das facilidades proporcionadas pelos recursos da Informática, uma imagem pode ser formada através dos canais vermelho $(R)$, verde $(G)$ e azul (B), possibilitando a separação dos canais em três imagens diferentes, sendo que a fusão desses três canais gera uma imagem, que pode ser visualizada em tons de cinza, com o auxílio de filtros. Partindo-se desse princípio surgiu a idéia da formação de uma imagem em que se utiliza um canal vermelho (R) de uma imagem e a fusão dos outros dois $(\mathrm{G}$ e $\mathrm{B})$ da outra imagem. Este processo é equivalente à aplicação de um filtro vermelho em uma das imagens e um filtro ciano na outra imagem, atendendo, por definição, ao princípio de formação de um modelo estereoscópico pelo método anaglifo convencional, conforme descrito na seção 2.4.1.2.

Os principais problemas detectados nesse processo são a diferença de geometria entre as fotografias, digital e convencional digitalizada, além das distorções causadas pela diferença nas orientações das fotos. Este problema pode ser minimizado pela retificação e reamostragem das fotografias utilizadas.

Para a efetivação dessa proposta metodológica de detecção de alterações, alguns estudos experimentais foram realizados e são apresentados na seção 6.2. 


\subsection{Extração de feições}

\subsubsection{Digitalização direta}

Um procedimento de coleta de coordenadas planimétricas, diretamente sobre a fotografia digital, pode ser utilizado como uma opção rápida de determinação da posição de uma feição identificada como nova.

Para tanto, o processo de orientação exterior pode ser executado com uma resseção espacial na foto digital e, o procedimento de georeferenciamento através de translações nas direções X e Y, e um fator de escala.

A seção 6.3.1 mostra os resultados do experimento realizado com este procedimento.

\subsubsection{Restituição fotogramétrica}

Ao se trabalhar com um modelo estereoscópico híbrido, tem-se a vantagem de detectar as alterações, como será apresentado na seção 6.2. Por outro lado, um ponto de interesse, pertencente a uma feição a ser extraída, que aparece na fotografia digital, não consta na fotografia convencional e este fato implica a impossibilidade de utilizar a intersecção fotogramétrica, para a determinação das coordenadas do referido ponto no espaço objeto, pois as coordenadas desse ponto não podem ser determinadas no espaço imagem da fotografia convencional.

Por esse motivo, adota-se neste trabalho o procedimento de intersecção fotogramétrica para a determinação de pontos, existentes nas duas fotografias, formando um mini MNT (modelo numérico de terreno) envolvendo a feição a ser extraída através da monorestituição. Um experimento, apresentado na seção 6.3.2, mostra que este procedimento funciona adequadamente. 


\subsubsection{Intersecção fotogramétrica}

A intersecção fotogramétrica é utilizada para calcular coordenadas tridimensionais $\mathrm{X}, \mathrm{Y}$ e Z, no espaço objeto, a partir de coordenadas bidimensionais medidas em duas imagens distintas, que serão tratadas nesta seção como fotografia convencional e fotografia digital.

De acordo com TOMMASELLI (1995), a transformação de coordenadas, do espaço objeto para o espaço imagem, pode ser feita pela transformação de similaridade, através da equação (26).

$$
\left[\begin{array}{l}
x_{i} \\
y_{i} \\
f
\end{array}\right]=\frac{1}{\lambda} \cdot\left[\begin{array}{lll}
m_{11} & m_{12} & m_{13} \\
m_{21} & m_{22} & m_{23} \\
m_{31} & m_{32} & m_{33}
\end{array}\right] \cdot\left[\begin{array}{c}
X-X_{0} \\
Y-Y_{0} \\
Z-Z_{0}
\end{array}\right]
$$

Onde:

$\mathrm{x}_{\mathrm{i}}, \mathrm{y}_{\mathrm{i}}$ são as coordenadas do ponto considerado, no espaço imagem;

$\mathrm{X}, \mathrm{Y}$ e Z são as coordenadas do ponto considerado, no espaço objeto;

$\mathrm{X}_{0}, \mathrm{Y}_{0}$ e $\mathrm{Z}_{0}$ são as coordenadas do centro perspectivo, no espaço objeto;

f é a distância focal da câmara;

$\mathrm{m}_{\mathrm{ij}}$ são os elementos da matriz de rotação, em função dos ângulos de orientação da câmara $\omega, \varphi$ e $\kappa$;

$\lambda$ é o fator de escala;

A transformação inversa leva das coordenadas medidas no espaço imagem, sobre a fotografia, para as coordenadas no espaço objeto, como mostra a equação (30). 


$$
\left[\begin{array}{l}
X \\
Y \\
Z
\end{array}\right]=\lambda \cdot\left[\begin{array}{lll}
m_{11} & m_{21} & m_{31} \\
m_{12} & m_{22} & m_{32} \\
m_{13} & m_{23} & m_{33}
\end{array}\right] \cdot\left[\begin{array}{c}
x_{i} \\
y_{i} \\
f
\end{array}\right]+\left[\begin{array}{c}
X_{0} \\
Y_{0} \\
Z_{0}
\end{array}\right]
$$

Uma vez conhecidos os parâmetros de orientação interior e exterior das duas fotografias em questão, pode-se reescrever a equação (30), com os dados da fotografia digital, da seguinte forma:

$$
\begin{aligned}
& X=\lambda_{d} \cdot u_{d}+X_{0}^{d} \\
& Y=\lambda_{d} \cdot v_{d}+Y_{0}^{d} \\
& Z=\lambda_{d} \cdot w_{d}+Z_{0}^{d}
\end{aligned}
$$

onde:

$\mathrm{X}^{\mathrm{d}}{ }_{\mathrm{o}}, \mathrm{Y}^{\mathrm{d}}{ }_{\mathrm{o}}, \mathrm{e} \mathrm{Z}_{\mathrm{o}}^{\mathrm{d}}$ são as coordenadas do centro perspectivo da câmara digital;

$$
\begin{gathered}
u_{d}=m_{11}^{d} x_{d}+m_{21}^{d} y_{d}+m_{31}^{d}\left(f^{d}\right) \\
v_{d}=m_{12}^{d} x_{d}+m_{22}^{d} y_{d}+m_{32}^{d}\left(f^{d}\right) \\
w_{d}=m_{13}^{d} x_{d}+m_{23}^{d} y_{d}+m_{33}^{d}\left(f^{d}\right)
\end{gathered}
$$

O fator de escala $\lambda_{\mathrm{d}}$ é calculado considerando-se os elementos das duas fotografias em questão, a partir da equação (30).

$$
\lambda_{d}=\frac{\left(X_{o}^{d}-X_{0}^{c}\right) \cdot w_{c}-\left(Z_{0}^{d}-Z_{0}^{c}\right) \cdot u_{c}}{w_{d} \cdot u_{c}-w_{c} \cdot u_{d}}
$$

onde:

$$
\begin{gathered}
u_{c}=m_{11}^{c} x_{c}+m_{21}^{c} y_{c}+m_{31}^{c}\left(f^{c}\right) \\
u_{c}=m_{12}^{c} x_{c}+m_{22}^{c} y_{c}+m_{32}^{c}\left(f^{c}\right) \\
w_{c}=m_{13}^{c} x_{c}+m_{23}^{c} y_{c}+m_{33}^{c}\left(f^{c}\right)
\end{gathered}
$$

As coordenadas tridimensionais no espaço objeto podem ser calculadas também a partir dos elementos da fotografia convencional: 


$$
\begin{aligned}
& X=\lambda_{c} \cdot u_{c}+X_{0}^{c} \\
& Y=\lambda_{c} \cdot v_{c}+Y_{0}^{c} \\
& Z=\lambda_{c} \cdot w_{c}+Z_{0}^{c}
\end{aligned}
$$

onde:

$$
\lambda_{d}=\frac{\left(X_{o}^{d}-X_{0}^{c}\right) \cdot w_{d}-\left(Z_{0}^{d}-Z_{0}^{c}\right) \cdot u_{d}}{w_{d} \cdot u_{c}-w_{c} \cdot u_{d}}
$$

Nota-se que as coordenadas tridimensionais, no espaço objeto, podem ser calculadas a partir das equações (31) e (35), podendo-se ainda utilizar, como valores mais confiáveis, os valores médios obtidos entre os dois conjuntos de coordenadas calculadas.

Pela atual proposta metodológica, trabalha-se com duas fotos retificadas para a formação de um modelo estereoscópico, com o objetivo de detectar as alterações ocorridas num determinado período de tempo.

Sabe-se que, no processo de retificação destas fotografias, os ângulos de orientação da câmara $(\omega, \varphi$ e $\kappa)$ são anulados, proporcionando uma simplificação considerável no modelo matemático apresentado pela equação (29).

Isso acontece porque todos os elementos da matriz de rotação que possuem termos iguais ao seno $(\omega, \varphi$ ou $\kappa)$ serão nulos, assim como os elementos que possuem termos iguais ao cosseno $(\omega, \varphi$ ou $\kappa)$ serão iguais a 1 , ou seja, a matriz de rotação será igual à matriz identidade.

Sendo assim, essa transformação de similaridade pode ser executada com a equação (37).

$$
\left[\begin{array}{c}
x_{i} \\
y_{i} \\
f
\end{array}\right]=\frac{1}{\lambda} \cdot\left[\begin{array}{lll}
1 & 0 & 0 \\
0 & 1 & 0 \\
0 & 0 & 1
\end{array}\right] \cdot\left[\begin{array}{c}
X-X_{0} \\
Y-Y_{0} \\
Z-Z_{0}
\end{array}\right]
$$


A determinação das coordenadas tridimensionais, no espaço objeto, pode ser feita através da transformação de similaridade em sua forma inversa, dada pela equação (38).

$$
\left[\begin{array}{l}
X \\
Y \\
Z
\end{array}\right]=\lambda \cdot\left[\begin{array}{lll}
1 & 0 & 0 \\
0 & 1 & 0 \\
0 & 0 & 1
\end{array}\right] \cdot\left[\begin{array}{c}
x_{i} \\
y_{i} \\
f
\end{array}\right]+\left[\begin{array}{c}
X_{0} \\
Y_{0} \\
Z_{0}
\end{array}\right]
$$

Neste trabalho, são utilizadas duas fotografias obtidas com câmaras diferentes; portanto com distâncias focais diferentes. Considerando-se inicialmente a fotografia digital retificada, pode-se reescrever a equação (38) da seguinte forma:

$$
\begin{aligned}
& X=\lambda_{d} \cdot x_{d}+X_{0}^{d} \\
& Y=\lambda_{d} \cdot y_{d}+Y_{0}^{d} \\
& Z=\lambda_{d} \cdot f_{d}+Z_{0}^{d}
\end{aligned}
$$

O fator de escala $\lambda_{d}$ é calculado considerando-se os elementos das duas fotografias em questão, a partir da equação (40).

$$
\lambda_{d}=\frac{\left(X_{o}^{d}-X_{0}^{c}\right) \cdot f_{c}-\left(Z_{0}^{d}-Z_{0}^{c}\right) \cdot x_{c}}{f_{d} \cdot x_{c}-f_{c} \cdot x_{d}}
$$

Da mesma forma, podem-se escrever as equações para a fotografia digital retificada:

onde:

$$
\begin{aligned}
& X=\lambda_{c} \cdot x_{c}+X_{0}^{c} \\
& Y=\lambda_{c} \cdot y_{c}+Y_{0}^{c} \\
& Z=\lambda_{c} \cdot f_{c}+Z_{0}^{c}
\end{aligned}
$$

$$
\lambda_{c}=\frac{\left(X_{o}^{d}-X_{0}^{c}\right) \cdot f_{d}-\left(Z_{0}^{d}-Z_{0}^{c}\right) \cdot x_{d}}{f_{d} \cdot x_{c}-f_{c} \cdot x_{d}}
$$

Pode-se notar que esse processo de determinação de coordenadas de um ponto de interesse, no espaço objeto, possibilita a utilização das fotografias retificadas ou simplesmente orientadas. Entretanto, propõe-se a utilização de fotografias retificadas, já que estas são geradas para a detecção das alterações. 


\subsubsection{Monorestituição}

Quando se conhece a posição de um ponto ( $x_{i}$ e $y_{i}$ na imagem) em apenas uma fotografia aérea e sua posição altimétrica aproximada $Z_{i}$, no espaço objeto, além dos parâmetros de orientação exterior da referida fotografia, podem-se determinar as coordenadas planimétricas desse ponto $\left(\mathrm{X}_{\mathrm{i}}, \mathrm{Y}_{\mathrm{i}}\right)$, através do conhecido procedimento de monorestituição.

O modelo de monorestituição apresentado por MAKAROVIC (1973) ${ }^{4}$ apud LUGNANI (1985) propõe a utilização da coordenada $Z_{i}$ extraída de um DTM (modelo digital de terreno) construído através das curvas de nível do mapeamento a ser atualizado, reproduzindo as coordenadas Xi e Yi, através da projeção inversa da colinearidade, pela equação (43).

$$
\begin{aligned}
& X=\frac{m_{11} \cdot x_{i}+m_{12} \cdot y_{i}+m_{13} \cdot f}{m_{31} \cdot x_{i}+m_{32} \cdot y_{i}+m_{33} \cdot f} \cdot\left(Z_{i}-Z_{0}\right)+X_{0} \\
& Y=\frac{m_{21} \cdot x_{i}+m_{22} \cdot y_{i}+m_{23} \cdot f}{m_{31} \cdot x_{i}+m_{32} \cdot y_{i}+m_{33} \cdot f} \cdot\left(Z_{i}-Z_{0}\right)+Y_{0}
\end{aligned}
$$

onde:

$\mathrm{x}_{\mathrm{i}}$ e $\mathrm{y}_{\mathrm{i}}$ são as fotocoordenadas;

f é a distância focal calibrada;

$m_{i j}$ são os elementos da matriz de rotação, em função dos ângulos de orientação da câmara digital $(\omega, \varphi, \kappa)$;

$\mathrm{X}_{0}, \mathrm{Y}_{0}, \mathrm{Z}_{0}$ são as coordenadas do centro perspectivo da câmara, no referencial do espaço objeto;

$\mathrm{X}, \mathrm{Y}$ são as coordenadas do ponto $\mathbf{P}$, no espaço objeto e no sistema de referência estabelecido (cartesiano tridimensional e dextrógiro);

$\mathrm{Z}_{\mathrm{i}}$ é a coordenada altimérica aproximada do ponto $\mathrm{P}$ no espaço objeto.

${ }^{4}$ MAKAROVIC, B. Digital mono-plotters. ITC Journal, 1973. p.583-599. 
Neste trabalho, utilizam-se fotografias retificadas em geometria epipolar, anulando os ângulos de orientação da câmara. Com isso, a matriz de rotação fica igual à matriz identidade, podendo-se escrever a equação (43) da seguinte forma:

$$
\begin{gathered}
X=\frac{x_{i}}{f} \cdot\left(Z_{i}-Z_{0}\right)+X_{0} \\
Y=\frac{y_{i}}{f} \cdot\left(Z_{i}-Z_{0}\right)+Y_{0}
\end{gathered}
$$

Nota-se que o termo $Z_{i}$ é obtido por interpolação e, segundo LUGNANI (1985), isso é feito iterativamente, ou seja, estima-se uma coordenada $Z_{i}$ inicial $\left(Z_{1}\right)$, e calculam-se as coordenadas $\mathrm{X}$ e $\mathrm{Y}$ iniciais $\left(\mathrm{X}_{1}\right.$ e $\left.\mathrm{Y}_{1}\right)$. Com as coordenadas $\mathrm{X}_{1}$ e $\mathrm{Y}_{1}$, pode-se estimar uma nova coordenada altimétrica $\mathrm{Z}_{2}$, e a partir dela calcular $\mathrm{X}_{2}$ e $\mathrm{Y}_{2}$. O processo deve ser repetido até que as discrepâncias $d X$ e dY se encontrem dentro de limites de tolerância aceitáveis, sendo que as referidas discrepâncias são dadas pelas equações (45).

$$
\begin{gathered}
d X=X_{i+1}-X_{i} \\
d Y=Y_{i+1}-Y_{i}
\end{gathered}
$$

A metodologia apresentada neste trabalho é concluída com a implementação da monorestituição, onde a coordenada altimétrica aproximada $\left(Z_{1}\right)$ é determinada a partir da interpolação das coordenadas altimétricas de pontos que constem das duas fotografias, nas proximidades da feição de interesse a ser extraída.

De acordo com MITISHITA (1997), vários modelos matemáticos podem ser utilizados para interpolar a altitude de um ponto de interesse. Um dos procedimentos mais simples, que pode ser utilizado para essa tarefa, é a triangulação plana aproximando-se o interior de cada face triangular a um plano médio, que passa pelos 
pontos definidores do triângulo e o ponto a ser interpolado, como mostra a Figura 19. A função de interpolação da altitude $\left(Z_{\mathrm{p}}\right)$, nesse caso, é dada pela equação (46).

$$
Z_{p(x, y)}=a x+b y+d
$$

Onde:

$\mathrm{Z}_{\mathrm{p}}=$ coordenada altimétrica interpolada de um ponto $\mathrm{P}$;

$\mathrm{x}$ e y são as coordenadas planimétricas de um ponto $\mathrm{P}$;

a, b e d são os parâmetros, calculados em função das coordenadas altimétricas dos pontos definidores do plano médio.

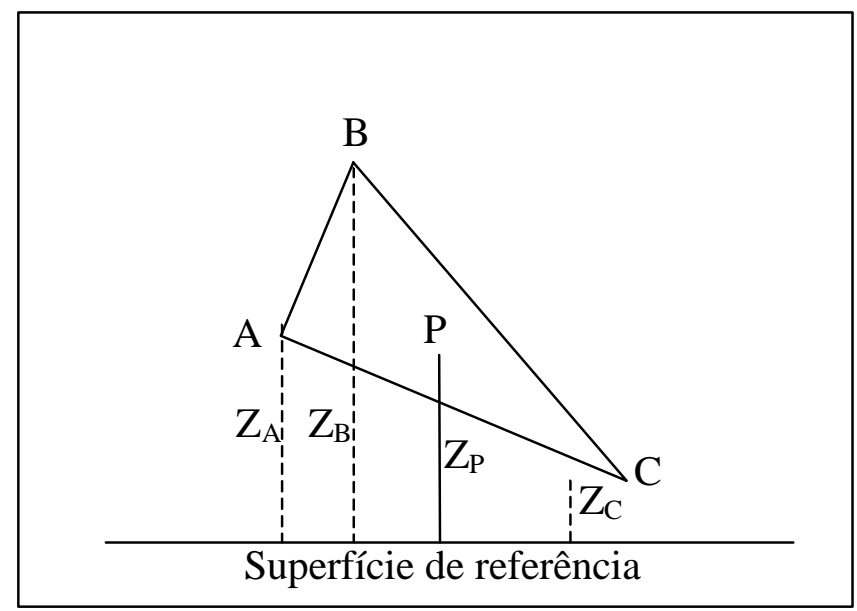

Figura 19 - Triângulo definidor do mini MNT.

Segundo MITISHITA (1997), esse procedimento apresenta bons resultados, quando aplicado para uma interpolação com pequeno espaçamento entre os pontos definidores do triângulo, porquanto esse método não trata matematicamente a continuidade entre os pontos. A vantagem da simplificação da modelagem matemática, aproximando a superfície a um plano, reside no fato se ter um ganho de tempo computacional e facilidade de programação. 


\section{IMPLEMENTAÇÃO DE UM PROTÓTIPO DE SISTEMA DE ATUALIZAÇÃO DE MAPEAMENTO}

\subsection{Considerações iniciais}

Para a execução dos experimentos que comprovam a eficiência da metodologia proposta, foram utilizados alguns programas e rotinas já desenvolvidas. No entanto, um dos objetivos propostos neste trabalho foi o de implementar um protótipo de sistema de atualização de mapeamento, mediante o uso dessas rotinas e desenvolvendo outras que se fazem necessárias. Optou-se, então, pelo desenvolvimento desse protótipo na linguagem $\mathrm{C}++$ e no ambiente do $\mathrm{C}++$ Builder, que possui algumas facilidades para a computação de imagens.

Neste capítulo procura-se mostrar todas as etapas do desenvolvimento do programa, implementado para avaliar a eficiência da metodologia proposta.

\subsection{Desenvolvimento do protótipo}

Várias pesquisas, na área de Fotogrametria, têm sido realizadas na Faculdade de Ciências e Tecnologia - FCT, da Unesp de Presidente Prudente - SP, pelo grupo de pesquisa em Fotogrametria, produzindo vários programas que resolvem casos particulares de cada pesquisa realizada.

Muitos esforços foram feitos, no sentido de agrupar os mais variados produtos das pesquisas, para que sejam utilizados, proporcionando um aumento de produtividade considerável. 
Dessa forma, procurou-se utilizar várias rotinas desenvolvidas em pesquisas anteriores que resolveram problemas similares aos que precisaram ser solucionados neste trabalho.

Operações simples como uma orientação interior, que utiliza uma transformação afim no plano, puderam ser anexadas ao programa elaborado (SAM Sistema de Atualização de Mapeamentos) por estarem desenvolvidas em linguagem $\mathrm{C}++$, a exemplo de outras rotinas que já estavam desenvolvidas e puderam ser utilizadas, como mostra a Tabela 02.

Tabela 02 - Rotinas utilizadas no programa.

\begin{tabular}{|l|c|c|}
\hline FINALIDADE DA ROTINA & ORIGEM/ADAPTAÇÃO & AUTOR \\
\hline Retificação de fotografias & DOS / C++ BUILDER & HASEGAWA \& CAMARGO (1998) \\
\hline Resseção fotogramétrica & DOS / C++ BUILDER & HASEGAWA \& CAMARGO (1998) \\
\hline $\begin{array}{l}\text { Leitura de arquivos (fotos) } \\
\text { grandes (reamostragem). }\end{array}$ & C++ BUILDER & OLIVEIRA et al. (1999) \\
\hline Zoom de imagens grandes & C++ BUILDER & OLIVEIRA et al. (1999) \\
\hline
\end{tabular}

Para o desenvolvimento deste programa partiu-se das rotinas implementadas e testadas por OLIVEIRA \& FALCON (1999).

O primeiro problema a ser resolvido foi a leitura do arquivo da fotografia aérea convencional digitalizada, pois o mesmo possui uma resolução próxima à da fotografia em papel fotográfico, ou seja, $1200 \mathrm{ppp}$ (pontos por polegada) produzindo um arquivo de $120 \mathrm{MB}$. Arquivos com esse tamanho não são facilmente manipulados em qualquer sistema de visualização e tratamento de imagens, sendo necessário implementar rotinas específicas para essa atividade.

Uma rotina para ler arquivos grandes, como os que foram utilizados neste trabalho, foi desenvolvida por OLIVEIRA et al. (1999) e inserida no programa SAM. Nessa rotina, executa-se uma reamostragem linear com acesso direto em disco, 
através da razão entre as dimensões da imagem (colunas e linhas) e as respectivas dimensões de uma janela quadrada, com tamanho fixo, utilizada para a visualização da imagem reamostrada.

Com a imagem da fotografia aérea convencional reamostrada na tela, o próximo passo foi implementar a orientação interior, no qual foi necessário transformar o referencial da imagem original do sistema levógiro (cujo centro do sistema está na origem do arquivo) para o sistema dextrógiro, que é o sistema de coordenadas das marcas fiduciais calibradas, que foram utilizadas para a orientação interior.

O modelo matemático utilizado para a orientação interior foi $\mathrm{o}$ da transformação afim no plano, conforme descrito na seção (2.4.2.1).

As marcas fiduciais constantes da fotografia convencional são pequenas e possuem coordenadas em milésimo de milímetros, sendo, portanto, necessária a utilização de uma rotina de zoom. Para tanto, foi utilizada a rotina desenvolvida por OLIVEIRA et al. (1999), na linguagem C++, compilada no ambiente do Builder, não necessitando de nenhuma adaptação, a exemplo da rotina de leitura e reamostragem de arquivos grandes utilizada anteriormente.

De posse do certificado de calibração da câmara fotogramétrica ZEISS RMK TOP-15, fornecido pela empresa que executou o vôo fotogramétrico convencional, utilizaram-se as coordenadas das marcas fiduciais para executar a orientação interior dessa fotografia, possibilitando assim a execução de medidas no sistema dextrógiro e em milímetros.

As coordenadas das marcas fiduciais calibradas, fornecidas pelo certificado de calibração, são mostradas na Tabela 03. 
Tabela 03: Coordenadas das marcas fiduciais calibradas.

\begin{tabular}{|c|c|c|}
\hline Marca & $\mathbf{x}(\mathbf{m m})$ & $\mathbf{y}(\mathbf{m m})$ \\
\hline $\mathbf{1}$ & 106,003 & $-106,006$ \\
\hline $\mathbf{2}$ & 106,004 & 106,006 \\
\hline $\mathbf{3}$ & $-106,002$ & 106,004 \\
\hline $\mathbf{4}$ & $-106,001$ & $-106,004$ \\
\hline
\end{tabular}

Com a orientação interior executada, passou-se para a implementação de uma rotina para recortar a área da imagem correspondente à área da fotografia digital que seria utilizada.

Retificar a fotografia aérea convencional, inteira, exigiria um esforço computacional muito grande e sem necessidade, pois o que importa, neste caso, é a área da fotografia digital, que é muito menor que a área de fotografia convencional. Esta rotina não está limitada a um tamanho específico de janela, sendo o usuário que a define visualmente, com a abertura da janela através do "mouse".

Escolhida a área na fotografia convencional, uma rotina desenvolvida originalmente em linguagem " $\mathrm{C}$ " para o sistema operacional DOS, por HASEGAWA \& CAMARGO (1998), e adaptada para o compilador C++ Builder, aplica a retificação para toda a fotografia, mas reamostra apenas a imagem retificada referente à imagem recortada, otimizando o processo e aumentando a velocidade de execução dessa etapa.

Os procedimentos com a imagem digital são mais simplificados pelas ferramentas existentes no compilador $\mathrm{C}++$ Builder, porque existem rotinas específicas para ler e reamostrar imagens pequenas, como neste caso (300KB), o que facilita a programação. 
A imagem digital encontra-se também no sistema de coordenadas levógiro, com a origem, deste sistema, a partir do primeiro pixel (canto superior esquerdo).

Alguns autores consideram o dispositvo CCD plano e estável, conforme discutido na seção (2.4.2.1); portanto, neste trabalho, a orientação interior se resume apenas na translação da origem da imagem para o pixel central da imagem, transformando o sistema de coordenadas levógiro para o sistema dextrógiro e disponibilizando o arquivo para a medição de coordenadas em milímetros.

Com a orientação interior executada, foi necessário fazer a orientação exterior. Para isso, foi utilizada a rotina desenvolvida por HASEGAWA \& CAMARGO (1998) que aplicam a resseção espacial em uma fotografia, discutida na seção (2.4.2.3). Essa rotina foi desenvolvida na linguagem "C", para sistema operacional DOS, sendo necessária sua adaptação para a Linguagem C++ no compilador Builder.

Depois de executada a resseção espacial e calculados os parâmetros de orientação exterior da fotografia aérea digital, o próximo passo foi realizar a retificação desta fotografia.

Neste momento, deve-se lembrar que os parâmetros de orientação exterior da fotografia digital podem ser determinados por uma orientação relativa dependente, da forma proposta na seção 4.1, pois os parâmetros de orientação exterior da fotografia convencional já são conhecidos.

A utilização da rotina de resseção espacial justifica-se apenas pelo fato de se utilizar uma rotina existente, bem como de se terem pontos de apoio em abundância nesse experimento. 
Na retificação da fotografia digital, foi utilizada a mesma rotina desenvolvida por HASEGAWA \& CAMARGO (1998), usada para retificar a fotografia convencional, agora reamostrando a imagem toda em $\mathrm{R}, \mathrm{G}$ e B.

Após essa etapa, que pode ser chamada de preparatória, onde se tem a fotografia digital e a porção da fotografia convencional correspondente devidamente retificadas, passou-se para a implementação do módulo de visualização estereoscópica, com o objetivo de detectar as alterações a serem restituídas.

De acordo com os experimentos executados, a visualização estereoscópica da área de interesse, pelo método anaglifo, seria possível após a retificação das fotografias e após uma composição dos canais ciano (G e B) de uma das fotografias e vermelho (R) da outra, uma vez que os pontos homólogos encontram-se no mesmo plano epipolar.

Sendo assim, a implementação desse módulo consiste em extrair as componentes $\mathrm{G}$ e $\mathrm{B}$ da fotografia convencional retificada e a componente $\mathrm{R}$ da fotografia digital retificada. Com isso, os elementos novos que constam na fotografia digital (mais recente) não encontram suas componentes correspondentes em G e B, sendo destacadas em vermelho, como pode ser visto na seção (6.2.3).

A janela de visualização do modelo anaglifo foi previamente dimensionada, com o objetivo de limitar a área do modelo à parte de interesse num dado momento, fato este que reduz o tempo e o esforço computacional, pois se o programa disponibilizasse o modelo da área toda, muitas feições sem interesse seriam mostradas. 
Para acionar a janela de visualização do modelo anaglifo basta indicar um ponto com o "mouse" em uma das fotos retificadas e seu homólogo na outra foto, procedimento este que indica o centro da janela de visualização do referido modelo.

Com o módulo de detecção de alterações desenvolvido, passou-se para a implementação de uma rotina que possibilitasse a extração de feições para a atualização cartográfica.

Como houve a necessidade de retificar a fotografia digital, para a montagem do modelo anaglifo, este produto tornou-se interessante, uma vez que havia a possibilidade de executar uma digitalização sobre a fotografia, utilizando apenas a fotografia digital retificada, sendo que a mesma possui todos os elementos novos que devem ser restituídos.

No momento da execução da resseção espacial da fotografia digital, foram calculados os parâmetros de orientação exterior, necessários para a execução da sua retificação. No entanto, a rotina utilizada nesse procedimento não aplica uma transformação do sistema fiducial para o sistema de coordenadas do espaço objeto, necessitando a realização de translações em x e y, além de um fator de escala.

Esse procedimento, aqui denominado de georeferenciamento da fotografia digital retificada, foi feito através da implementação de uma rotina que usa as coordenadas dos pontos de apoio no sistema de referência do mapeamento a ser atualizado e as coordenadas, dos mesmos pontos, medidas sobre a referida fotografia.

Para a extração das feições de interesse, foi necessário desenvolver um módulo de coleta vetorial das coordenadas $\mathrm{E}$ e $\mathrm{N}$ dos pontos indicados através do "mouse", sobre a fotografia digital retificada e georeferenciada. 
Somente determinar as coordenadas dessas feições não é o suficiente para atualizar um mapeamento, onde se têm inúmeras feições em vários "layers" (níveis) diferentes. Portanto, neste módulo de registro vetorial foi implementada uma rotina que registra as coordenadas de forma organizada, ou seja, que monta um arquivo gráfico no formato DXF (Drawing Exchange Format), compatível com vários softwares gráficos utilizados em Cartografia Digital e Sistemas de Informações Geográficas. Na Tabela 04, mostra-se a organização do segmento de entidades em formato DXF.

Tabela 04: Modelo de representação das feições no formato DXF.

\begin{tabular}{|c|c|}
\hline 1 & INDICADOR DO TIPO DE FEIÇÃO \\
\hline $\mathbf{0}$ & INÍCIO DE VÉRTICE \\
\hline Vertex & PALAVRA RESERVADA, INDICA "VÉRTICE" \\
\hline 8 & NÚMERO DO VÉRTICE \\
\hline Atualizado & NOME DO NÍVEL (layer) \\
\hline 10 & IDENTIFICADOR DA COORDENADA X (E) \\
\hline 458387.890 & COORDENADA X $(\mathrm{E})$ \\
\hline 20 & IDENTIFICADOR DA COORDENADA Y (N) \\
\hline 7558678.200 & COORDENADA Y $(\mathrm{N})$ \\
\hline $\begin{array}{l}\text { 0 } \\
\text { Vertex } \\
8 \\
\text { Atualizado } \\
10 \\
458425.890 \\
20 \\
7558695.300 \\
0\end{array}$ & IDEM AOS ITENS ACIMA \\
\hline SEQEND & INDICA TÉRMINO DE FEIÇÃO \\
\hline $\begin{array}{l}\text { 0 } \\
\text { ENDSEC } \\
0 \\
\text { EOF }\end{array}$ & INDICA TÉRMINO DE ARQUIVO \\
\hline
\end{tabular}

Com esse procedimento, o arquivo é montado seguindo padrões, como a cor vermelha das feições e o "layer" específico, dito atualizado, além de as entidades serem todas armazenadas como polilinhas.

Finalmente, o arquivo, com as feições que devem ser introduzidas no mapeamento desatualizado, pode ser gravado e importado por vários softwares CAD. 


\subsection{Funcionamento do protótipo}

Nesta etapa, foram realizados testes com o objetivo de comprovar a eficiência do funcionamento do protótipo, no atual estágio de desenvolvimento. Para tanto, foram utilizadas as fotografias aéreas convencional (0310) e digital (DCP 311).

A tela do programa disponibiliza duas janelas iniciais que possibilitam a visualização das fotografias convencional e digital, como mostra a Figura 20.

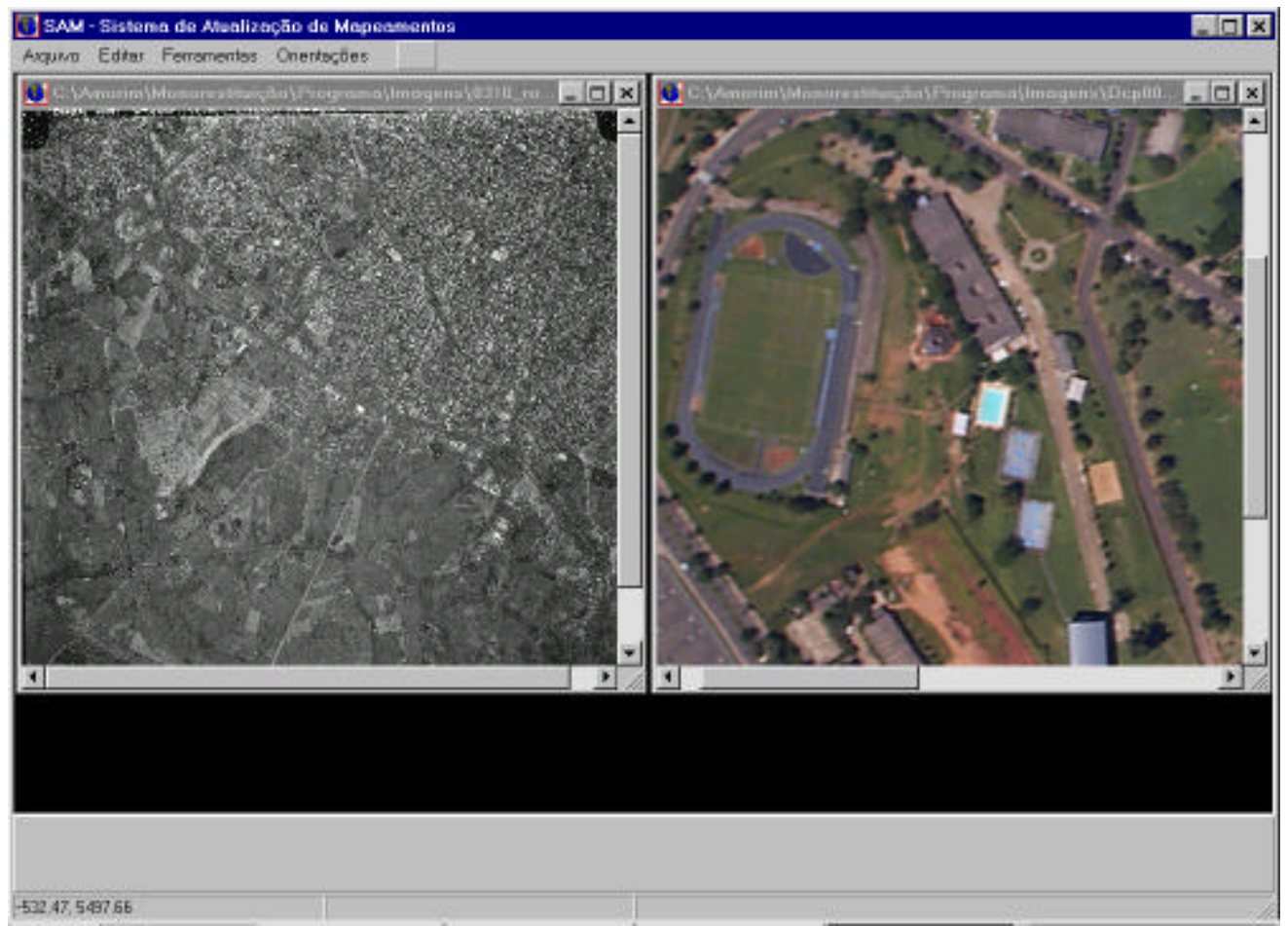

Figura 20 - Tela inicial do Sistema de Atualização de Mapeamentos - SAM.

A orientação interior da fotografia convencional é executada lendo-se as coordenadas das marcas fiduciais sobre a fotografia, com o auxílio de uma janela de aproximação (zoom), como mostra a Figura 21. 


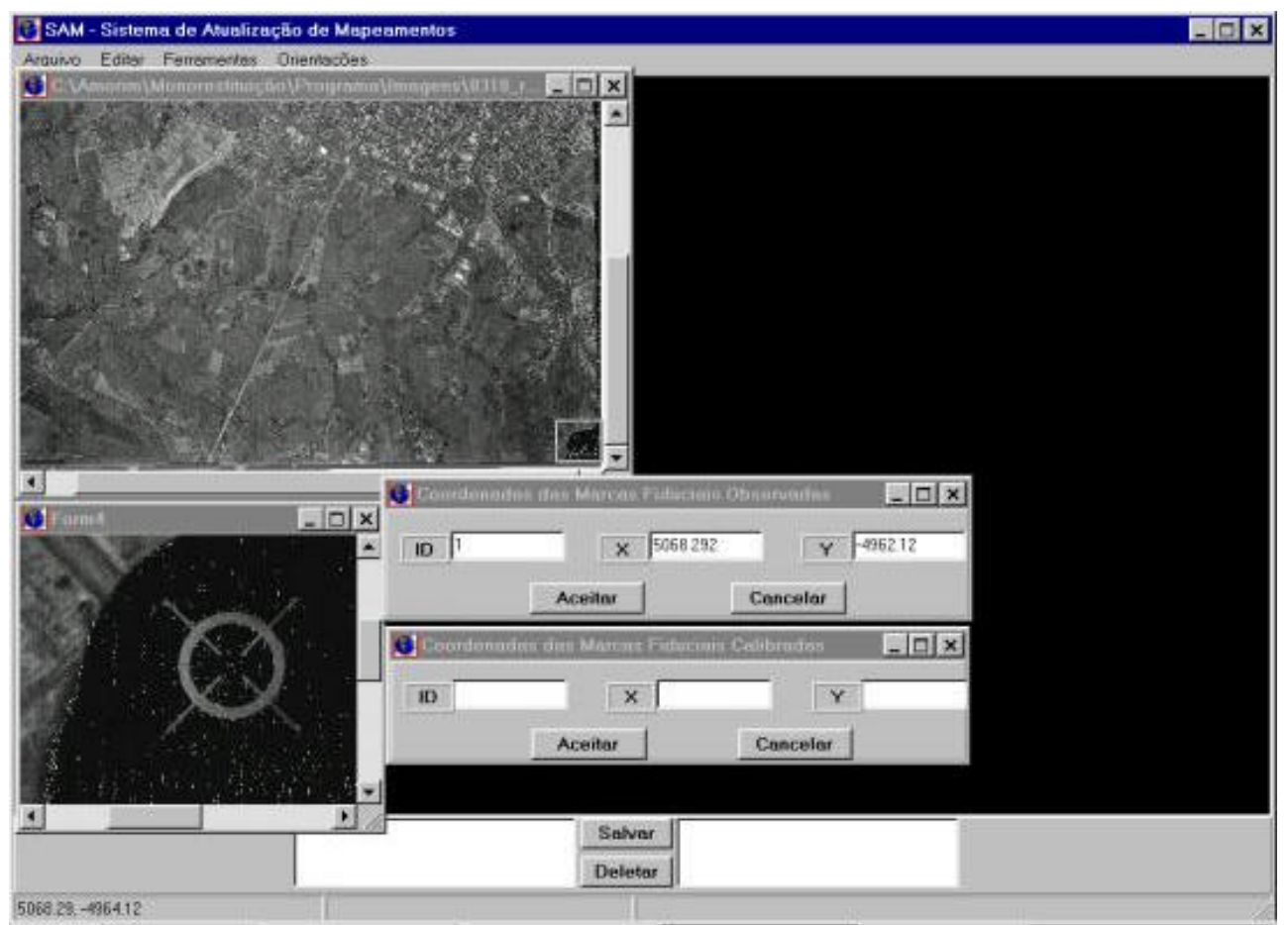

Figura 21 - Orientação interior da fotografia convencional.

Concluindo-se esse processo, uma janela é disponibilizada, como mostra a

Figura 22, para a verificação dos resultados da orientação interior, com a possibilidade de refazer ou aceitar a operação após a análise dos resultados apresentados.

As coordenadas das marcas fiduciais calibradas e os erros da transformação encontram-se em milímetros e as coordenadas das marcas fiduciais observadas estão em pixeis.

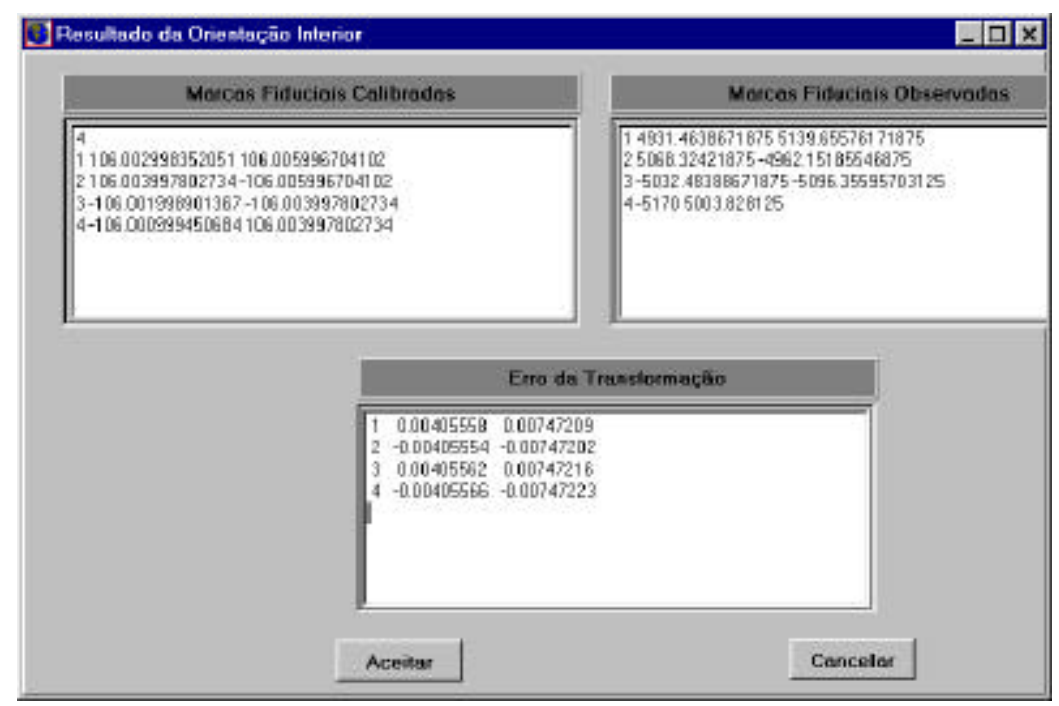

Figura 22 - Resultados da orientação interior. 
O próximo passo foi recortar, da imagem convencional, a parte correspondente à área da fotografia digital que será utilizada, e aplicar a retificação. Com essa fotografia retificada, o próximo passo é visualizar a fotografia digital, aplicar a resseção espacial e retificá-la, como mostra a Figura 23.

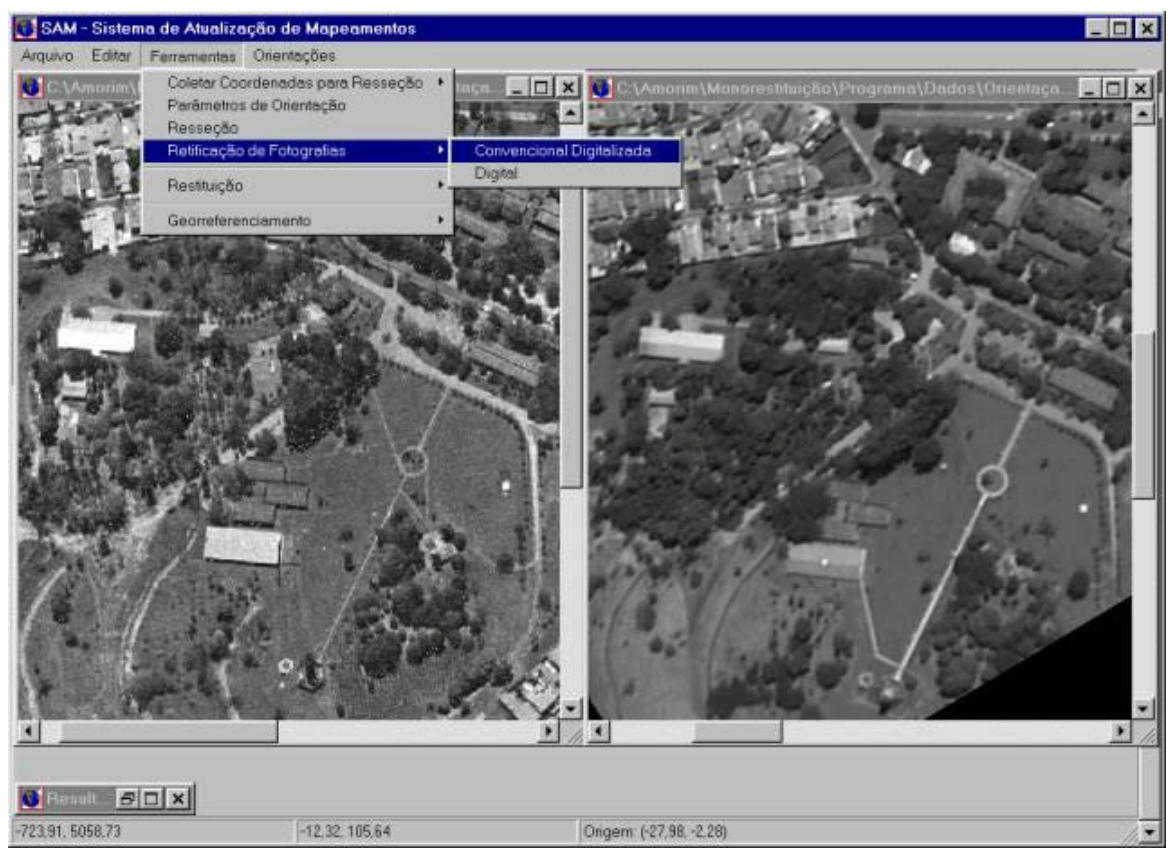

Figura 23 - Fotografias, convencional e digital, retificadas.

Com as duas fotografias retificadas na tela, pode-se montar o modelo anaglifo. Isso é feito escolhendo-se a opção "modelo anaglifo" do menu "Ferramentas" e indicando um ponto na fotografia convencional, bem como no seu homólogo da fotografia digital. Assim, com o referido modelo disponibilizado em tela podem-se identificar as feições novas, como mostra a Figura 24.

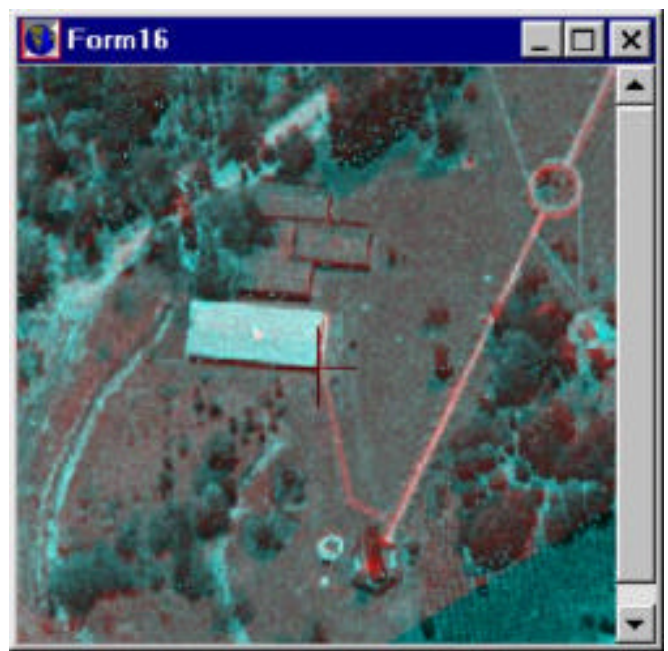

Figura 24 - Formação do modelo anaglifo. 
Como discutido anteriormente, a visualização tridimensional é possível neste caso, mas não é o fato mais importante, pois o grande objetivo é a simples identificação da nova feição, como pode ser observado na Figura 24. Nessa figura a feição aparece destacada em vermelho, uma vez que suas componentes correspondentes em verde e azul não são encontradas na fotografia convencional.

Com a feição identificada e a foto digital georeferenciada, pode-se escolher a opção "extrair feições", no menu de ferramentas do sistema, abrindo a janela de extração de feições com as opções de "Terminar Feição", "Nova Feição" e "Finalizar Vetorização", como mostra a Figura 25.

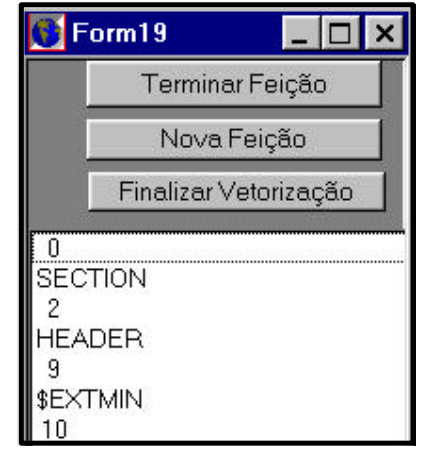

Figura 25 - Janela de extração de feições.

A partir daí, basta escolher com o "mouse" os pontos desejados na fotografia digital retificada e georeferenciada, iniciando e finalizando as feições que devem ser extraídas. Coletadas as feições de interesse, o arquivo deve ser finalizado e gravado, através da opção "Salvar Vetorização", dentro do menu "Arquivo". Com isso obtém -se o arquivo em formato DXF que poderá ser importado em qualquer sistema de CAD. Vale ressaltar que esta ferramenta é utilizada para executar o procedimento descrito na seção 4.3.1.

$\mathrm{Na}$ seção 6.3 serão apresentados os testes de precisão efetuados com as fotografias convencional e digital que foram utilizadas até o momento, ou seja, as fotos 0310 e DCP311 que se encontram na escala 1:25000. 


\section{ANÁLISE EXPERIMENTAL}

\subsection{Experimentos com o método de orientação do modelo estereoscópico híbrido}

\subsubsection{Materiais e equipamentos}

Como o objetivo principal deste trabalho é a atualização cartográfica integrando várias fontes de informações, o primeiro passo foi o levantamento das informações disponíveis para a sua execução, fixando como área teste uma região da cidade de Presidente Prudente SP.

Em 1995 a Prefeitura Municipal de Presidente Prudente contratou um mapeamento em escala 1:5000 da área urbana, sendo o recobrimento fotogramétrico em escala 1:25000, datado de setembro do mesmo ano.

Com o propósito de executar um estudo de viabilidade para a execução deste trabalho, decidiu-se adquirir uma cópia do referido recobrimento fotogramétrico em papel fotográfico e também os diapositivos digitalizados matricialmente com a resolução de 1200 ppp (pontos por polegada), próxima da resolução do filme fotogramétrico.

Além desses materiais, também foram utilizados os seguintes equipamentos:

- $\quad$ Rastreador GPS (Trimble - 4600)

- Câmara Digital DC210

- Microcomputador Pentiun 233 MMX

- Impressora jato de tinta colorida (HP 820 Cxi)

- Software Remap-Plus

- Software CCESC (para calibração e orientação), GALO (1993).

- Software CALIBRA (para calibração), TOMMASELLI \& NOBREGA (1997). 


\subsubsection{Definição da área teste}

Foi escolhida uma região da cidade de Presidente Prudente, próxima à Universidade Estadual Paulista - UNESP, devido à existência de pontos notáveis bem definidos nas fotos e pela proximidade dos laboratórios de apoio aos trabalhos, além da facilidade de deslocamento aos pontos para a execução do levantamento terrestre (apoio de campo).

\subsubsection{Aquisição das fotografias aéreas digitais}

Foi planejado um vôo para o recobrimento da área em questão utilizando-se para tanto as seguintes especificações:

Aeronave: Cesna bi-motor

Câmara: DC210

Distância Focal: 58 mm

Altura de vôo: $1450 \mathrm{~m}$

Escala aproximada: 1:25000

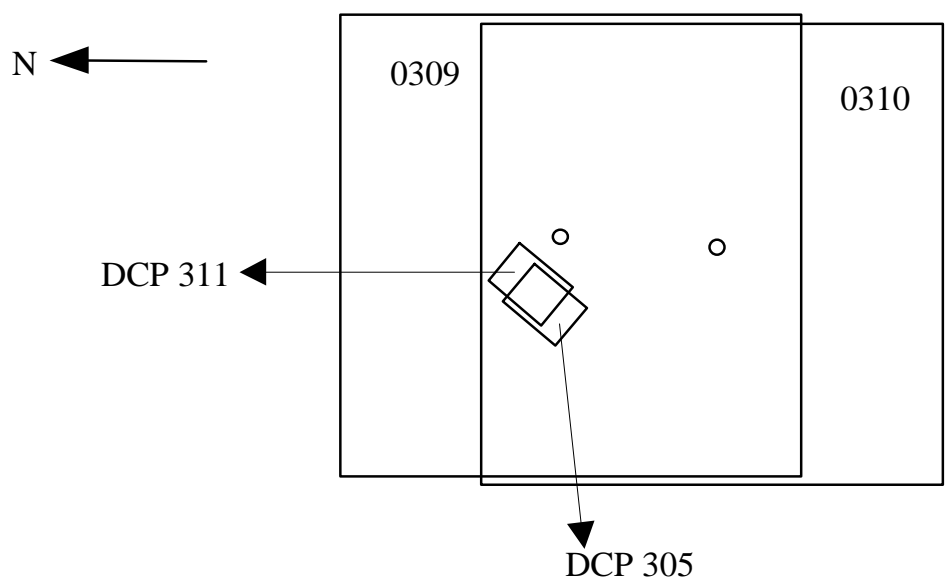

Figura 26 - Posição das fotografias digitais (DCP 311 e DCP 305) em relação às fotografias convencionais. 


\subsubsection{Experimentos executados sem a calibração prévia da câmara digital.}

\subsubsection{Apoio utilizado para os experimentos.}

Os pontos de apoio foram planejados em feições bem definidas e espacialmente bem distribuídas nos modelos estereoscópicos a serem orientados, como podem ser vistos na Figura 27.

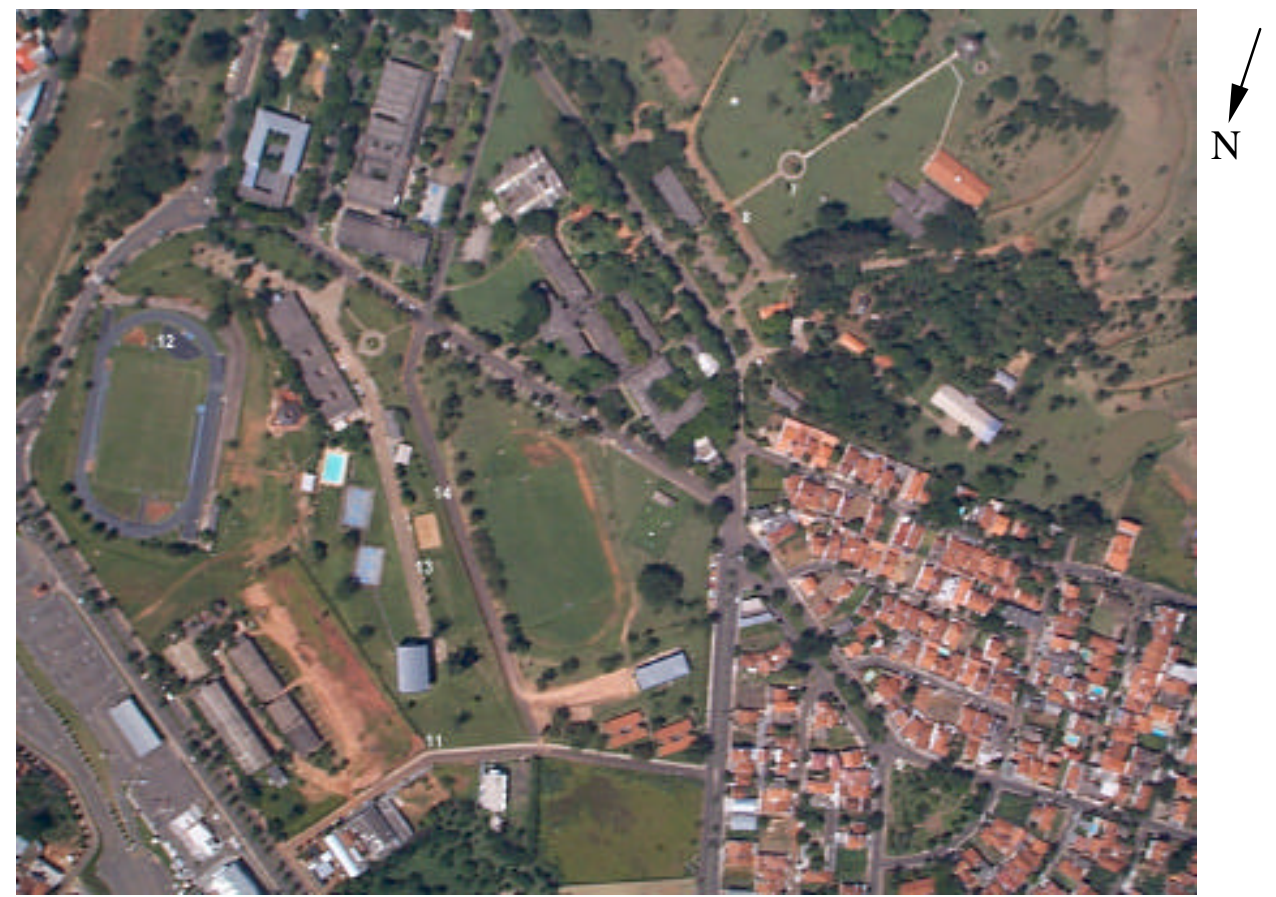

Figura 27 - Fotografia aérea digital (DCP 311) com pontos de apoio.

As coordenadas dos pontos de apoio/verificação foram determinadas executando-se um levantamento com o Rastreador GPS, trimble 4600, de propriedade da Fundação de Ciência, Tecnologia e Ensino - FUNDACTE, da Unesp de Presidente Prudente. 
Tabela 05 - Coordenadas dos pontos de apoio (SAD-69)

\begin{tabular}{cccc}
\hline Pontos & $\mathbf{E}(\mathbf{m})$ & $\mathbf{N}(\mathbf{m})$ & $\mathbf{h}(\mathbf{m})$ \\
\hline 7 & 457957.083 & 7553615.724 & 440.272 \\
8 & 457976.194 & 7553655.491 & 438.627 \\
9 & 457649.619 & 7553952.258 & 423.956 \\
11 & 457964.118 & 7554123.618 & 414.381 \\
12 & 458291.881 & 7553935.930 & 406.678 \\
13 & 458046.059 & 7553987.596 & 424.035 \\
14 & 458051.780 & 7553959.571 & 424.029 \\
\hline
\end{tabular}

\subsubsection{Formação dos modelos estereoscópicos}

\subsection{Orientação do modelo estereoscópico convencional}

Para a orientação desse modelo, foi utilizado o programa CCESC implementado por GALO (1993). O modelo foi formado com as fotografias aéreas convencionais (0309 e 0310) na escala 1:25000, digitalizadas matricialmente via scanner com 1200 ppp, diretamente a partir do diapositivo.

O objetivo da formação deste modelo foi obter os parâmetros de orientação exterior da foto convencional, para utilizá-los como injunção na orientação do modelo estereoscópico híbrido, principal objeto de estudo deste trabalho.

\subsection{Orientação do modelo híbrido}

Conhecidos os parâmetros de orientação exterior da foto convencional e obtida a fotografia aérea digital em escala 1:25000 da área de interesse, próxima ao câmpus da Unesp, orientou-se o modelo híbrido utilizando, também, o programa CCESC (GALO, 1993), que permite processar de modo foto-variante, ou seja, permite orientar modelos estereoscópicos utilizando as fotografias 0309 e DCP 311, tomadas com diferentes distâncias focais, que é o caso em estudo, visto que a distância focal da câmara convencional utilizada foi de $153,52 \mathrm{~mm}$ enquanto a distância focal nominal da câmara digital foi de $58 \mathrm{~mm}$. 
Tabela 06 - Discrepâncias entre as coordenadas dos pontos levantados em campo e seus correspondentes calculados após a orientação do modelo híbrido.

\begin{tabular}{cccc}
\hline Pontos & $\Delta \mathbf{E}(\mathbf{m})$ & $\Delta \mathbf{N}(\mathbf{m})$ & $\Delta \mathbf{h}(\mathbf{m})$ \\
\hline 7 & 0.000 & 0.000 & 0.000 \\
8 & 0.000 & 0.000 & -0.005 \\
9 & -0.001 & 0.000 & 0.007 \\
11 & 0.000 & 0.000 & -0.004 \\
12 & 0.000 & -0.001 & -0.005 \\
13 & -1.051 & 0.457 & -10.192 \\
14 & 0.550 & -2.704 & 14.003 \\
\hline
\end{tabular}

OBS.: Os pontos de 7 ao 12 foram usados como apoio e os pontos 13 e 14 são de verificação.

Pode-se notar que as discrepâncias nos pontos utilizados como apoio foram praticamente nulas, mas o que expressa significativamente o resultado são as discrepâncias nos pontos de verificação. As discrepâncias em planimetria dos pontos de verificação não comprometeram de forma considerável os resultados, por terem sido utilizadas fotografias aéreas em escalas 1:25000; ao passo que as discrepâncias em altimetria estão acima de 10 metros.

Várias fontes de erro podem ter afetado os resultados; entre elas podem-se citar, principalmente, as diferenças de geometria entre as câmaras convencional e digital, erros de pontaria, pois as fotos são de épocas diferentes, além da pouca diferença de nível detectada entre os pontos de apoio, sendo que a mesma ficou em aproximadamente $2,4 \%$ da altura de vôo.

A ocorrência da pequena diferença de nível entre os pontos de apoio foi provocada pela pequena área de abrangência da foto digital $\left(0,58 \mathrm{Km}^{2}\right)$, ou seja, $875,0 \mathrm{~m}$ X $662,5 \mathrm{~m}$, e pode ter afetado os resultados porque, nesse caso, foi feita uma auto-calibração da câmara digital, já que foi usada a distância focal nominal de 58 mm com 10 mm de desvio padrão. 


\subsection{Orientação do modelo estereoscópico com duas fotos aéreas digitais}

O recobrimento com as fotografias aéreas digitais (DCP 311 e DCP 305) proporcionou $70 \%$ de superposição longitudinal na área de interesse, em escala 1:25000, para possibilitar a formação de um modelo mediante o uso de duas fotos com a mesma câmara, ou seja, a mesma geometria.

O objetivo desse teste foi comparar os resultados dessa orientação com os resultados do modelo híbrido, principalmente nos pontos de verificação.

Tabela 07 - Discrepâncias entre as coordenadas dos pontos levantados em campo e suas correspondentes calculadas após a orientação do modelo digital.

\begin{tabular}{cccc}
\hline Pontos & $\Delta \mathbf{E}(\mathbf{m})$ & $\Delta \mathbf{N}(\mathbf{m})$ & $\Delta \mathbf{h}(\mathbf{m})$ \\
\hline 7 & 0.000 & 0.000 & 0.008 \\
8 & 0.000 & 0.000 & -0.008 \\
9 & 0.000 & 0.000 & 0.000 \\
11 & 0.000 & 0.000 & 0.002 \\
12 & 0.000 & 0.000 & -0.001 \\
13 & -0.443 & 0.062 & 1.043 \\
14 & -0.292 & 0.669 & -0.850 \\
\hline
\end{tabular}

OBS.: Os pontos de 7 ao 12 foram usados como apoio e os pontos 13 e 14 são de verificação.

As discrepâncias detectadas nos pontos de verificação diminuíram, em relação ao modelo anteriormente orientado, tanto em planimetria quanto em altimetria, como já era esperado, pois as condições geométricas e de pontaria são similares.

Uma forma de melhorar os resultados é a prévia calibração da câmara digital. Uma vez que a câmara convencional possui o certificado de calibração, pode-se entrar com as distâncias focais calibradas como injunção na orientação relativa dependente a ser executada no modelo híbrido.

Nota-se ainda, para esse tipo de trabalho, a necessidade de ter um maior número de pontos de verificação, para possibilitar análises mais consistentes dos resultados através de testes estatísticos. 


\subsubsection{Experimentos executados com a calibração prévia da câmara digital.}

\subsubsection{Calibração da câmara digital}

Diante dos resultados obtidos, pelo experimento anterior, tomou-se a decisão de executar uma pré-calibração da câmara digital com o objetivo de melhorar os resultados.

Para a execução dessa etapa foi utilizada uma placa de metal, munida de orifícios de $2 \mathrm{~mm}$ de diâmetro com espaçamento de $100 \mathrm{~mm}$ entre si, além de pinos feitos de alumínio com diâmetro de $18 \mathrm{~mm}$ e comprimento de $150 \mathrm{~mm}$, como mostra a Figura 28.

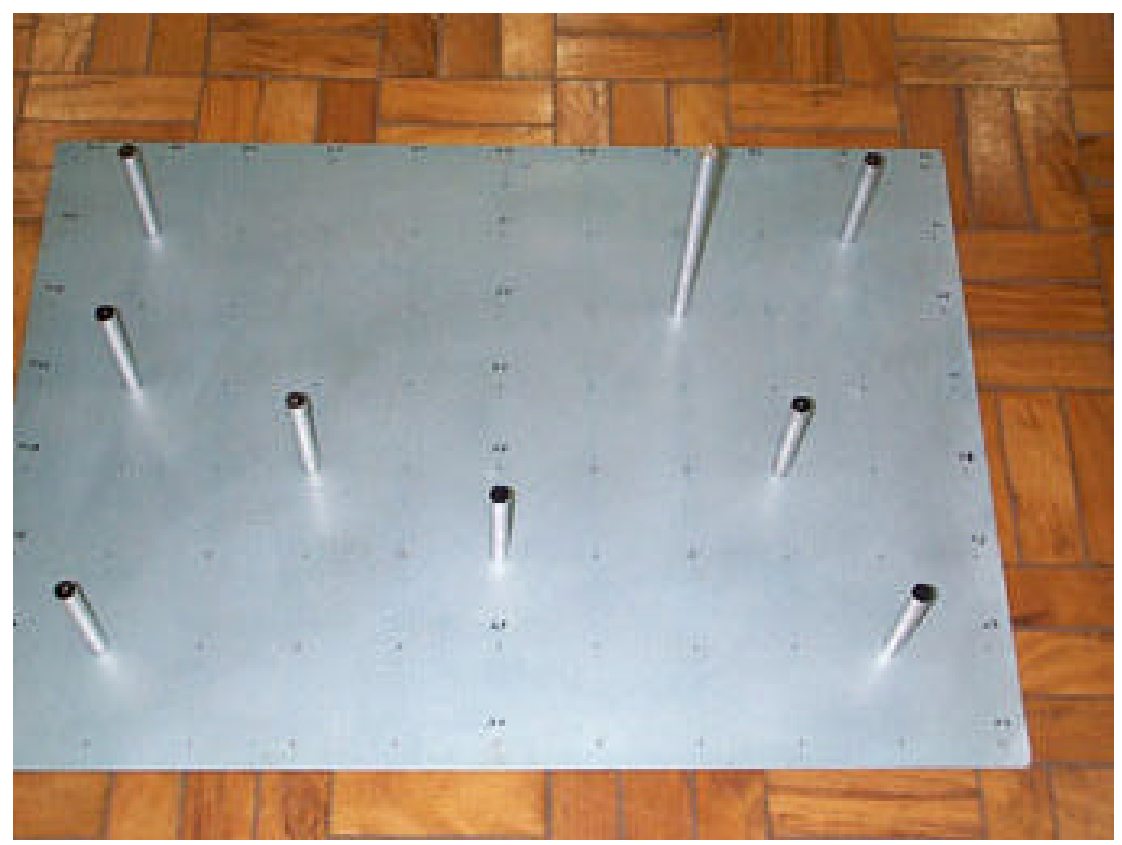

Figura 28 - Campo de calibração

Foram tomadas 11 imagens de diversas posições com a câmara DC210, a ser calibrada, e posteriormente processadas. As imagens foram importadas num 
software de manipulação de imagens, executando-se a leitura das coordenadas de imagem de 30 pontos em cada imagem.

Após esse procedimento, as coordenadas foram exportadas para o software Remap-plus (CAD) onde foi executada a orientação interior, ou seja, as coordenadas foram reduzidas a um suposto sistema "fiducial" da fotografia digital.

Como esta câmara não é dotada de marcas fiduciais, consideram-se os pixeis extremos da matriz CCD como se fossem as referidas marcas, utilizando as coordenadas corrigidas ${ }^{5}$ dos pixeis, o que possibilitam, então, a orientação interior.

Em seguida foram montados os arquivos para a calibração a ser executada com o programa CALIBRA, implementado por TOMMASELLI \& NOBREGA (1997). Os resultados da referida calibração encontram-se na Tabela 08.

Tabela 08 - Resultados da calibração da câmara digital DC210.

\begin{tabular}{|l|c|c|}
\hline \multicolumn{2}{|c|}{ Calibração da câmara digital DC210, considerando K1 e ds. } \\
\hline \multicolumn{1}{|c|}{ Parâmetros } & Valor Estimado & Desvio Padrão Estimado \\
\hline $\mathrm{C}_{\mathrm{x}}(\mathrm{mm})$ & 0.145 & 0.106130 \\
\hline $\mathrm{C}_{\mathrm{y}}(\mathrm{mm})$ & 1.179 & 0.000002 \\
\hline $\mathrm{K}_{1}$ & 0.000006 & 0.000461 \\
\hline $\mathrm{d}_{\mathrm{s}}$ & -0.000852 & 0.214250 \\
\hline $\mathrm{f}(\mathrm{mm})$ & 53.985 & 0.081941 \\
\hline $\mathrm{N}^{\mathrm{o}}$ de iterações & \multicolumn{2}{|c|}{6} \\
\hline
\end{tabular}

Onde: $\mathrm{C}_{\mathrm{x}}$ e $\mathrm{C}_{\mathrm{y}}=$ coordenadas do ponto principal.

$\mathrm{K}_{1}=$ distorção radial

$\mathrm{d}_{\mathrm{s}}=$ fator de escala na direção $\mathrm{x}$ (desconsiderado por representar menos que $2 \mu$ para a maior distância calculada, neste caso)

$\mathrm{f}=$ distância focal

Vale ressaltar que o desvio padrão considerado para as observações foi de 0,03 mm, o que equivale ao tamanho de um pixel, e nota-se pelos resultados

\footnotetext{
${ }^{5}$ Estas coordenadas são referentes ao centro do pixel, tornando necessária a correção para as bordas, considerando as dimensões externas ( $35 \mathrm{x} 26,5 \mathrm{~mm})$.
} 
apresentados na Tabela 08 que o desvio padrão da distância focal calibrada foi menor que 3 pixeis, o que indica, numa primeira análise, um resultado satisfatório.

\subsubsection{Orientação do modelo híbrido com os parâmetros calibrados}

Como pôde ser observado, nos experimentos anteriores, quando foi utilizada a distância focal nominal da câmara digital os resultados não foram considerados satisfatórios, principalmente na altimetria, pela magnitude dos erros em $\mathrm{Z}$ e pelo reduzido número de pontos de verificação. Resolveu-se então determinar fotogrametricamente os pontos que seriam utilizados para a orientação do modelo híbrido, assim como os pontos de verificação. Para esse procedimento foi utilizado o mesmo modelo convencional (foto 0309 / foto 0310) que havia sido utilizado para determinar os parâmetros de orientação, necessários à injunção do modelo híbrido.

Foram feitas observações nas referidas fotos, considerando pontos notáveis tanto nas fotografias aéreas convencionais quanto na fotografia aérea digital a ser utilizada, determinando-se assim as coordenadas (UTM) dos mesmos no sistema referencial SAD69, como mostra a Tabela 09.

Tabela 09 - Pontos determinados fotogrametricamente (SAD 69)

\begin{tabular}{cccl}
\hline Pontos & $\mathbf{E}(\mathbf{m})$ & $\mathbf{N}(\mathbf{m})$ & $\mathbf{h}(\mathbf{m})$ \\
\hline 7 & 457959,120 & 7553616,428 & 439,141 \\
8 & 457977,497 & 7553655,830 & 436,875 \\
9 & 457653,272 & 7553951,409 & 423,374 \\
12 & 458293,527 & 7553936,318 & 406,783 \\
15 & 457846,019 & 7554013,195 & 425,377 \\
16 & 457828,603 & 7553968,411 & 430,653 \\
17 & 457819,744 & 7553546,722 & 442,225 \\
18 & 458222,630 & 7553869,648 & 424,981 \\
19 & 458120,904 & 7553690,014 & 436,324 \\
22 & 457775,846 & 7553702,961 & 435,699 \\
23 & 458091,308 & 7553925,108 & 427,447 \\
25 & 457706,344 & 7553901,432 & 425,013 \\
\hline
\end{tabular}


Além de aumentar o tamanho da amostra, faz-se necessária uma análise da exatidão cartográfica composta por duas fases, sendo a primeira um teste de detecção de tendências (que apura se os resultados estão isentos de erros sistemáticos) e a segunda, uma análise de precisão. As discrepâncias são calculadas a partir das coordenadas extraídas da carta a ser analisada e das coordenadas (dos mesmos pontos) obtidas por meios confiáveis, onde se tem a estimativa de precisão dos mesmos.

\subsection{Análise de detecção de tendências}

Considerando a Distribuição " $t$ " de Student, pode-se dizer que um produto está isento de efeitos sistemáticos quando :

$$
|t|<t_{(n-1, \alpha)}
$$

Como temos três coordenadas a serem avaliadas, o teste deve ser aplicado nas direções E, N e h:

$$
\begin{aligned}
& \left|t_{E}\right|<t_{(n-1, \alpha)} \\
& \left|t_{N}\right|<t_{(n-1, \alpha)} \\
& \left|t_{h}\right|<t_{(n-1, \alpha)}
\end{aligned}
$$


Os valores de $t_{E}, t_{N} e t_{h}$, são calculados por:

$$
\begin{aligned}
& t_{E}=\frac{1}{S_{E}} *(\overline{\Delta E}) * n^{\frac{1}{2}} \\
& t_{N}=\frac{1}{S_{N}} *(\overline{\Delta N}) * n^{\frac{1}{2}} \\
& t_{h}=\frac{1}{S_{h}} *(\overline{\Delta h}) * n^{\frac{1}{2}}
\end{aligned}
$$

Onde:

$\Delta \mathrm{E}$ é a média das discrepâncias em $\mathrm{E}$;

$\Delta \mathrm{N}$ é a média das discrepâncias em $\mathrm{N}$;

$\Delta \mathrm{h}$ é a média das discrepâncias em h;

$\mathrm{S}_{\mathrm{E}}$ é o desvio padrão amostral em E;

$\mathrm{S}_{\mathrm{N}}$ é o desvio padrão amostral em $\mathrm{N}$;

$\mathrm{S}_{\mathrm{h}}$ é o desvio padrão amostral em $\mathrm{h}$.

A obtenção de $t_{(n-1, \alpha)}$ é feita através da tabela de distribuição "t" de Student que pode ser encontrada em vários livros de estatística, onde "n" é o tamanho da amostra e $\alpha$ é o intervalo de confiança.

\subsection{Análise de Precisão (qui quadrado)}

Pela Legislação Brasileira de Cartografia e Aerolevantamento, o desvio padrão planimétrico é determinado a partir das coordenadas E e N; portanto, entendese que o erro padrão a ser analisado terá a resultante igual nas direções E e N. A partir do exposto anteriormente o desvio padrão planimétrico esperado nesta análise fica assim determinado:

$$
\sigma_{E}=\sigma_{N}=\frac{E P P}{\sqrt{2}}
$$


Considera-se, para efeito de análise de exatidão de produtos cartográficos chamados de CLASSE “A”, um erro padrão planimétrico (EPP) de $0,3 \mathrm{~mm}$ na escala do produto cartográfico.

As fotografias aéreas utilizadas neste trabalho encontram-se na escala 1:25000 e deram origem ao mapeamento em escala 1:5000 digital contratado pela Prefeitura Municipal de Presidente Prudente. Sendo assim, a análise de precisão será executada com os parâmetros estabelecidos para essa escala, ou seja, 0,3 mm na escala 1:5000 que significa 1,5 m.

Sendo assim, temos:

$$
\sigma_{E}=\sigma_{N}=\frac{1,5}{\sqrt{2}}=1,06 \mathrm{~m}
$$

Para a altimetria, é estabelecido um erro padrão de $1 / 3$ da eqüidistância das curvas de nível, ou seja, 1,67 m já que a eqüidistância é de 5 metros.

Considerando os elementos amostrais, pode-se ter:

$$
\begin{aligned}
& \chi_{E, n-1}^{2}=\frac{n-1}{\sigma_{E}^{2}} * S_{E}^{2} \\
& \chi_{N, n-1}^{2}=\frac{n-1}{\sigma_{N}^{2}} * S_{N}^{2} \\
& \chi_{h, n-1}^{2}=\frac{n-1}{\sigma_{h}^{2}} * S_{h}^{2}
\end{aligned}
$$

Onde:

$\mathrm{n}=$ tamanho da amostra;

$\sigma=$ desvio padrão resultante (planimétrico e altimétrico);

$\mathrm{S}=$ desvio padrão amostral estimado. 
Para que o produto analisado esteja dentro dos limites de tolerâncias estabelecidos pela Legislação Brasileira de Cartografia e Aerolevantamento é necessário satisfazer a seguinte condição:

Planimetria:

$$
\chi_{P, n-1}^{2} \leq \chi_{n-\alpha, \alpha}^{2}
$$

Altimetria:

$$
\chi_{A, n-1}^{2} \leq \chi_{n-1, \alpha}^{2}
$$

No caso em questão, o tamanho da amostra varia de acordo com o número de pontos usados como apoio em cada teste utilizado, mas trabalha-se sempre com um intervalo de confiança de $90 \%$, tanto para o teste de detecção de tendências quanto para o teste de precisão.

\subsection{Testes com o par (Foto 0309 / DCP 311)}

De posse dos parâmetros de orientação exterior da foto 0309, o modelo híbrido foi orientado considerando esses parâmetros como injunções (fixos) e executando, portanto, uma orientação relativa dependente. Como uma das metas deste trabalho é a utilização do menor número de pontos de apoio possível, ou até mesmo sem pontos de apoio, foram feitos testes com 2 e 3 pontos de apoio.

A Tabela 10 mostra as análises estatísticas feitas nos testes com 2 e 3 pontos de apoio, a partir das discrepâncias entre as coordenadas calculadas dos 12 pontos de verificação e suas homólogas (consideradas fixas) apresentadas na Tabela 09. 
Tabela 10 - Comparação das análises dos testes com 2 e 3 pontos de apoio. (Fotos 0309 / DCP 311)

\begin{tabular}{|l|r|r|r|l|r|r|r|}
\hline \multicolumn{4}{|c|}{ Teste com 2 pontos de apoio (7,12) } & \multicolumn{3}{c|}{ Teste com 3 pontos de apoio (7,8,12) } \\
\hline & $\Delta \mathrm{E}(\mathrm{m})$ & $\Delta \mathrm{N}(\mathrm{m})$ & $\Delta \mathrm{h}(\mathrm{m})$ & & $\Delta \mathrm{E}(\mathrm{m})$ & $\Delta \mathrm{N}(\mathrm{m})$ & $\Delta \mathrm{h}(\mathrm{m})$ \\
\hline Desv. Pad. & 0,695 & 1,110 & 7,385 & Desv. Pad. & 0,637 & 1,003 & 5,234 \\
\hline Média & $-0,375$ & 0,759 & $-5,986$ & Média & $-0,291$ & 0,289 & $-1,478$ \\
\hline $\mathrm{t}(0,10 ; 9)$ & 1,38 & 1,38 & 1,38 & $\mathrm{t}(0,10 ; 8)$ & 1,40 & 1,40 & 1,40 \\
\hline $\mathrm{t}(\mathrm{E}, \mathrm{N}, \mathrm{h})$ & $-1,707$ & 2,163 & $-2,563$ & $\mathrm{t}(\mathrm{E}, \mathrm{N}, \mathrm{h})$ & $-1,370$ & 0,865 & $-0,847$ \\
\hline QUIQUAD(9;0,9) & 14,70 & 14,70 & 14,70 & QUIQUAD $(8 ; 0,9)$ & 13,40 & 13,40 & 13,40 \\
\hline QUIQUAD(E,N,h) & 3,868 & 9,871 & 175,975 & QUIQUAD(E,N,h) & 2,886 & 8,053 & 78,593 \\
\hline
\end{tabular}

Obs.: Foram utilizados os 12 pontos de verificação apresentados na Tabela 09.

Como se pode observar, os resultados, na maioria dos casos, para as coordenadas $\mathrm{E}$ e $\mathrm{N}$, relativamente às cartas em escala 1:5000, apresentam discrepâncias dentro dos limites de tolerância, enquanto, para a coordenada h, os resultados ultrapassam significativamente o limite de tolerância, o que pode ser comprovado no teste de precisão realizado.

Já na detecção de tendências, nota-se que o teste realizado com 3 pontos de apoio mostrou-se livre de tendências em todas as direções e dentro da precisão desejada em planimetria, mas a altimetria não alcançou o nível de precisão desejada.

\subsection{Testes com o par (Foto 0310 / DCP 311)}

Diante dos resultados anteriores, foi feita uma análise minuciosa sobre o posicionamento relativo entre as fotografias aéreas convencionais, digitais e a área de estudo. Pode-se notar que a área de estudo ocupa uma região, em relação à foto da convencional (0309), muito próxima de seu ponto principal (ver Figura 26), ou seja, planimetricamente os centros perspectivos das fotografias (convencional e digital) estão muito próximos. Não bastando esse problema, o centro perspectivo da 
fotografia convencional está mais alto do que o centro perspectivo da fotografia digital, fato este impossível de ser corrigido devido à diferença de geometria entre as câmaras utilizadas. Esses problemas não proporcionam boas condições para o cruzamento dos feixes de raios, afetando diretamente os resultados.

Na fotografia convencional (0310), a área de estudo ocupa uma posição geometricamente mais favorável para esse tipo de trabalho, já que se encontra na borda da foto convencional, portanto com o ponto principal da fotografia convencional mais distante do ponto principal da fotografia digital, proporcionando melhores condições geométricas para o cruzamento dos raios. Sendo assim foram executados testes, desta vez com o par (Foto 0310 / DCP 311), utilizando 2 e 3 pontos de apoio, como mostra a Tabela 11.

Tabela 11 - Comparação das análises dos testes com 2 e 3 pontos de apoio. (Fotos 0310 / DCP 311)

\begin{tabular}{|l|r|r|r|l|r|r|r|}
\hline \multicolumn{4}{|c|}{ Teste com 2 pontos de apoio (7,12) } & \multicolumn{3}{c|}{ Teste com 3 pontos de apoio (7,9,12) } \\
\hline & $\Delta \mathrm{E}(\mathrm{m})$ & $\Delta \mathrm{N}(\mathrm{m})$ & $\Delta \mathrm{h}(\mathrm{m})$ & & $\Delta \mathrm{E}(\mathrm{m})$ & $\Delta \mathrm{N}(\mathrm{m})$ & $\Delta \mathrm{h}(\mathrm{m})$ \\
\hline Desv. Pad. & 0,319 & 0,902 & 0,666 & Desv. Pad. & 0,243 & 0,799 & 1,157 \\
\hline Média & $-0,043$ & 0,028 & $-0,578$ & Média & $-0,042$ & 1,093 & $-1,501$ \\
\hline $\mathrm{t}(0,10 ; 9)$ & 1,38 & 1,38 & 1,38 & $\mathrm{t}(0,10 ; 8)$ & 1,40 & 1,40 & 1,40 \\
\hline $\mathrm{t}(\mathrm{E}, \mathrm{N}, \mathrm{h})$ & $-0,423$ & 0,099 & $-2,743$ & $\mathrm{t}(\mathrm{E}, \mathrm{N}, \mathrm{h})$ & $-0,523$ & 4,103 & $-3,891$ \\
\hline QUIQUAD(9;0,9) & 14,70 & 14,70 & 14,70 & QUIQUAD $(8 ; 0,9)$ & 13,40 & 13,40 & 13,40 \\
\hline QUIQUAD(E,N,h) & 0,814 & 6,524 & 1,432 & QUIQUAD(E,N,h) & 0,419 & 4,545 & 3,838 \\
\hline
\end{tabular}

Obs.: Foram utilizados os 12 pontos de verificação apresentados na Tabela 09.

Pode-se notar, pelas informações da Tabela 11 que os resultados apresentaram-se dentro do nível de precisão desejado.

Quanto ao teste de detecção de tendências nota-se que a maioria dos resultados foi afetada por erros sistemáticos, principalmente em altimetria. 


\subsubsection{Análise dos resultados dos experimentos com o método de orientação do modelo estereoscópico híbrido}

Nos dois experimentos anteriores, apresentados nas seções 6.1.5.2.3 e 6.1.5.2.4, os testes de precisão e tendências foram executados com as coordenadas de pontos determinados fotogrametricamente; portanto possuem uma precisão menor do que pontos determinados com GPS geodésico.

Um fato interessante que vale ser ressaltado é a calibração da câmara digital ter sido feita em laboratório, com a distância (simulando a altura do vôo) de 1,5 a 2,0 metros. Como a câmara digital DC 210 possui autofoco e distância focal variável, pode ocorrer uma diferença no valor da distância focal, quando se afasta ou se aproxima do objeto a ser fotografado. Desse modo, é recomendável para experimentos futuros que a calibração seja executada com fotos aéreas e pontos présinalizados.

Outra consideração importante é que este experimento foi realizado com o objetivo principal de verificar o comportamento da orientação de um modelo híbrido, ou seja, com fotografias de características geométricas diferentes. Nesse momento é importante que os pontos de apoio e verificação sejam bem definidos nas duas fotos. Esse fato não ocorrerá quando o objetivo for a atualização cartográfica, pois as feições novas constarão somente da foto mais recente (fotografia digital), justificando o uso do modelo de monorestituição proposto.

\subsection{Detecção de alterações em imagens multitemporais}

A metodologia proposta por LUGNANI (1985) trata da detecção de alterações através de modelos estereoscópicos, utilizando-se naquele momento restituidores analógicos ou analíticos, e esse foi um dos fatores que motivaram a execução dos experimentos mostrados nesta seção. 
Pouco explorado, esse é um dos procedimentos que foram objeto de estudos deste trabalho, objetivando agilizar os processos de atualização cartográfica.

Para a atualização de mapeamentos topográficos planialtimétricos, faz-se necessária a visualização tridimensional do modelo a ser restituído, sendo utilizadas para isso, algumas técnicas de separação das imagens de tal forma que cada imagem seja vista por um dos olhos. Entre as conhecidas técnicas de obtenção de visão estereoscópica, serão testadas neste trabalho as técnicas de Estereoscópio de Espelhos, Cintilamento ou Luz Intermitente e Anaglifo.

\subsubsection{Visualização estereoscópica utilizando estereoscópio de espelho.}

Num primeiro momento, foi feito um experimento cujo principal objetivo foi identificar alterações através da visualização estereoscópica de um modelo formado com as fotografias aéreas, digital e convencional, impressas em papel. Entretanto, devido à grande diferença geométrica entre as referidas fotos e também pela diferente orientação da linha de vôo, isso não foi possível. Partiu-se então para a visualização desse modelo utilizando o método de Cintilamento ou Luz Intermitente.

\subsubsection{Visualização estereoscópica por cintilamento ou luz intermitente.}

Obter a visão tridimensional, por si só, ainda não é o suficiente para os objetivos que se deseja alcançar com este trabalho. É necessário que as feições novas sejam realçadas de alguma maneira, para serem identificadas isoladamente e com boas condições de segurança ao operador do sistema de atualização de mapeamentos. 
Foi formado um modelo estereoscópico por cintilamento, utilizando-se o software "3D Stereo Image Factory Plus" (versão-demonstração), bem como um par de imagens obtidas com a câmara digital DC210, mostradas nas Figuras 29 e 30, em escala 1:25000, do Câmpus da Unesp de Presidente Prudente - SP.

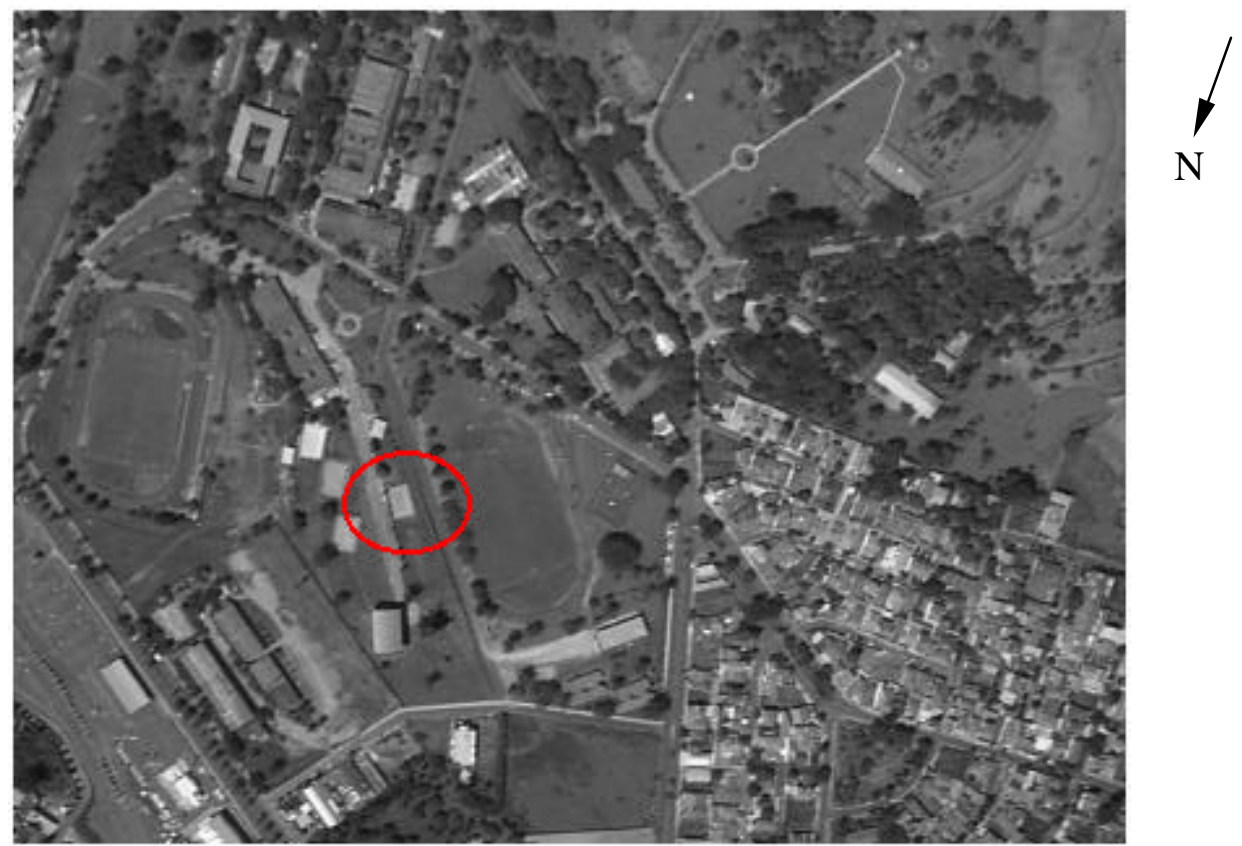

Figura 29 - Fotografia aérea DCP311, destacando uma feição existente.
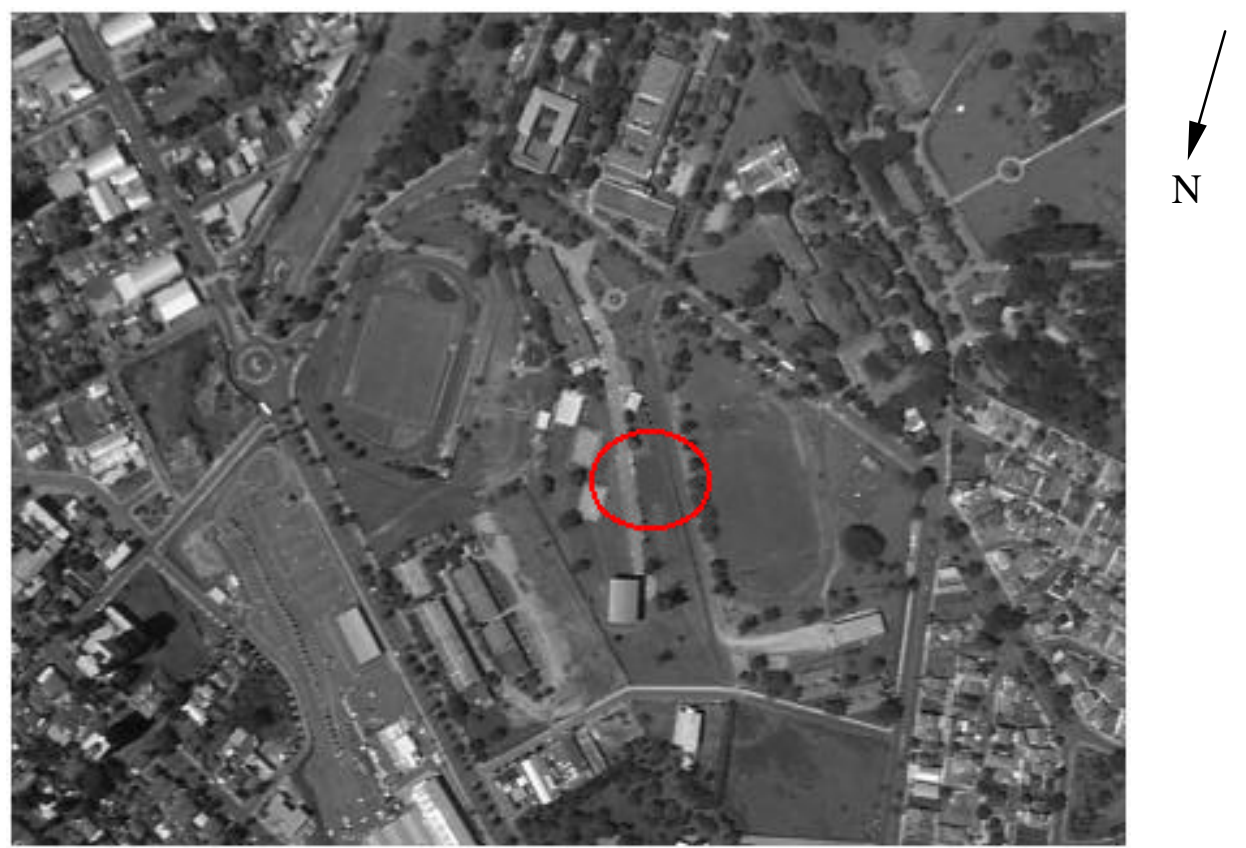

Figura 30 - Fotografia aérea DCP305, com a feição de interesse eliminada. 
Na tentativa de obter um bom resultado em termos de detecção da alteração, uma feição que constava nas duas fotos foi suprimida em uma delas, como mostra a Figura 30. Constando em apenas uma das fotos, essa feição deverá ser mostrada na tela do computador somente quando a fotografia que a contém for visualizada.

Isso realmente acontece, mas como a freqüência do monitor é alta, o resultado é apenas um brilho diferente nessa feição (aparece um pouco mais clara), podendo ser confundida com outras feições que têm coloração parecida.

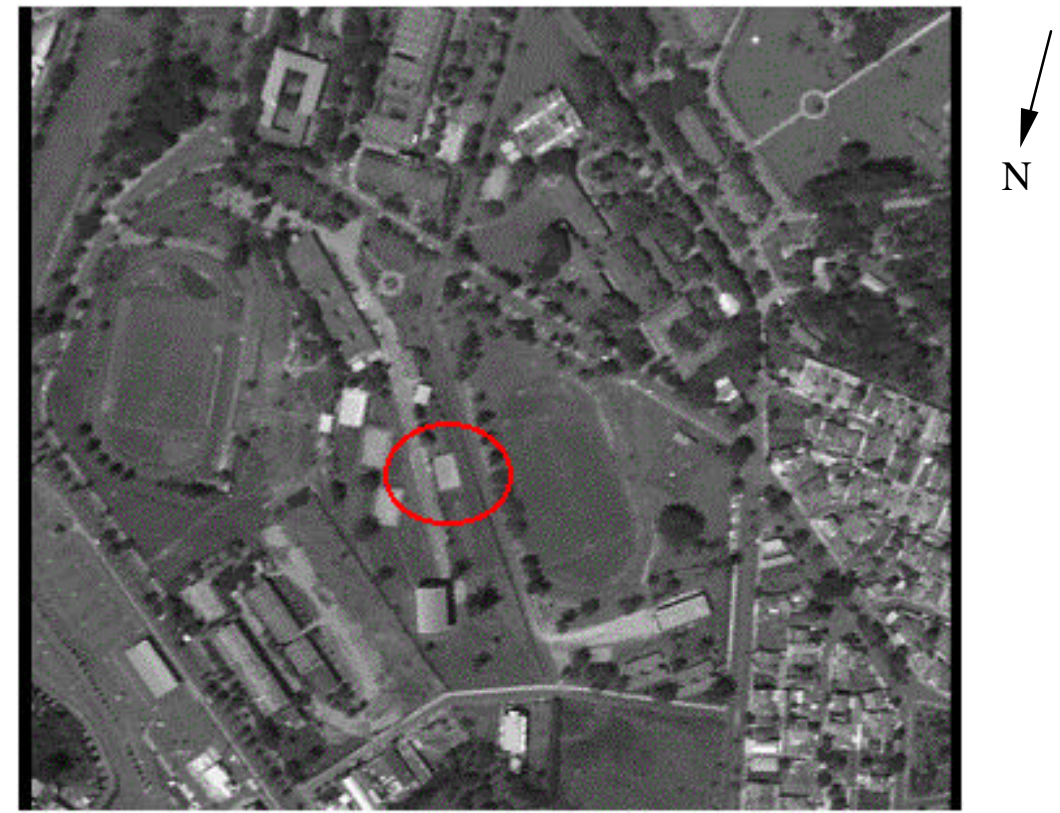

Figura 31 - Modelo estereoscópico por cintilamento (DCP 305 / DCP311), destacando a feição de interesse.

Usando óculos de cristal líquido e olhando diretamente no monitor do computador, pode-se observar a formação do modelo estereoscópico. No entanto, o principal objetivo, que é a identificação da feição nova a ser atualizada, ficou prejudicado pela alta freqüência em que são mostradas as imagens no monitor. 
Outro experimento foi executado, agora utilizando uma foto digital (DCP311) e parte de uma foto convencional (0310), que é a idéia principal deste trabalho (formação de um modelo híbrido). Da mesma forma que na formação do modelo por estereoscópio de espelhos, os resultados, tanto na formação do modelo estereoscópico híbrido quanto na identificação das feições a serem mapeadas, não atenderam às expectativas. A grande diferença geométrica entre as fotos e a diferença na orientação da linha de vôo novamente influenciaram significativamente os resultados, e a identificação das novas feições foi prejudicada pela alta freqüência em que as imagens são observadas.

Se por um lado a alta freqüência do monitor é importante para uma perfeita visualização do modelo estereoscópico, por outro lado uma baixa freqüência seria útil para a detecção de alterações, pois o efeito seria de um objeto "piscando" na tela do computador. Isso aconteceria porque uma feição isolada (somente em uma das imagens) seria exibida, por exemplo, com a metade da freqüência das demais feições.

A partir desses problemas, decidiu-se executar mais um experimento, desta vez com o método por anaglifo.

\subsubsection{Visualização estereoscópica por anaglifo.}

De posse dos resultados anteriores, mais um experimento foi executado, agora utilizando o método anaglifo para a visualização do modelo estereoscópico a partir das fotografias DCP305 e DCP311, utilizadas nos experimentos anteriores, tendo como resultado o modelo estereoscópico mostrado na Figura 32. 


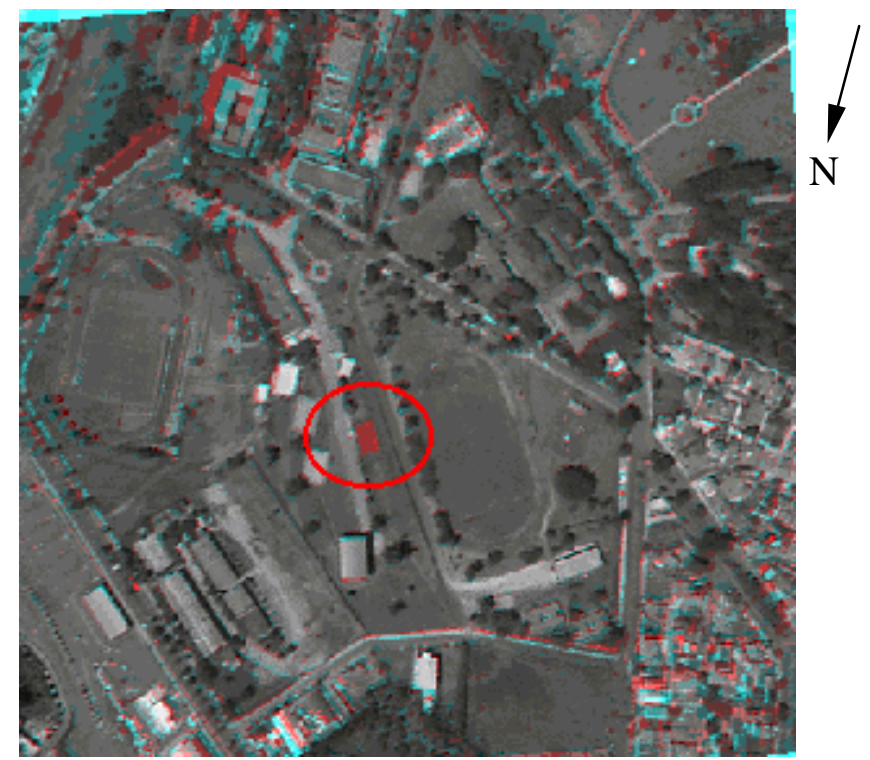

Figura 32 - Modelo estereoscópico por Anaglifo (DCP 305 / DCP311).

Pode-se notar que, neste caso, o modelo estereoscópico foi formado sem maiores problemas, apresentando um resultado satisfatório quanto à identificação da feição de interesse. Vale ressaltar que estas fotografias possuem as mesmas características geométricas e orientações aproximadas, porquanto foram tomadas com a mesma câmara (Kodak DC210) e no mesmo vôo.

Com os resultados positivos obtidos nesse experimento, partiu-se para a tentativa de formar o modelo estereoscópico híbrido, desta vez com a visualização pelo método anaglifo, utilizando a fotografia DCP311 (digital) e, parte da fotografia 0310 (convencional) mostrada na Figura 33. 


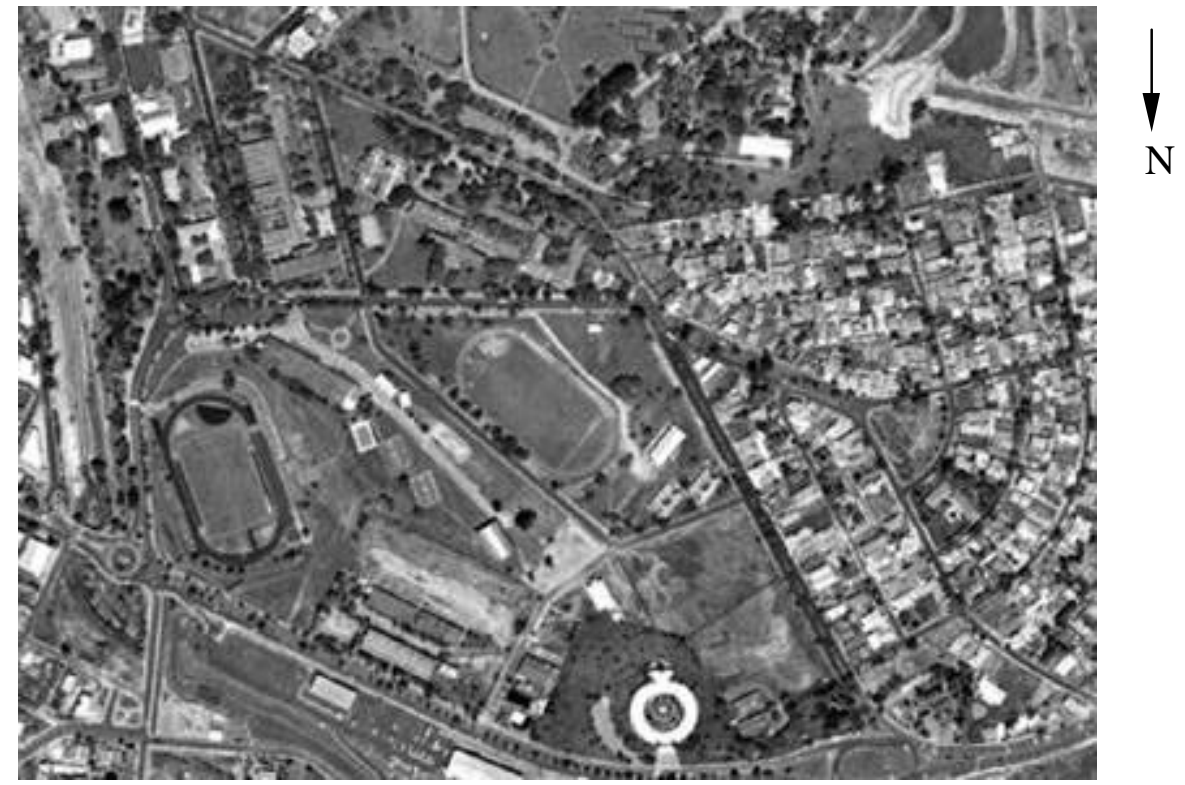

Figura 33 - Parte da fotografia aérea convencional 0310.

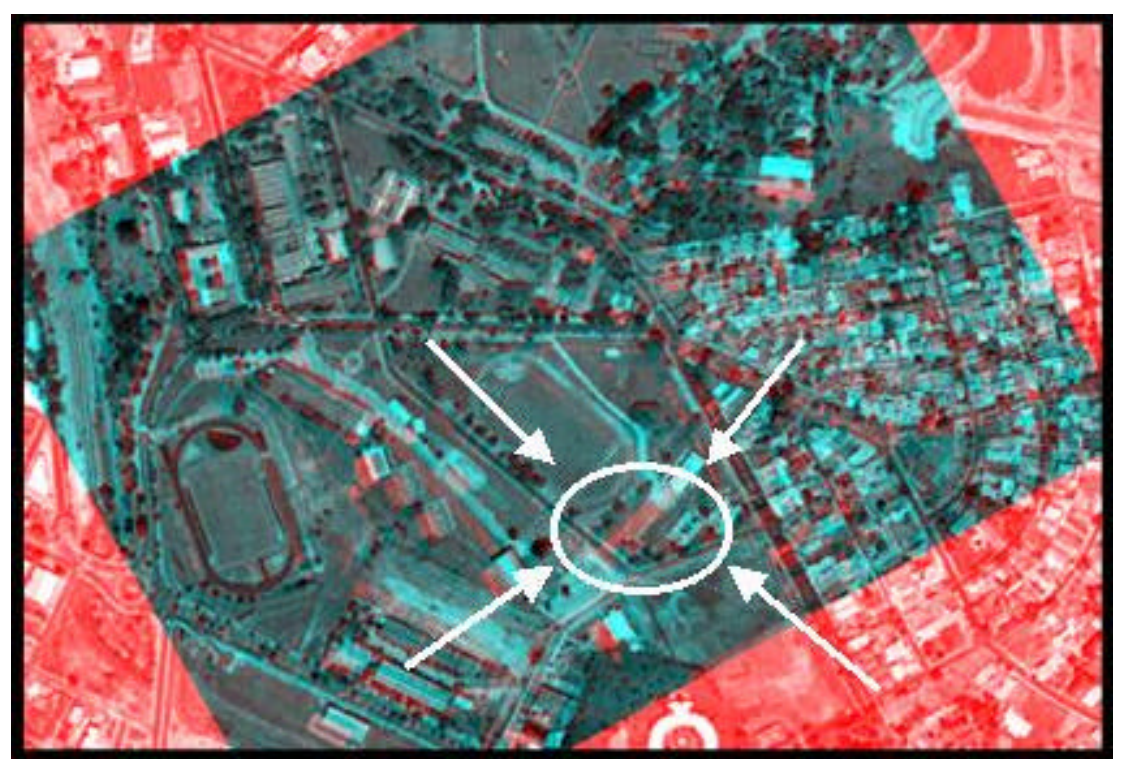

Figura 34 - Modelo estereoscópico por anaglifo (DCP 311 / 0310). 
Novamente a diferença geométrica prejudicou os resultados na visualização estereoscópica, mas em contrapartida nota-se que as feições novas podem ser identificadas claramente, principalmente quando visualizadas no monitor, uma vez que a visualização na Figura 34 também é prejudicada pela qualidade da impressão.

Nota-se, pela feição destacada na Figura 34 (nova entrada do Centro de Convivência Infantil - CCI), que a mesma não consta na fotografia aérea convencional de 1995 e existe na fotografia aérea digital (1998), detectando-se, portanto, a feição nova.

As diferenças geométricas e de orientação que prejudicam a visualização do modelo estereoscópico podem ser minimizadas executando-se, anteriormente à formação do modelo estereoscópico por anaglifo, os seguintes procedimentos:

a) Supondo-se o conhecimento prévio dos parâmetros de orientação exterior da fotografia aérea convencional, basta executar a sua orientação interior;

b) Executar a orientação relativa dependente na fotografia digital (nova), ou uma resseção espacial (desde que se tenham pontos de apoio em número suficiente);

c) Retificação e reamostragem epipolar nas duas fotografias.

Para satisfazer estas condições e finalmente identificar as feições que devem ser restituídas, utilizou-se o protótipo do sistema desenvolvido na linguagem $\mathrm{C}++\mathrm{em}$ ambiente Borland C++ Builder, descrito detalhadamente no Capitulo 5. 


\subsection{Atualização cartográfica utilizando a metodologia proposta}

\subsubsection{Digitalização direta sobre a fotografia digital}

Além da possibilidade de identificação e extração das feições novas é necessário que se tenha a confiabilidade métrica das coordenadas dos pontos que definem a posição das feições restituídas, pois estas deverão fazer parte de um mapeamento produzido, segundo as normas de Cartografia e Aerolevantamento, de acordo com a classe e com a escala de restituição.

Com o objetivo de testar a eficiência, não só da metodologia proposta mas também do próprio programa em desenvolvimento, alguns experimentos foram executados, utilizando-se uma rede geodésica com 31 pontos, executada com um GPS Trimble (4600) como parâmetros de comparação e verificação dos resultados obtidos.

O método utilizado para levantamento foi o cinemático, partindo-se de um ponto conhecido (EP02) com coordenadas $\mathrm{E}=457991.925 \mathrm{~m}, \mathrm{~N}=7553597.818 \mathrm{~m} \mathrm{e}$ $\mathrm{h}=441.127 \mathrm{~m}$, referenciado ao $\mathrm{SAD}-69$.

A Tabela 12 mostra as coordenadas dos pontos que foram usados como apoio e verificação: 
TABELA 12 - Coordenadas dos pontos de apoio e verificação.

\begin{tabular}{|c|c|c|c|c|c|c|}
\hline Ponto & $\mathbf{E}(\mathbf{m})$ & $\sigma \mathbf{E}(\mathrm{m})$ & $\mathbf{N}(\mathbf{m})$ & $\sigma \mathbf{N}(\mathbf{m})$ & h (m) & $\sigma h(\mathbf{m})$ \\
\hline EP02 & 457991.925 & 0.000 & 7553597.818 & 0.000 & 441.127 & 0.000 \\
\hline 01 & 457957.046 & 0.004 & 7553615.625 & 0.044 & 440.249 & 0.019 \\
\hline 02 & 457958.882 & 0.009 & 7553614.720 & 0.008 & 440.249 & 0.022 \\
\hline 03 & 457949.635 & 0.011 & 7553597.644 & 0.010 & 440.918 & 0.026 \\
\hline 04 & 457947.741 & 0.012 & 7553597.556 & 0.011 & 440.909 & 0.029 \\
\hline 05 & 457892.995 & 0.011 & 7553483.142 & 0.011 & 443.494 & 0.029 \\
\hline 06 & 457877.500 & 0.012 & 7553490.531 & 0.011 & 443.097 & 0.031 \\
\hline 07 & 457867.865 & 0.017 & 7553539.324 & 0.016 & 440.323 & 0.046 \\
\hline 08 & 457817.168 & 0.019 & 7553545.984 & 0.021 & 440.327 & 0.049 \\
\hline 09 & 457974.768 & 0.018 & 7553653.988 & 0.018 & 440.728 & 0.036 \\
\hline 10 & 457972.774 & 0.019 & 7553654.923 & 0.019 & 440.716 & 0.036 \\
\hline 11 & 457888.884 & 0.011 & 7553852.333 & 0.012 & 432.924 & 0.043 \\
\hline 12 & 457919.472 & 0.005 & 7553851.613 & 0.005 & 433.838 & 0.020 \\
\hline 13 & 457920.154 & 0.005 & 7553907.440 & 0.005 & 431.918 & 0.021 \\
\hline 14 & 458031.167 & 0.021 & 7553895.390 & 0.024 & 429.887 & 0.099 \\
\hline 15 & 458051.765 & 0.003 & 7553959.588 & 0.004 & 424.133 & 0.016 \\
\hline 16 & 458062.521 & 0.020 & 7553970.061 & 0.023 & 424.104 & 0.094 \\
\hline 17 & 458045.971 & 0.021 & 7553987.709 & 0.025 & 424.149 & 0.100 \\
\hline 18 & 458035.132 & 0.023 & 7553977.358 & 0.029 & 424.347 & 0.112 \\
\hline 19 & 458058.004 & 0.001 & 7554029.210 & 0.001 & 421.341 & 0.006 \\
\hline 20 & 458069.098 & 0.003 & 7553999.420 & 0.004 & 421.461 & 0.015 \\
\hline 21 & 458087.166 & 0.015 & 7553995.760 & 0.019 & 419.936 & 0.071 \\
\hline 22 & 458098.032 & 0.008 & 7553965.955 & 0.011 & 419.950 & 0.039 \\
\hline 23 & 458220.077 & 0.018 & 7554054.531 & 0.019 & 407.690 & 0.057 \\
\hline 24 & 458227.089 & 0.016 & 7554071.301 & 0.018 & 407.714 & 0.048 \\
\hline 25 & 458314.738 & 0.018 & 7553967.469 & 0.021 & 407.778 & 0.052 \\
\hline 26 & 458291.880 & 0.013 & 7553935.967 & 0.015 & 407.738 & 0.036 \\
\hline 27 & 458420.515 & 0.001 & 7553791.550 & 0.001 & 403.719 & 0.002 \\
\hline 28 & 458409.241 & 0.001 & 7553839.325 & 0.001 & 402.853 & 0.004 \\
\hline 29 & 458143.343 & 0.001 & 7554261.400 & 0.001 & 401.841 & 0.003 \\
\hline 30 & 458188.076 & 0.001 & 7554197.308 & 0.001 & 401.759 & 0.003 \\
\hline 31 & 457447.353 & 0.001 & 7553893.703 & 0.001 & 415.968 & 0.002 \\
\hline
\end{tabular}

Obs.: $\sigma \mathrm{E}, \sigma \mathrm{N}$ e $\sigma \mathrm{h}=$ desvio padrão, fornecido pelo relatório do processamento.

Os pontos foram escolhidos de forma a dar uma certa rigidez geométrica à fotografia digital, quando utilizados como apoio, além de serem distribuídos de acordo com as características naturais encontradas nesta área, pois não foram utilizados pontos pré - sinalizados como apoio ou mesmo para verificação, como mostra a Figura 35. 


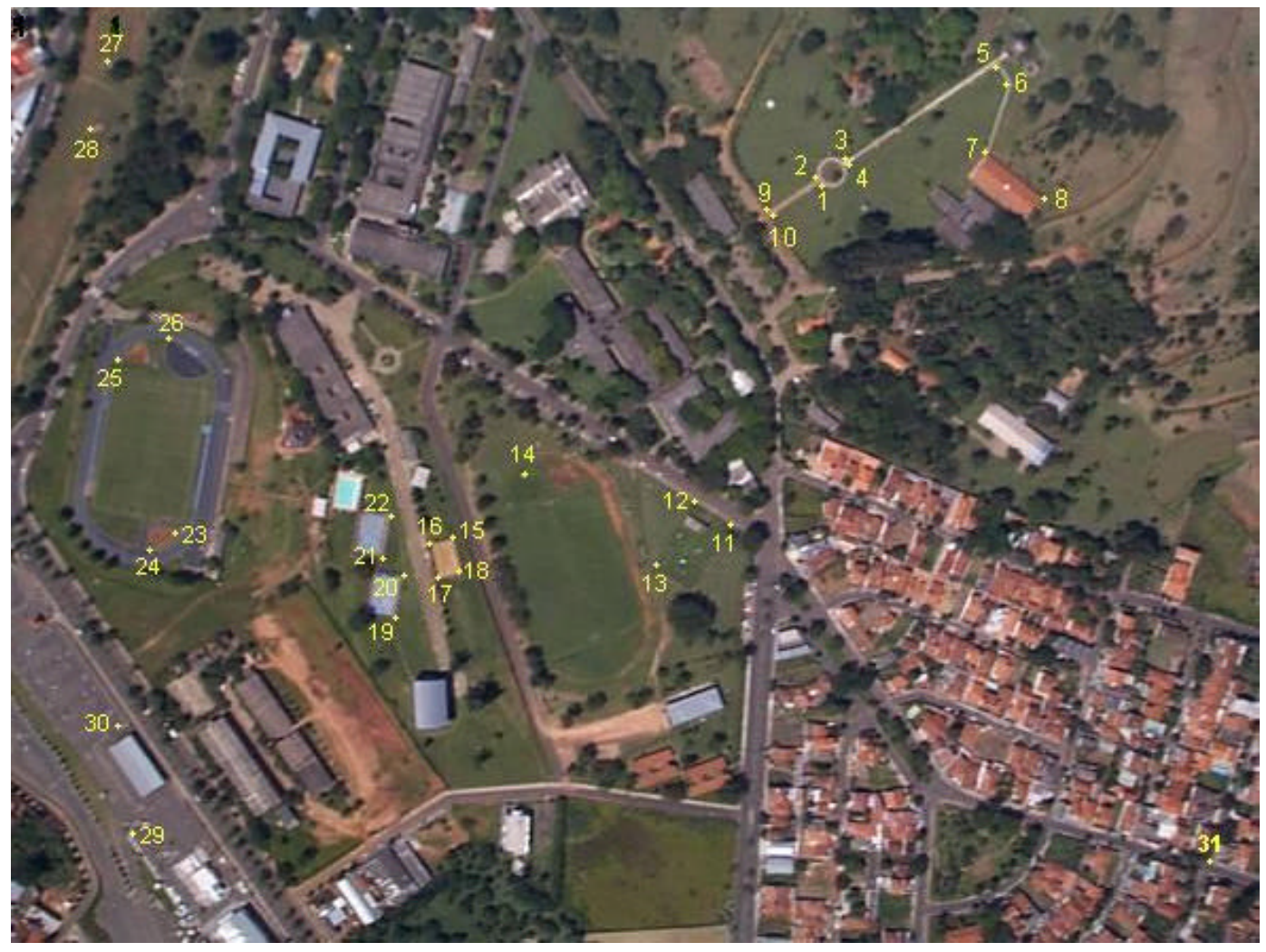

Figura 35 - Rede de pontos de apoio e verificação.

Pode-se notar, pela configuração dos pontos mostrados na Figura 35, que estes estão bem distribuídos espacialmente, com a finalidade de apoiar os cantos da fotografia. Um fato relevante que deve ser observado é que optou-se, nessa etapa, por escolher a maioria dos pontos diretamente no solo, evitando-se problemas com o posicionamento por GPS, assim como os desvios provocados pela projeção fotográfica nas construções que pode dificultar a pontaria do operador na coleta das informações necessárias.

Foram realizados três testes, utilizando os seguintes pontos de apoio para o georeferenciamento:

1) $5,13,14,26$ e 31 ;

2) $5,13,14,26,27$ e 31 ;

3) $5,13,14,26,29$ e 31 . 
Para melhor analisar os resultados pode-se fazer uma comparação entre as discrepâncias, obtidas nos três testes, como mostra a Tabela 13.

Tabela 13 - Comparação das discrepâncias calculadas nos Testes 1, 2 e 3.

\begin{tabular}{|c|c|c|c|c|c|c|}
\hline \multirow{2}{*}{ Ponto } & \multicolumn{2}{|c}{ Teste 1} & \multicolumn{2}{c|}{ Teste 2} & \multicolumn{2}{c|}{ Teste 3} \\
\cline { 2 - 7 } & $\mathrm{dE}$ & $\mathrm{dN}$ & $\mathrm{dE}$ & $\mathrm{dN}$ & $\mathrm{dE}$ & $\mathrm{dN}$ \\
\hline 1 & $-0,244$ & $-0,215$ & $-1,064$ & 0,465 & 0,096 & 1,255 \\
\hline 2 & $-2,258$ & 1,140 & $-2,298$ & 1,070 & $-1,138$ & 2,630 \\
\hline 3 & $-1,755$ & 1,894 & $-0,275$ & 1,824 & $-1,355$ & 3,614 \\
\hline 4 & 0,181 & 1,296 & $-0,619$ & 0,476 & $-0,179$ & 2,996 \\
\hline 5 & $-0,755$ & 0,482 & $-0,025$ & $-0,338$ & 0,735 & 2,762 \\
\hline 6 & $-1,430$ & 1,081 & $-1,710$ & 1,021 & $-0,970$ & 4,071 \\
\hline 7 & $-1,095$ & 0,964 & $-0,365$ & 0,914 & 0,245 & 3,434 \\
\hline 8 & 0,418 & 2,284 & 1,158 & 1,494 & 1,158 & 4,004 \\
\hline 9 & $-1,552$ & 1,228 & $-1,112$ & 0,398 & $-1,832$ & 2,258 \\
\hline 10 & $-1,766$ & 0,653 & $-1,776$ & $-0,177$ & $-1,756$ & 0,913 \\
\hline 11 & 1,244 & 0,323 & 1,224 & 0,293 & 0,994 & 0,053 \\
\hline 12 & 1,252 & $-0,377$ & 1,232 & $-1,167$ & 1,762 & $-1,447$ \\
\hline 13 & 1,494 & $-1,390$ & 1,714 & $-1,430$ & 2,094 & $-2,320$ \\
\hline 14 & $-2,033$ & $-0,280$ & $-2,073$ & $-0,350$ & $-0,903$ & $-2,010$ \\
\hline 15 & $-0,655$ & 1,308 & 0,075 & 0,488 & $-1,235$ & $-1,142$ \\
\hline 16 & 0,281 & 0,481 & $-0,529$ & 1,171 & $-1,859$ & $-1,349$ \\
\hline 17 & $-1,569$ & 0,009 & $-0,079$ & $-0,051$ & $-1,459$ & $-1,991$ \\
\hline 18 & $-1,058$ & 0,958 & $-1,088$ & 0,148 & $-0,908$ & $-2,432$ \\
\hline 19 & $-0,586$ & 0,310 & $-0,606$ & 0,750 & $-0,566$ & $-2,430$ \\
\hline 20 & 1,048 & 0,430 & 1,008 & 0,370 & $-0,402$ & $-2,490$ \\
\hline 21 & 0,736 & 1,320 & $-0,074$ & 2,000 & $-0,704$ & $-2,350$ \\
\hline 22 & $-0,158$ & 0,935 & $-0,968$ & 0,105 & $-0,778$ & $-0,135$ \\
\hline 23 & $-0,073$ & 1,751 & 0,627 & 1,651 & $-0,953$ & 0,791 \\
\hline 24 & 1,019 & 1,971 & 0,959 & 1,861 & $-0,661$ & 0,051 \\
\hline 25 & $-0,102$ & 2,739 & 1,338 & 2,599 & $-0,782$ & $-0,181$ \\
\hline 26 & 0,340 & 0,597 & 0,250 & 0,467 & $-0,270$ & $-1,203$ \\
\hline 27 & 1,955 & 0,210 & 1,845 & 0,030 & 0,165 & $-0,950$ \\
\hline 28 & 3,301 & 1,285 & 2,381 & 1,865 & 1,391 & $-0,375$ \\
\hline 29 & 4,023 & 10,380 & 2,463 & 10,330 & 1,893 & 5,330 \\
\hline 30 & 1,506 & 9,158 & 1,456 & 9,078 & 0,286 & 4,728 \\
\hline 31 & $-1,587$ & 0,733 & $-2,287$ & 0,823 & $-2,537$ & $-0,087$ \\
\hline
\end{tabular}

Obs.: As células hachuradas são referentes aos pontos que foram utilizados como apoio

Quando foram introduzidos os pontos de grandes discrepâncias no processamento do georeferenciamento observou-se que, as discrepâncias $\mathrm{dE}$ e dN nos demais pontos, aumentaram consideravelmente, notando-se a necessidade de melhor analisar esses resultados. Para tanto, faz-se necessária uma análise estatística 
dos dados apresentados. Nesse sentido algumas considerações devem ser feitas quanto ao tratamento estatístico que deve ser utilizado neste caso.

O teste "t" de Student foi aplicado com o objetivo de verificar se as observações apresentam-se afetadas por erros sistemáticos, num intervalo de confiança de $95 \%$ considerando a hipótese alternativa $\mathrm{H}_{\mathrm{a}}: \mu \neq 0$; portanto, numa distribuição bi-caudal. Além do teste "t", foi executado um teste de precisão (Qui quadrado), com as mesmas considerações abordadas na seção 6.1.5.2.2, ou seja, as fotografias na escala 1:25000, possibilitando a restituição em escala 1:5000, e segundo o Padrão de Exatidão Cartográfica adotado para cartas Classe "A".

Para melhor analisar os resultados pode-se fazer uma comparação entre as análises estatísticas realizadas nos testes 1,2 e 3, como mostra a Tabela 14 .

Tabela 14 - Comparação das análises estatísticas dos Testes 1, 2 e 3.

\begin{tabular}{|l|r|r|l|r|r|l|r|r|}
\hline \multicolumn{4}{|c|}{ Teste 1} & \multicolumn{3}{c|}{ Teste 2} & \multicolumn{3}{c|}{ Teste 3} \\
\hline & \multicolumn{1}{|c|}{$\mathrm{dE}$} & \multicolumn{1}{c|}{$\mathrm{dN}$} & & $\mathrm{dE}$ & $\mathrm{dN}$ & & $\mathrm{dE}$ & \multicolumn{1}{c|}{$\mathrm{dN}$} \\
\hline Desv. Pad. & 1,554 & 2,574 & Desv. Pad. & 1,281 & 2,667 & Desv. Pad. & 1,007 & 2,330 \\
\hline Média & 0,102 & 1,828 & Média & 0,054 & 1,719 & Média & $-0,458$ & 0,541 \\
\hline $\mathrm{t}(0,025 ; 25)$ & 2,060 & 2,060 & $\mathrm{t}(0,025 ; 24)$ & 2,064 & 2,064 & $\mathrm{t}(0,025 ; 24)$ & 2,064 & 2,064 \\
\hline $\mathrm{t}(\mathrm{E}, \mathrm{N})$ & 0,336 & 3,620 & $\mathrm{t}(\mathrm{E}, \mathrm{N})$ & 0,212 & 3,223 & $\mathrm{t}(\mathrm{E}, \mathrm{N})$ & $-2,272$ & 1,161 \\
\hline QUIQUAD(25;0,9) & 34,380 & 34,380 & QUIQUAD(24;0,9) & 33,200 & 33,200 & QUIQUAD(24;0,9) & 33,200 & 33,200 \\
\hline QUIQUAD(E,N) & 53,740 & 147,453 & QUIQUAD(E,N) & 35,033 & 151,938 & QUIQUAD(E,N) & 21,653 & 116,005 \\
\hline
\end{tabular}

Pode-se verificar, pelos resultados apresentados na Tabela 14, que as amostras não foram aceitas pelo teste de detecção de tendência, bem como pela análise de precisão, na maioria dos casos. Isso mostra que os resultados estão sendo afetados por um erro sistemático, além de não serem aceitos por estarem fora do intervalo de confiança de $90 \%$ estabelecido pelo teste de precisão.

Com os resultados apresentados na análise estatística realizada, pôde-se observar que os pontos que apresentaram as maiores discrepâncias são os que possuem as altitudes menores. 
Esse fato mostra que as altas discrepâncias, em pontos com altitudes menores, são fruto do desvio devido ao relevo, pois a fotografia aérea digital foi apenas retificada, e as coordenadas consideradas para efeito de atualização cartográfica são as coordenadas planas, não considerando, portanto, a altimetria.

Para comprovar esse fato pode-se calcular o efeito desse erro sobre os resultados, porque existem pontos de verificação nestes locais e as suas altitudes são conhecidas com boa precisão e confiabilidade.

A partir das especificações da câmara, utilizada para a obtenção da fotografia aérea digital e das coordenadas do ponto 29 , o erro introduzido nas coordenadas planas, calculadas, desse ponto é de 7,50 m.

Nota-se, portanto, que o procedimento de digitalização direta sobre a fotografia digital, conforme explorado neste experimento, pode ser adotado apenas em áreas planas.

Uma opção que pode tornar atrativa esta técnica é a execução de um pósprocessamento, aplicando-se uma correção dos erros provocados pelo desvio do relevo, a partir de um MNT gerado através das curvas de nível existentes no próprio mapeamento que está sendo atualizado.

\subsubsection{Monorestituição das feições de interesse}

Os testes realizados na seção 6.3.1, a partir da digitalização das feições diretamente sobre a fotografia digital, apresentaram resultados fortemente afetados pelo desvio do relevo, quando se deseja atualizar o mapeamento de uma área acidentada. Além disso, apenas as coordenadas planimétricas são determinadas a partir da fotografia digital. 
Pela proposta metodológica deste trabalho, as coordenadas planialtimétricas dos pontos que definem as feições a serem restituídas são determinadas pelo procedimento de monorestituição, conforme descrito na seção 4.3.2.2.

Utilizando-se as mesmas fotografias (0310 e DCP311), agora com a orientação relativa dependente, e os mesmos pontos de verificação, utilizados nos experimento apresentado na seção 6.3.1, foi realizado um novo experimento.

Nesse experimento, as coordenadas de alguns pontos que representam feições novas e, portanto, existentes apenas na fotografia digital, foram determinadas no espaço objeto, a partir do modelo de monorestituição.

Vale ressaltar que nesse experimento as coordenadas foram lidas no espaço imagem diretamente sobre as fotografias (diapositivos); portanto, as distâncias focais das equações envolvidas foram consideradas negativas.

A Figura 36 mostra a feição definida pelos pontos 5, 6 e 7, que tiveram suas coordenadas determinadas.

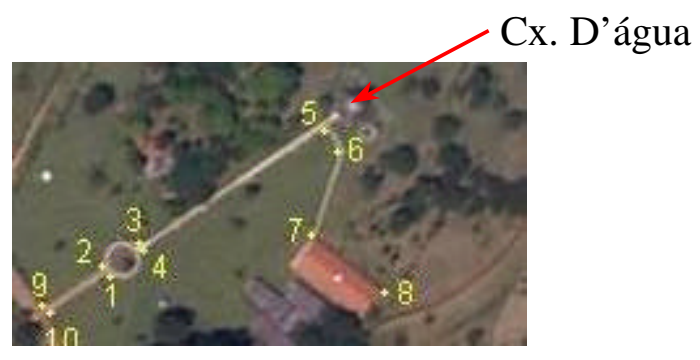

Figura 36 - Detalhe da feição definida pelos pontos 5, 6 e 7.

Para executar a monorestituição desses pontos faz-se necessária a determinação de uma coordenada altimétrica aproximada para cada um deles.

Aplicando-se a metodologia proposta, na seção 4.3.2.1, um triângulo foi definido pelos pontos 2, Cx. D’água e 8, mostrados na Figura 36 que constam nas 
duas fotografias retificadas, permitindo, portanto, o cálculo das suas coordenadas planialtimétricas por intersecção fotogramétrica.

A Tabela 15 mostra as coordenadas, no espaço imagem, dos pontos $2, \mathrm{Cx}$ D'água e 8, medidas sobre as fotografias convencional retificada e digital retificada.

Tabela 15 - Coordenadas dos pontos 2, Cx D’água e 8, no espaço imagem.

\begin{tabular}{|c|c|c|c|c|}
\hline Pontos & $\mathbf{x}_{\mathbf{c}}(\mathbf{m m})$ & $\mathbf{y}_{\mathbf{c}}(\mathbf{m m})$ & $\mathbf{x}_{\mathbf{d}}(\mathbf{m m})$ & $\mathbf{y}_{\mathbf{d}}(\mathbf{m m})$ \\
\hline 2 & $-7,03$ & 98,50 & $-6,12$ & $-7,57$ \\
\hline Cx. D'água & $-9,69$ & 93,10 & $-8,96$ & $-13,48$ \\
\hline 8 & $-12,45$ & 95,87 & $-11,88$ & $-10,40$ \\
\hline
\end{tabular}

A Tabela 16 mostra as coordenadas calculadas, por intersecção fotogramétrica, no espaço objeto.

Tabela 16 - Resultados da intersecção fotogramétrica na determinação das coordenadas dos pontos 2, Cx. D’água e 8, no espaço objeto.

\begin{tabular}{|c|c|c|c|}
\hline Pontos & $\mathbf{E}(\mathbf{m})$ & $\mathbf{N}(\mathbf{m})$ & $\mathbf{h}(\mathbf{m})$ \\
\hline 2 & 457958,917 & 7553614,618 & 440,553 \\
\hline Cx, D’água & 457889,504 & 7553471,127 & 443,634 \\
\hline 8 & 457817,079 & 7553545,882 & 440,458 \\
\hline
\end{tabular}

Aplicando-se o modelo matemático de interpolação linear, apresentado pela equação (46), foram calculados os parâmetros definidores do triângulo, utilizados para a determinação das coordenadas altimétricas aproximadas de cada ponto a ser restituído.

Tomando-se a média das altitudes (h), apresentadas pela Tabela 16, como coordenada altimétrica aproximada inicial dos pontos a serem restituídos (5, 6 e 7) iniciou-se a aplicação do modelo matemático iterativo de monorestituição. 
A tabela 17 mostra as coordenadas dos pontos 5,6 e 7 , que podem ser vistos na figura 36, medidas apenas sobre a fotografia digital retificada, pois esses pontos não constam na fotografia convencional.

Tabela 17 - Coordenadas dos pontos 5, 6 e 7, no espaço imagem.

\begin{tabular}{|c|c|c|}
\hline Pontos & $\mathbf{x}_{\mathbf{d}} \mathbf{( \mathbf { m m } )}$ & $\mathbf{y}_{\mathbf{d}} \mathbf{( \mathbf { m m } )}$ \\
\hline 5 & $-8,82$ & $-12,98$ \\
\hline 6 & $-9,44$ & $-12,68$ \\
\hline 7 & $-9,86$ & $-10,67$ \\
\hline
\end{tabular}

Após a $3^{\mathrm{a}}$ iteração, obtiveram-se os resultados apresentados na Tabela 18.

Tabela 18 - Coordenadas dos pontos 5, 6 e 7, no espaço objeto.

\begin{tabular}{|c|c|c|c|}
\hline Pontos & $\mathbf{E}(\mathbf{m})$ & $\mathbf{N}(\mathbf{m})$ & $\mathbf{h}(\mathbf{m})$ \\
\hline 5 & 457892,896 & 7553483,111 & 443,343 \\
\hline 6 & 457877,588 & 7553490,382 & 442,914 \\
\hline 7 & 457866,982 & 7553539,549 & 441,362 \\
\hline
\end{tabular}

Os pontos 5, 6 e 7, fazem parte da rede geodésica, possibilitando o cálculo das discrepâncias entre as coordenadas calculadas pela monorestituição e suas correspondentes determinadas em campo, por GPS, como mostra a Tabela 19.

Tabela 19 - Discrepâncias das coordenadas calculadas, dos pontos 5, 6 e 7, em relação aos pontos de verificação.

\begin{tabular}{|c|c|c|c|}
\hline Pontos & $\mathbf{d E}(\mathbf{m})$ & $\mathbf{d N}(\mathbf{m})$ & $\mathbf{d h}(\mathbf{m})$ \\
\hline 5 & 0,099 & 0,031 & 0,151 \\
\hline 6 & $-0,088$ & 0,149 & $-0,246$ \\
\hline 7 & $-0,117$ & $-0,225$ & $-1,039$ \\
\hline
\end{tabular}

Pelos resultados apresentados na Tabela 19, pode-se notar que as coordenadas foram determinadas com boa precisão, uma vez que as discrepâncias encontradas (exatidão) encontram-se abaixo do padrão estabelecido (PEC) para cartas de Classe “A” em escala 1:25000, ou seja, 1,06m nas direções E e N, bem como 1,67m em altimetria. 
Por outro lado, devem ser observadas as condições em que se encontram as posições dos pontos restituídos em relação ao triângulo utilizado como MNT local.

A posição dos pontos restituídos encontra-se em condições muito favoráveis à aplicação do modelo de interpolação linear utilizado.

Sabendo-se que podem ser encontradas situações menos favoráveis, para a aplicação da interpolação linear, resolveu-se executar um novo experimento, com a mesma metodologia aplicada anteriormente, desta vez utilizando-se condições menos favoráveis, ou seja, sabendo-se previamente que os pontos a serem restituídos não estão muito próximos, em altimetria, do plano definido pelos vértices do triângulo.

O objetivo desse experimento foi a determinação das coordenadas dos pontos 15, 16, 17 e 18, que definem uma feição (quadra de vôlei de areia), como podem ser vistos na Figura 37.

Nesse novo experimento, foram determinadas as coordenadas planialtimétricas, por intersecção fotogramétrica, de dois pontos que se encontram nos cantos de duas construções, sendo um no ginásio de esportes (GE) e o outro no ambulatório (ASA), além de um ponto já conhecido (19), os quais podem ser vistos na Figura 37.

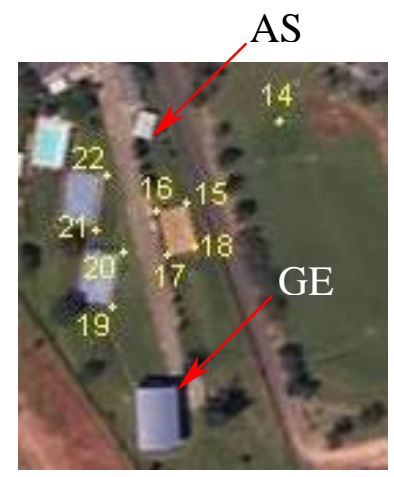

Figura 37 - Detalhe da feição definida pelos pontos 15, 16, 17 e 18. 
A Tabela 20 mostra as coordenadas dos pontos 19, GE e ASA, medidos sobre as fotografias convencional e digital, em milímetros.

Tabela 20 - Coordenadas dos pontos 19, GE e ASA, no espaço imagem.

\begin{tabular}{|c|c|c|c|c|}
\hline Pontos & $\mathbf{x}_{\mathbf{c}}(\mathbf{m m})$ & $\mathbf{y}_{\mathbf{c}}(\mathbf{m m})$ & $\mathbf{x}_{\mathbf{d}}(\mathbf{m m})$ & $\mathbf{y}_{\mathbf{d}}(\mathbf{m m})$ \\
\hline 19 & $-3,23$ & 113,80 & $-2,07$ & 9,10 \\
\hline GE & $-5,21$ & 114,49 & $-4,15$ & 9,79 \\
\hline ASA & $-2,16$ & 110,37 & $-0,94$ & 5,41 \\
\hline
\end{tabular}

Os pontos 19, GE e ASA, constam nas duas fotografias retificadas (0310 e DCP 311), possibilitando o cálculo das suas coordenadas por intersecção fotogramétrica, no espaço objeto, como mostra a Tabela 21.

Tabela 21 - Resultados da intersecção fotogramétrica na determinação das coordenadas dos pontos 19, GE e ASA, no espaço objeto.

\begin{tabular}{|c|c|c|c|}
\hline Pontos & $\mathbf{E}(\mathbf{m})$ & $\mathbf{N}(\mathbf{m})$ & $\mathbf{h}(\mathbf{m})$ \\
\hline 19 & 458058,018 & 7554027,790 & 424,554 \\
\hline GE & 458005,849 & 7554047,508 & 420,114 \\
\hline ASA & 458086,075 & 7553939,106 & 418,827 \\
\hline
\end{tabular}

Aplicando-se o mesmo procedimento utilizado anteriormente, foram obtidos os parâmetros definidores do triângulo, possibilitando o cálculo das coordenadas altimétricas aproximadas de cada ponto a ser restituído, pelo processo de interpolação linear.

A tabela 22 mostra as coordenadas dos pontos 15, 16, 17 e 18, medidas apenas sobre a fotografia digital retificada, pois esses pontos não constam da fotografia convencional. 
Tabela 22 - Coordenadas dos pontos 15, 16, 17 e 18, no espaço imagem.

\begin{tabular}{|c|c|c|}
\hline Pontos & $\left.\mathbf{x}_{\mathbf{d}} \mathbf{( m m}\right)$ & $\left.\mathbf{y}_{\mathbf{d}} \mathbf{( m m}\right)$ \\
\hline 15 & $-2,32$ & 6,32 \\
\hline 16 & $-1,89$ & 6,74 \\
\hline 17 & $-2,55$ & 7,45 \\
\hline 18 & $-2,99$ & 7,04 \\
\hline
\end{tabular}

Após a $3^{\text {a }}$ iteração, obtiveram-se os resultados apresentados na Tabela 23.

Tabela 23-Coordenadas dos pontos 15, 16, 17 e 18, no espaço objeto.

\begin{tabular}{|c|c|c|c|}
\hline Pontos & $\mathbf{E}(\mathbf{m})$ & $\mathbf{N}(\mathbf{m})$ & $\mathbf{h}(\mathbf{m})$ \\
\hline 15 & 458051,451 & 7553960,418 & 416,735 \\
\hline 16 & 458062,313 & 7553970,641 & 419,149 \\
\hline 17 & 458045,792 & 7553988,432 & 418,943 \\
\hline 18 & 458034,647 & 7553978,491 & 416,523 \\
\hline
\end{tabular}

A Tabela 24 mostra as discrepâncias calculadas entre as coordenadas dos pontos 15, 16, 17 e 18, e suas correspondentes determinadas em campo, por GPS.

Tabela 24 - Discrepâncias das coordenadas calculadas, dos pontos 15, 16, 17 e 18, em relação aos pontos de verificação.

\begin{tabular}{|c|c|c|c|}
\hline Pontos & $\mathbf{d E}(\mathbf{m})$ & $\mathbf{d N}(\mathbf{m})$ & $\mathbf{d h}(\mathbf{m})$ \\
\hline 15 & 0,314 & $-0,830$ & 7,398 \\
\hline 16 & 0,208 & $-0,580$ & 4,955 \\
\hline 17 & 0,179 & $-0,723$ & 5,206 \\
\hline 18 & 0,485 & $-1,133$ & 7,824 \\
\hline
\end{tabular}

A Tabela 24 apresenta resultados que levam a crer que o modelo de interpolação linear pode ser aplicado, nessas condições, quando se deseja apenas a determinação das coordenadas planimétricas dos pontos de interesse, pois pode-se notar que os valores das discrepâncias calculadas atendem ao PEC nas direções E e N. No entanto, quando a altitude se faz necessária, pode-se utilizar as curvas de 
nível do mapeamento em questão, desatualizado, com o objetivo de gerar um Modelo Numérico de Terreno na região de interesse, onde foi identificada uma feição que deve ser extraída a partir do modelo de monorestituição.

Esse procedimento, apresenta melhores resultados para a obtenção de altitudes de pontos de interesse, quando estes situam-se em superfícies de relevo irregular, não sendo viável sua aproximação com uma superfície plana. 


\section{CONCLUSÕES E RECOMENDAÇÕES}

Entre os métodos de atualização cartográfica existentes e mais utilizados atualmente encontram-se as técnicas de posicionamento por GPS que proporcionam grande facilidade na determinação de coordenadas, quando comparadas aos métodos topográficos convencionais muito usados até há poucos anos. Entre essas facilidades pode-se citar a possibilidade de trabalho a qualquer hora do dia ou da noite ou até mesmo com chuva, o que permite um bom ganho de tempo, que em muitos trabalhos é fundamental, além de não se requerer intervisibilidade entre os pontos levantados e de ser suficiente uma equipe reduzida. Dependendo do equipa-mento e do método de posicionamento por GPS ainda pode-se ter precisão igual ou melhor do que na topografia, em menos tempo de levantamento. Mesmo apresentando as vantagens citadas acima, a utilização dessas técnicas, para a atualização cartográfica, em nada contribui para a identificação das feições a serem restituídas.

Mostrou-se neste trabalho uma nova técnica de detecção de alterações, através da construção de um modelo estereoscópico por anaglifo, onde se faz uma fusão dos canais $\mathrm{G}$ e $\mathrm{B}$ da fotografia aérea convencional retificada com o canal $\mathrm{R}$ da fotografia aérea digital retificada. Esse modelo por anaglifo destaca, em vermelho, as feições novas a serem restituídas, produzindo bons resultados.

As técnicas fotogramétricas foram e ainda são muito utilizadas na construção de mapeamentos, mas não se pode dizer o mesmo quando o assunto é atualização 
cartográfica. Sendo assim, esta foi uma das principais motivações que levaram à realização deste trabalho.

A proposta inicial deste trabalho foi a integração de várias fontes de informações para a idealização de uma metodologia que possibilitasse a atualização cartográfica com confiabilidade e redução de custo. Essa redução de custo é proporcionada principalmente pela utilização de materiais e informações já existentes e também pela implementação de rotinas de fácil utilização que levem à redução do tempo de execução dos trabalhos.

Neste momento, torna-se difícil apresentar dados que possibilitem uma análise concreta, principalmente traduzida em números, quanto ao aspecto econômico, pois além das inúmeras variáveis que fazem parte do processo, os experimentos aqui apresentados possuem alguns custos que dificilmente seriam dimensionados, pelo caráter científico da pesquisa.

No entanto, de acordo com a Tabela 25 , as fases de apoio e aerotriangulação apresentam custos em torno de $20 \%$ do total de um aerolevantamento convencional, sendo que essas etapas seriam eliminadas com o uso da metodologia proposta. Além disso, propõe-se a restituição localizada, ou seja, apenas das feições novas, não necessitando, portanto, do vôo e da restituição da área toda, fatos esses que proporcionariam um aumento significativo de produtividade.

Tabela 25 - Custos percentuais de um aerolevantamento convencional

\begin{tabular}{cc}
\hline ETAPAS & CUSTO (\%) \\
\hline Vôo & 10 \\
Apoio & 18 \\
Aerotriangulação & 2 \\
Restituição & 35 \\
Reambulação & 5 \\
Edição e prudutos finais & 30 \\
\hline TOTAL & 100 \\
\hline
\end{tabular}

Fonte: Valores fornecidos por empresas de aerolevantamento. 
Quanto à utilização da fotografia aérea convencional do mapeamento desatualizado, pôde-se notar pela metodologia proposta que ela foi de fundamental importância na detecção de alterações, além de possuir sua orientação conhecida, possibilitando a redução ou mesmo a eliminação de novos pontos de apoio.

Quanto à utilização da fotografia aérea digital, além de ser fundamental na detecção das alterações, nota-se que a mesma tornou-se a principal fonte de informações para extrair as feições que atualizam o mapeamento em questão.

Conforme discutido, na seção 6.1.4.2.2, a área de recobrimento da fotografia digital, utilizada neste trabalho, é muito pequena $\left(0,58 \mathrm{Km}^{2}\right)$ quando comparada à área da fotografia aérea convencional $\left(33,06 \mathrm{Km}^{2}\right)$. Este fato poderia ser uma desvantagem desta metodologia, mas, por outro lado, câmaras mais sofisticadas apresentam sensores CCD maiores do que o sensor da câmara Kodak DC210, como mostra a Tabela 01 do capitulo 3, tornando esta metodologia mais viável economicamente.

Quanto à extração de feições, este trabalho mostra, na seção 6.1, que é possível aplicar as equações de colinearidade para orientar um estéreo-par híbrido, bem como determinar as coordenadas planialtimétricas de pontos de interesse, quando estes constam nas duas fotografias que formam o referido estéreo-par.

Quanto à extração de feições, através da digitalização diretamente sobre a fotografia digital, os resultados apresentados na seção 6.3.1 mostram a desvantagem desse procedimento quando aplicado em áreas com relevo irregular. No entanto, esse procedimento pode ser adotado para terrenos planos onde se deseja efetuar a atualização cartográfica. 
O fato de um ponto, pertencente a uma feição nova, constar de apenas uma das fotografias (digital), fez com que se buscasse uma maneira de determinar sua posição tridimensional no espaço objeto, sem que fosse necessário saber sua posição na fotografia aérea convencional. Esse problema pode ser solucionado pela utilização de um modelo de monorestituição, como foi discutido na seção 4.3.2.2, determinando-se as coordenadas planialtimétricas de um ponto, conhecendo-se as suas coordenadas de imagem em apenas uma fotografia e sua altitude aproximada, no espaço objeto, através de um MNT (Modelo Numérico de Terreno). Neste trabalho, um experimento foi realizado, aplicando-se o modelo de monorestituição, sem a necessidade da utilização de um MNT da área toda, fato este que reduz consideravelmente o esforço computacional.

Como se pode observar, na seção 6.3.2, três pontos foram determinados por intersecção fotogramétrica, na vizinhança das feições identificadas, como se fossem parte de um MNT, possibilitando-se a execução da monorestituição das referidas feições e apresentando resultados satisfatórios em termos de exatidão.

Um problema que deve ser considerado é a qualidade da câmara digital a ser utilizada, assim como a qualidade da imagem, posto que, quanto maior o tamanho do pixel, maior será o erro na coleta das coordenadas observadas de um ponto de interesse, fato este que prejudicará os resultados finais.

A partir das considerações anteriores, sobre a resolução, um fato foi notado ao final dos experimentos, com respeito ao erro de pontaria do operador. A fotografia aérea digital utilizada neste trabalho tem um pixel de $0.03038 \mathrm{~mm}$ na imagem, e a escala aproximada é de 1: 25000, o que representa um pixel de aproximadamente 0,76 m no terreno. Portanto é recomendável, em estudos futuros, a implementação 
de uma metodologia de obtenção de coordenadas observadas ao nível sub-pixel, além de um recurso de aproximação da imagem "zoom”, podendo-se melhorar a pontaria quando da coleta das coordenadas dos pontos de interesse.

Quanto à calibração da câmara, utilizada neste trabalho, notou-se um valor alto para o parâmetro $C_{y}$, o que sugere alguma inconsistência na determinação desse parâmetro de calibração ou a existência de um deslocamento indesejável do dispositivo CCD. A ocorrência do deslocamento desse dispositivo é reforçada pelos resultados apresentados na seção 6.3.1, os quais mostram uma forte tendência na direção y, indicando que eles estão afetados por erros sistemáticos.

É recomendável, portanto, que se execute essa operação em estudos futuros, com dois conjuntos de imagens, obtidos em momentos diferentes, utilizando-se um mesmo campo de calibração.

Acredita-se que a metodologia proposta, conforme apresentada neste trabalho, possa sofrer adaptações conforme as necessidades de cada tipo de aplicação, abrindo espaço para novas pesquisas, por exemplo, com a utilização de imagens de satélites.

Finalmente, conclui-se que esta metodologia pode proporcionar melhores condições de trabalho no processo de atualização cartográfica, reduzindo o tempo de execução e consequentemente os custos, além de atender ao PEC. 


\section{REFERÊNCIAS BIBLIOGRÁFICAS}

AGOURIS, P. \& STEFANIDIS, A. (1996). Integration of photogrammetric and geographic databases. International Archives of Photogrammetry and Remote Sensing. ISPRS. Commission - IV. Viena, Áustria. p.24-29.

AL-GARNI, A. (1996). Urban photogrammetric data base for multi-purpose cadastral based information system: the Riyadh city case. ISPRS Journal Photogrammetry \& Remote Sensing. Vol. 51, February, 1996. p- 28-38.

AMORIM, A. (1993). Utilização de câmaras de pequeno formato no cadastro técnico urbano. (Dissertação de Mestrado). Universidade Federal de Santa Catarina - UFSC. Florianópolis - SC. 105p.

AMORIM, A. \& SILVA, R. S. (1994). Cadastro multifinalitário urbano georeferenciado, como instrumento para a administração pública, em municípios de médio porte. In: Congresso Brasileiro de Cadastro Técnico Multifinalitário, $1^{\circ}$, Florianópolis - SC, Anais ... p. 100 - 105. Tomo - III. 
ANDERS, K. H. \& FRITSCH, D. (1996). Automatic Interpretation of digital maps for data revision. International Archives of Photogrammetry and Remote Sensing. ISPRS. Commission - IV. Viena, Áustria. p.90-94.

ANDRADE, J. B. de (1998). Fotogrametria. SBEE. Curitiba-PR. 258p.

BROWN, D. C. (1971). Close-range camera calibration. Photogrammetric Engineering, pag. 855-866.

CHO, W. et al. (1992). Resampling of digital image for epipolar geometry. Report n. 418. Columbus, Ohio, USA.

GALO, M. (1993). Calibração e aplicação de câmaras digitais. (Dissertação de Mestrado). Universidade Federal do Paraná - UFPR. Curitiba-PR.

GONZALEZ, R. C. \& WOODS R. E. (1993). Digital image processing. AddisonWesley Publishing Company. Tennessee University. USA.

GRUEN, A. (1996). Digital photogrammetric stations revisited. International Archives of Photogrammetry and Remote Sensing. ISPRS. Commission - II. Viena, Austria. p.127-134. 
HASEGAWA, J. K. \& CAMARGO, P. de O. (1998). Mapeamento com filmadora: uma análise de viabilidade. In: Congresso Brasileiro de Cadastro Técnico Multifinalitário, $3^{\circ}$ COBRAC. Florianópolis - SC, Anais - CD.

JOHNSSON, K. (1996). Generalization of image data to GIS polygons for change detection and data base revision. International Archives of Photogrammetry and Remote Sensing. ISPRS. Commission - IV. Viena, Austria. p.384-389.

KODAK. (2000). Especificações técnicas. http://www.kodak.com • (Aug., 10).

LUGNANI, J. B. (1985). Aprimoramentos para a atualização cartográfica. (Tese de Livre Docência). Universidade Federal do Paraná -UFPR. Curitiba - PR.

LUGNANI, J. B. (1987). Introdução à Fototriangulação. Universidade Federal do Paraná - UFPR. Curitiba - PR. 134p

MASAHARU, H. et al (1996). Semi-automatic detection of land use change from digital aerial. International Archives of Photogrammetry and Remote Sensing. ISPRS. Commission - IV. Viena, Austria. p.547-552.

MILLER, S. B. et al. (1996). Automation in digital photogrammetric systems. International Archives of Photogrammetry and Remote Sensing. ISPRS. Commission - II. Viena, Austria. p.250-255. 
MILLS, J. P. \& NEWTON, I. (1996). New approach to the verification and revision of large-scale mapping. ISPRS Journal Photogrammetry \& Remote Sensing. Vol. 51, February, p- 17-27.

MITISHITA, E. A. (1997). Monorestituição digital de aerofotos, associada com sistema de computação gráfica C. A. D., para fins de mapeamento na área florestal. (Tese de Mestrado). Universidade Federal do Paraná - UFPR. CuritibaPR.

OLIVEIRA, L. A. J. et al. (1999). Sistema de atualização cartográfica com imagens de alta resolução espacial. In: Congresso Brasileiro de Cartografia, 19², Recife PE. Anais/CD.

OLIVEIRA, L. J. de \& FALCON, R. R. (1999). Utilização de câmaras digitais na atualização de mapeamento. (Trabalho de graduação) Universidade Estadual Paulista - UNESP.

SINGH, A. (1989). Digital change detection techniques using remotely-sensed data. International journal of Remote Sensing, Vol. 10, nº 6, pag. 989-1003.

STAMM, J. C. \& BRIGGS, R. (1999). Change detection in digital ortho Images. The Worldwide Magazine For Geomatics - Vol. 13. April, p.44-47.

SHORTIS, M. R. \& BEYER, H. A. (1996). Sensor technology for digital photogrammetry anda machine vision. In: Close range photogrammetry and machine vision, Edited by ATKINSON, K. B., Department of Photogrammetry and Surveying. University College London. 371p. 
TOMMASELLI, A. M. G. (1987). Construção analítica de modelos e suas aplicações: uma abordagem utilizando injunções relativas. Revista Brasileira de Cartografia, No 41. Rio de Janeiro - RJ. p. 43-58.

TOMMASELLI, A. M. G. (1995). Intersecção fotogramétrica. Relatório Técnico, Contrato: Fundacte / Hydratec. Presidente Prudente - SP.

TOMMASElli, A. M. G. \& NOBREGA R. A. A. (1997). Qualidade Geométrica de Câmaras Digitais: avaliação de câmara Kodak DC - 40. $3^{\circ}$ GIS BRASIL, Curitiba PR. Anais/CD.

WOLF, P. R. (1983). Elements of Photogrammetry. The University of Wisconsin, Madisson. $2^{\text {rd }}$ ed. Mc Graw-Hill Book Company. 628p.

WOLF, P. R. \& DEWITT, B. A. (2000). Elements of Photogrammetry: with applications in GIS.. The University of Wisconsin, Madisson. $3^{\text {rd }}$ ed. Mc GrawHill Book Company. 700p.

YOICHI, O. (1996). Semi-Automatic digital photogrammetric system on PC. International Archives of Photogrammetry and Remote Sensing. ISPRS. Commission - II. Viena, Austria. p.288-293. 